\title{
Knowledge, practice, and coverage (KPC) survey: Baseline report, Bagh District
}

Munir Afridi

Saman Naz

Nayyer Munir

Follow this and additional works at: https://knowledgecommons.popcouncil.org/departments_sbsr-rh

Part of the Demography, Population, and Ecology Commons, Environmental Public Health Commons, Family, Life Course, and Society Commons, International Public Health Commons, and the Medicine and Health Commons How does access to this work benefit you? Let us know!

\section{Recommended Citation}

Afridi, Munir, Saman Naz, and Nayyer Munir. 2007. "Knowledge, practice, and coverage (KPC) survey: Baseline report, Bagh District." Islamabad: Population Council. 


\section{Knowledge, Practice and Coverage} Baseline Survey

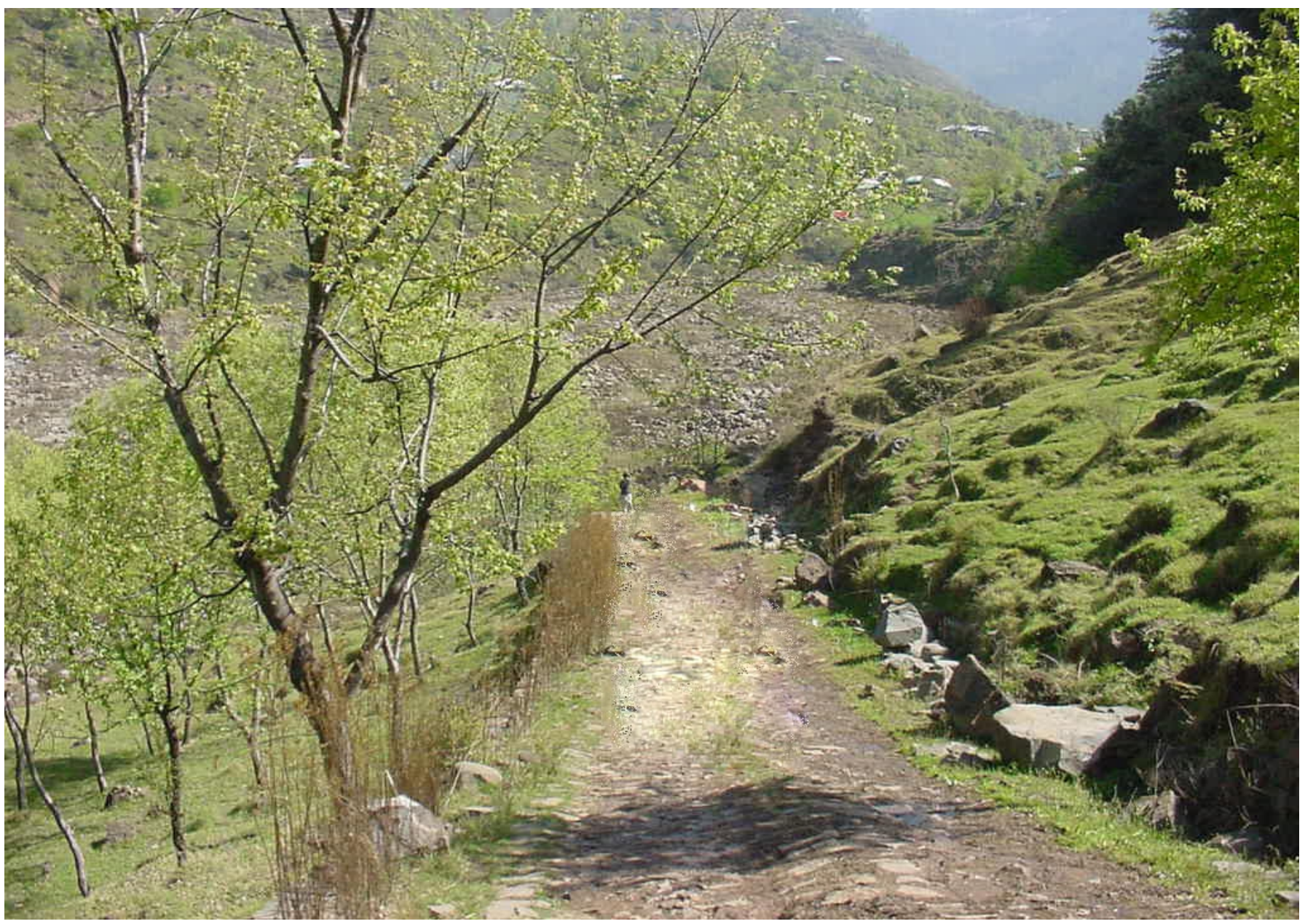

Munir Afridi

Saman Naz

Nayyer Munir

(2) Population Council

Bagh District September 2007 


\section{Knowledge, Practice and Coverage (KPC) Survey}

\section{Baseline Report}

Bagh District 
PRIDE Project is committed to Better Health for the people of Bagh and Mansehra Districts through improved health systems, improved health services and community participation. The project is generously supported by the American people through the United States Agency for International Development (USAID). PRIDE is implemented by a consortium of international partners including The International Rescue Committee (IRC) as the lead agency;

Management Sciences for Health (MSH) supporting health system strengthening; JHPIEGO, an affiliate of Johns Hopkins University, supporting health service strengthening; and The Population Council supporting monitoring and evaluation.

\section{(2) Population Council}

The Population Council, an international, non-profit, non-governmental organization established in 1952, seeks to improve the well-being and reproductive health of current and future generations around the world and to help achieve a humane, equitable, and sustainable balance between people and resources.

The Council analyzes population issues and trends; conducts research in the reproductive sciences; develops new contraceptives; works with public and private agencies to improve the quality and outreach of family planning and reproductive health services; helps governments design and implement effective population policies; communicates the results of research in the population field to diverse audiences; and helps strengthen professional resources in developing countries through collaborative research and programs, technical exchanges, awards, and fellowships.

For inquiries, please contact:

Population Council

\#7, Street 62, F-6/3, Islamabad, Pakistan

Tel: 92512277439

Fax: 92512821401

Email: info@pcpak.org

web: http://www.popcouncil.org

\section{PRIDE}

House \# 138 , St \# 14, E-7, Islamabad, Pakistan

Tel: + 92(0)51-2654142

Email: munir.afridi@pride.org.pk

Layout \& Design: Ali Ammad

Title design: Tanvir Malik

This report is made possible by the generous support of the American people through the United States Agency for International Development (USAID). The contents are the responsibility of the PRIDE project and do not necessarily reflect the views of USAID or the United States Government. 


\section{Contents}

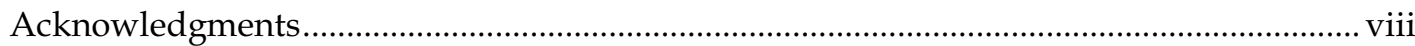

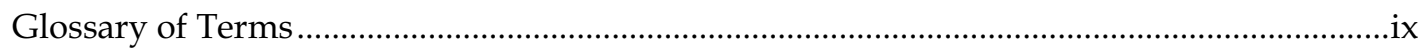

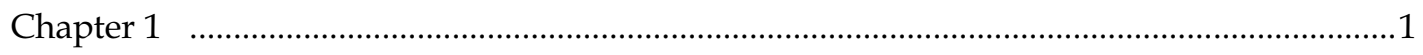

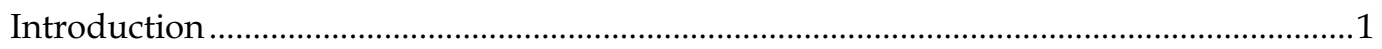

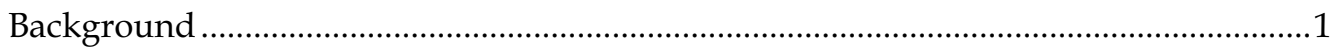

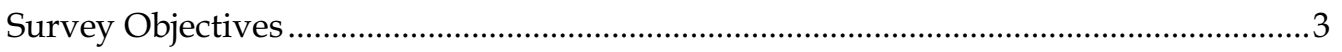

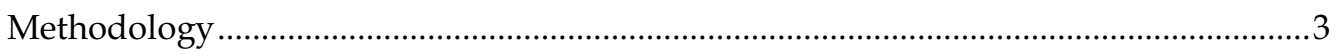

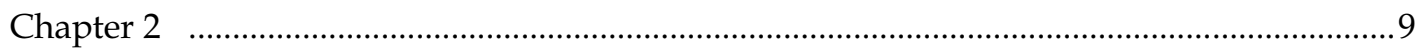

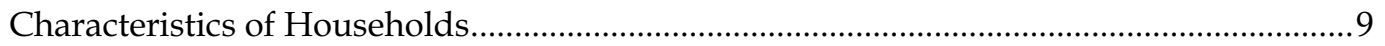

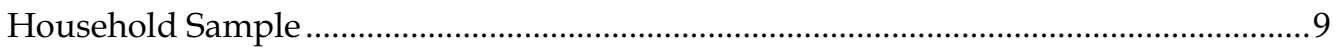

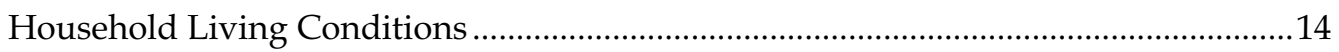

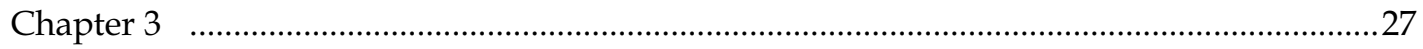

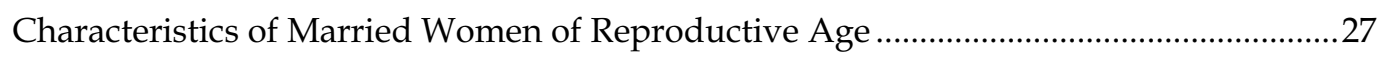

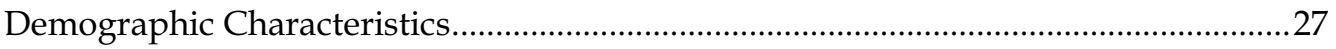

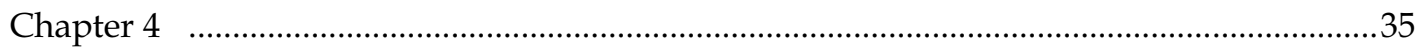

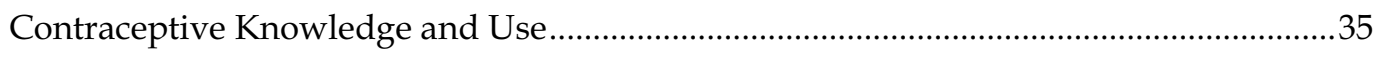

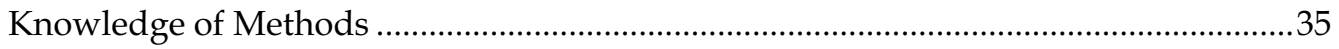

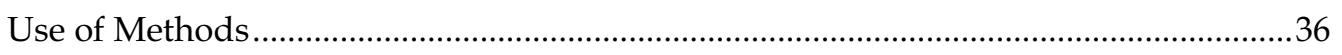

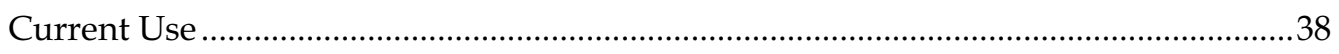

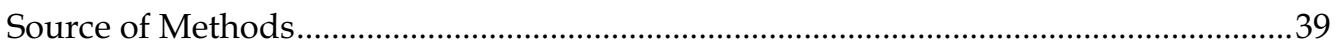

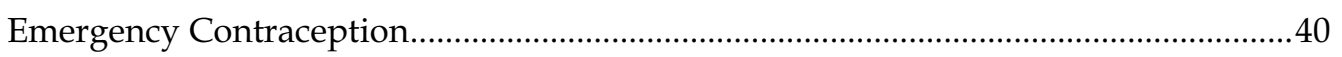

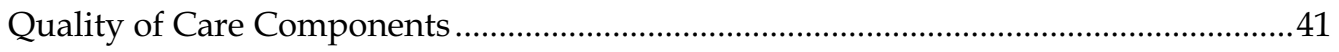

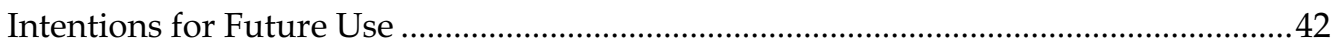

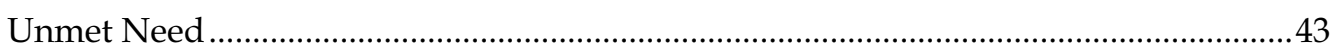

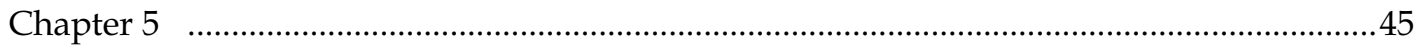

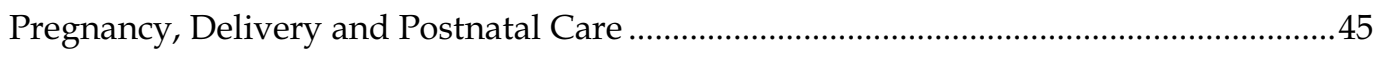

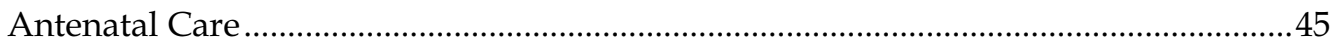

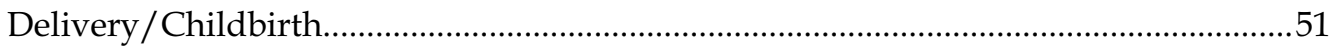

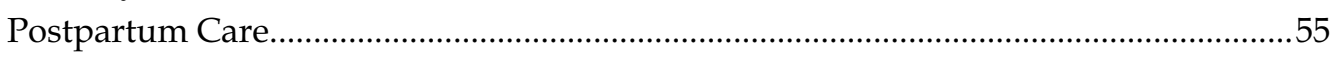

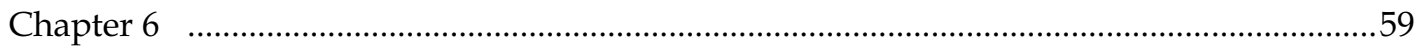

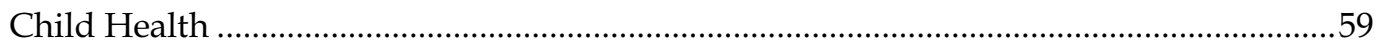

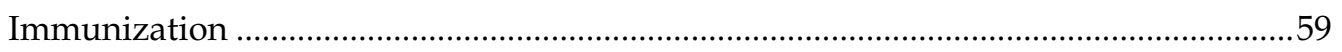

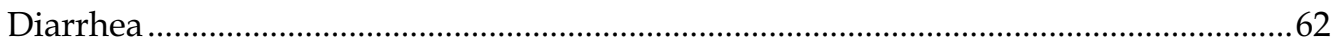

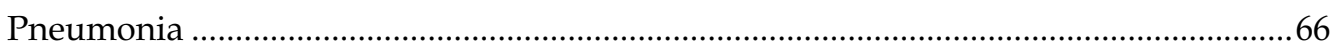

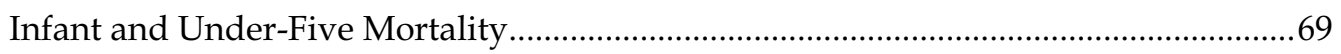

Chapter 7 . . w w

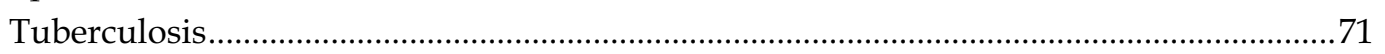

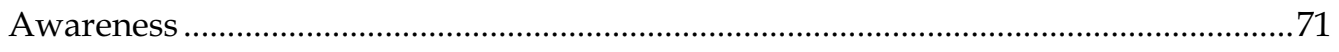

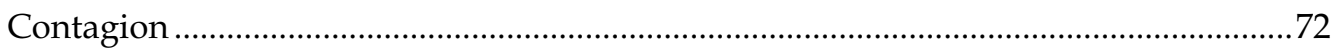




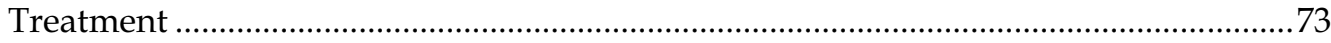

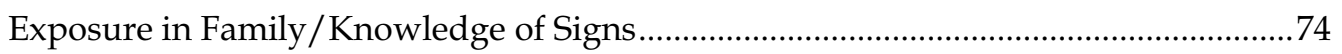

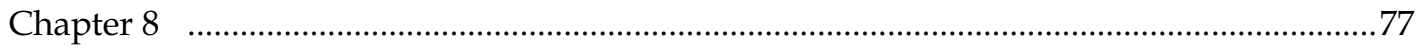

Community Involvement in Health .................................................................................77

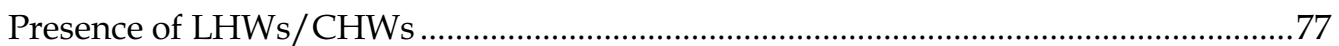

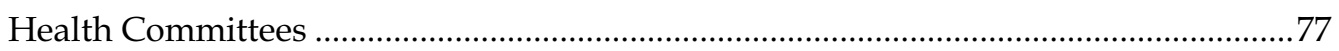

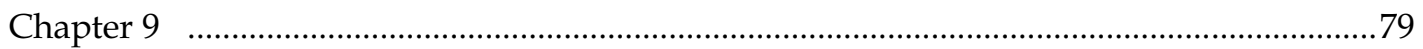

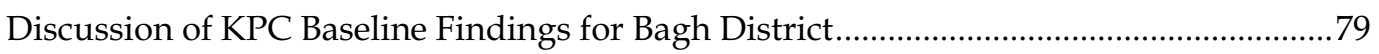

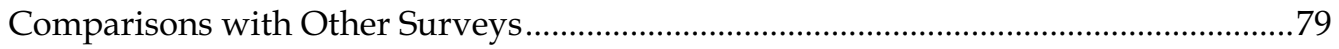

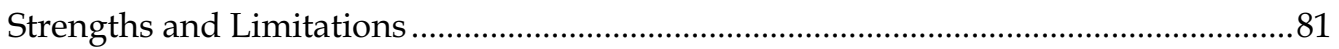

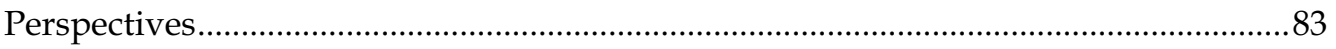

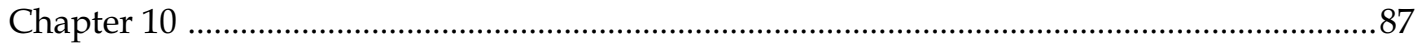

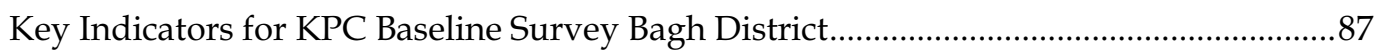

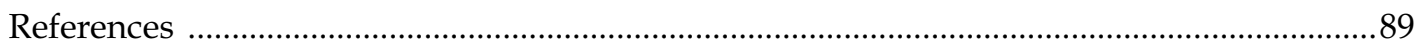

\section{List of Tables}

Table 1.1: Number of blocks/villages and households selected, by residence .........................4

Table 2.1: Number of households sampled and interviewed, and household members, by tehsil and district ............................................................................................

Table 2.2: Percentage distribution of household population by age and sex ..........................10

Table 2.3: Percentage of household population (ages 15 years and over) according to

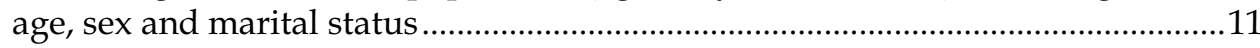

Table 2.4: Household population ages 5 years and above according to sex, age and

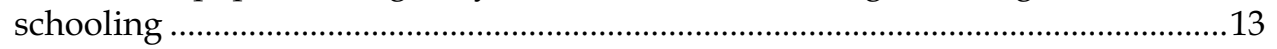

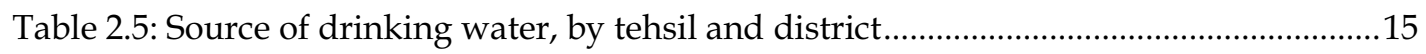

Table 2.6: Time taken to get water, by tehsil and district..........................................................16

Table 2.7: Treatment of drinking water to make it safer, by tehsil and district .......................16

Table 2.8: Type of toilet facility used by household members, by tehsil and district ............17

Table 2.9: Type of fuel used for cooking, by tehsil and district................................................18

Table 2.10: Ownership of household commodities / animals, by tehsil and district.............19

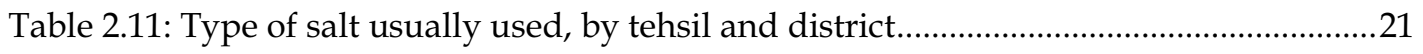

Table 2.12: Source of knowledge about iodized salt, by tehsil and district .............................22

Table 2.13: Knowledge about ill effects of iodine deficiency, by tehsil and district................23

Table 2.14: Measures taken to avoid mosquito bites, by tehsil and district..............................25

Table 3.1: Ever-married women of reproductive age interviewed for the KPC baseline

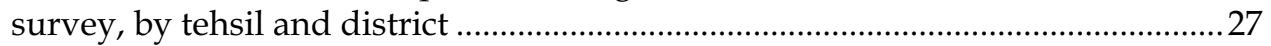

Table 3.2: Age, age at marriage and mean age at marriage of eligible women, by tehsil

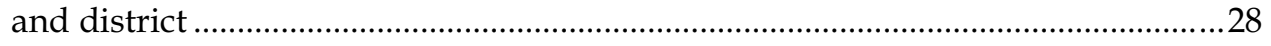

Table 3.3: Marital status of eligible women, by tehsil and district............................................29

Table 3.4: Education level of eligible women and their husbands, by tehsil and district.......30

Table 3.5: Mother tongue of eligible women, by tehsil and district............................................ 
Table 3.6: Eligible women according to age, by children ever born, number of women and mean number of children (ever born and living)...............................................32

Table 3.7: Occupation of eligible women's husbands, by tehsil and district............................33

Table 4.1: Contraceptive methods ever used by currently married women, by tehsil and district.

Table 4.2: Percent of current use of contraceptive methods by currently married women, by tehsil and district.

Table 4.3: Percent of currently married women who were current contraceptive users according to the source of their last supply, by tehsil and district..

Table 5.1: Eligible women according to the number of antenatal visits they had, by tehsil and district. .46

Table 5.2: Eligible women according to the location where antenatal care was given, by tehsil and district.

Table 5.3: Providers of antenatal care, by tehsil and district ......

Table 5.4: Women who had a live birth in the last 3 years according to number of ANC visits, by reason for first ANC visit .

Table 5.5: Eligible women according to reason for not having antenatal visits, by tehsil and district

Table 5.6: Eligible women according to type of person attending at delivery and skill level, by tehsil and district. 53

Table 5.7: History of postnatal care, by tehsil and district . .56

Table 6.1: Children under age 3 who received polio vaccination during national immunization day campaigns

Table 6.2: Danger signs of diarrhea requiring immediate treatment cited by mothers of children ages 0-23 months, by tehsil and district 66

Table 6.3: Identification of signs/symptoms of pneumonia by mothers of children 0-23 months, by tehsil and district.

Table 7.1: Ever-married women who knew about TB according to their knowledge about ways in which TB can be spread from person to person, by tehsil and district.

Table 7.2: Ever-married women who believed TB to be treatable according to their beliefs about the duration of TB treatment, by tehsil and district. 73

Table 7.3: Ever-married women according to whether or not anyone in their family ever suffered from TB, by tehsil and district.

Table 7.4: Ever-married women who cited symptoms of TB according to symptom, by tehsil and district. 75

Table 9.1: Comparison of Bagh KPC indicators with selected national survey data...............80

Table 10.1: PRIDE key indicators from KPC baseline survey, Bagh district. . .87

\section{List of Figures}

Figure 2.1: Marital status of household population (ages 15 years and over), by sex............... 12

Figure 2.2: Years of schooling for males and females ages 5 years and over (percent)............. 14

Figure 2.3: Sources of drinking water for Bagh district..... 15 
Figure 2.4: Ownership of selected household goods, by tehsil (percent)................................... 20

Figure 2.5: Ownership of livestock, by tehsil (percent) ................................................................ 20

Figure 2.6: Awareness of iodized salt among non-users, by tehsil (percent) .............................. 22

Figure 2.7: Reported manifestations of iodine deficiency, by tehsil (percent) ............................ 23

Figure 2.8: Knowledge about ill effects of iodine deficiency, by tehsil (percent)....................... 24

Figure 2.9: Action taken or not taken to prevent mosquito bites, by tehsil (percent) ............... 25

Figure 3.1: Age at marriage (by age group) of eligible women in Bagh district ........................ 29

Figure 3.2: Mother tongue of eligible women in Bagh district .................................................. 31

Figure 4.1: Currently married women's knowledge of specific contraceptive methods

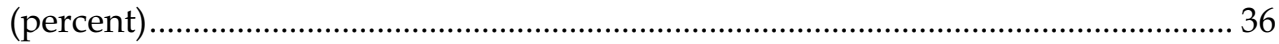

Figure 4.2: Ever use of specific contraceptive methods by currently married women (percent).

Figure 4.3: Currently married women's knowledge and ever use of emergency contraception, by tehsil and district (percent).

Figure 4.4: Quality of care components at ANC visits for currently married women (\%) ....... 42

Figure 4.5: Currently married women who were non-users of FP according to their future intention to use a contraceptive method, by tehsil (percent) ...

Figure 4.6: Currently married women who were pregnant or non-pregnant, by their contraceptive need (percent)

Figure 5.1: Services performed during antenatal check-up, by tehsil and district (\%) .............. 48

Figure 5.2: First antenatal care visit according to the reason for the visit, by tehsil and district (percent)

Figure 5.3: Tetanus toxoid injections received during last pregnancy, by tehsil and district

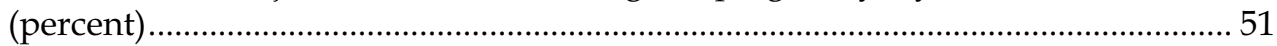

Figure 5.4: Place of last delivery, by tehsil and district (percent)............................................... 52

Figure 5.5: Women who experienced a problem(s) during their last delivery and postpartum period, by type of problem experienced (percent) ............................... 54

Figure 5.6: Safe delivery practices used at home births, by tehsil and district (percent).......... 55

Figure 5.7: Percentage of respondents who had knowledge about danger signs in newborns, by tehsil and district (percent) 57

Figure 5.8: Women's knowledge of the number of danger signs in a newborn within one hour of birth, by tehsil and district (percent) ......................................................... 58

Figure 6.1: Children ages 12-23 months who were fully immunized, based on records and recall, by tehsil and district (percent).

Figure 6.2: Children ages 12-23 months according to immunizations received, by tehsil and district (percent)

Figure 6.3: Status of immunization cards of mothers of children ages 12-23 months, by tehsil and district (percent)

Figure 6.4: Children ages 0-23 months who had diarrhea during the last two weeks, by tehsil and district (percent)

Figure 6.5: Mothers of children ages 0-23 months who sought advice or treatment from service providers for episodes of diarrhea, by tehsil and district (percent)

Figure 6.6: Mothers according to whether or not they treated the last bout of diarrhea in their children ages 0-23 months with ORT, by tehsil and district (percent) 
Figure 6.7: Mothers of children ages 0-23 months who had heard about pneumonia, by tehsil and district (percent)

Figure 6.8: Mothers of children ages 0-23 months according to what should be done if their child breathes fast with difficulty, by tehsil and district (percent).

Figure 7.1: Ever-married women who had or had not heard about tuberculosis, by tehsil (percent).

Figure 7.2: Ever-married women according to whether or not they knew that TB was a treatable disease, by tehsil (percent) 73

Figure 7.3: Ever-married women who reported whether or not they could identify at least

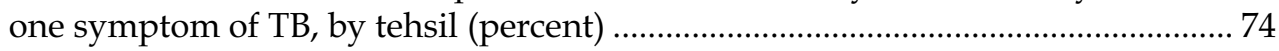

Figure 8.1: Percentage of 59 selected communities that have VHCs/CBOs................................ 78 


\section{Acknowledgments}

The PRIDE KPC Baseline Survey will be an important part of the foundation of the PRIDE project as a whole. Firstly, we would like to acknowledge The United States Agency for International Development (USAID) for their financial support.

The Population Council was primarily responsible for designing the study, carrying out the fieldwork, monitoring the quality of the data collection, analysis of data, and writing the reports. Dr. Arshad Mahmood, Director of Monitoring and Evaluation, used his capable technical and managerial skills to oversee the entire study with enthusiasm and energy and contributed substantially from the design phase to the analysis of the data and report preparation.

The study was carried out by several Population Council staff members, from design and pre-testing to final report writing. We would particularly like to acknowledge Dr. Munir Afridi, Nayyar Munir, Saman Naz and Ashfa Hashmi for monitoring fieldwork and ensuring quality data collection in the field. Irfan Masood managed the entry and cleaning of the data. Saman Naz, Nayyar Munir and Muhammad Ashraf prepared graphs and tables under the guidance of Dr. Arshad Mahmood. Dr. Munir Afridi and Saman Naz jointly prepared the first draft of the KPC survey report. Nadeem Akhtar also participated in the writing process. We are grateful to Peter C. Miller who wrote the discussion section for this report and Minhaj ul Haque for his computation support.

We also acknowledge the administrative support to the field teams by the PRIDE district offices. The quality of data collection depends on the training of field staff; we greatly appreciate the training provided by Dr. Gul Rashida and her team.

Ali Ammad was responsible for designing the layout and formatting of the report. Chantelle Allen reviewed the report and suggested very useful changes. Pamela Ledbetter carefully edited and proofread this report.

Finally, we must express our gratitude to the women of Bagh, who gave their time freely and cooperated with us in order to make this study possible. We hope to repay them by using the information they provided to improve primary healthcare services, including maternal and neonatal health services, in the district of Bagh. 


\section{Glossary of Terms}

\begin{tabular}{|c|c|}
\hline $\mathrm{ACMW}$ & All Currently Married Women \\
\hline $\mathrm{ADHO}$ & Assistant District Health Officer \\
\hline $\mathrm{ANC}$ & Antenatal Care \\
\hline $\mathrm{BCC}$ & Behavior Change Communication \\
\hline BCG & Bacille Calmette-Guérin \\
\hline $\mathrm{BHU}$ & Basic Health Unit \\
\hline $\mathrm{CBO}$ & Community Based Organization \\
\hline $\mathrm{CHW}$ & Community Health Worker \\
\hline CMR & Child Mortality Rate \\
\hline CPR & Contraceptive Prevalence Rate \\
\hline DHQ & District Headquarter Hospital \\
\hline $\mathrm{DPT}$ & Diphtheria, Pertussis and Tetanus \\
\hline EC & Emergency Contraception \\
\hline $\operatorname{EDO}(\mathrm{H})$ & Executive District Officer (Health) \\
\hline $\mathrm{FP}$ & Family Planning \\
\hline IMR & Infant Mortality Rate \\
\hline IR & Intermediate Result \\
\hline IRC & International Rescue Committee \\
\hline IUD & Intra Uterine Device \\
\hline JHPIEGO & $\begin{array}{l}\text { Johns Hopkins Program for International Education in Gynecology } \\
\text { and Obstetrics }\end{array}$ \\
\hline KPC & Knowledge, Practice and Coverage \\
\hline LHW & Lady Health Worker \\
\hline $\mathrm{MO}$ & Medical Officer \\
\hline $\mathrm{MCH}$ & Maternal and Child Health \\
\hline MICS & Multiple Indicators Cluster Survey \\
\hline MSH & Management Sciences for Health \\
\hline MWRA & Married Women of Reproductive Age \\
\hline NGO & Non-government Organization \\
\hline NIPS & National Institute of Population Studies \\
\hline NNS & National Nutrition Survey \\
\hline NWFP & North West Frontier Province \\
\hline ORT & Oral Rehydration Therapy \\
\hline PAIMAN & Pakistan Initiative for Mothers and Newborns \\
\hline PC & Population Council \\
\hline PHC & Primary Health Care \\
\hline PRHFPS & Pakistan Reproductive Health and Family Planning Survey \\
\hline PRIDE & $\begin{array}{l}\text { Primary Healthcare Revitalization, Integration and Decentralization } \\
\text { in Earthquake-affected Areas }\end{array}$ \\
\hline PSLM & Pakistan Social and Living Standard Measurement Survey \\
\hline PSU & Primary Sampling Unit \\
\hline RHC & Rural Health Center \\
\hline
\end{tabular}




$\begin{array}{ll}\text { RHSC A } & \text { Reproductive Health Services Center- A } \\ \text { SMART } & \text { Safe Motherhood Applied Research and Training } \\ \text { TB } & \text { Tuberculosis } \\ \text { TBA } & \text { Traditional Birth Attendant } \\ \text { TFR } & \text { Total Fertility Rate } \\ \text { THQ } & \text { Tehsil Headquarter Hospital } \\ \text { TOR } & \text { Term of Reference } \\ \text { TT } & \text { Tetanus Toxoid } \\ \text { USAID } & \text { United State Agency for International Development } \\ \text { VHC } & \text { Village Health Committee } \\ \text { WHO } & \text { World Health Organization } \\ \text { WMO } & \text { Woman Medical Officer }\end{array}$




\section{Chapter 1}

\section{Introduction}

\section{Background}

The Primary Healthcare Revitalization, Integration and Decentralization in Earthquake-affected Areas (PRIDE) program is designed to improve primary healthcare services and health outcomes for populations in Bagh and Mansehra districts in northern Pakistan that were affected by the devastating earthquake that struck the region on 8 October 2005. PRIDE, which began in August 2006, is a fouryear program funded by the United States Agency for International Development (USAID). The project's aim is to strengthen the financial and human resource management capacities of district health authorities and primary healthcare providers. Access to and quality of primary healthcare services will be improved through an essential package of health services and improved skills of primary healthcare personnel. Community demand for quality services will be improved through an innovative social mobilization process aimed at increasing knowledge and care-seeking behaviors.

PRIDE is implemented by a consortium of international partners working with local government stakeholders and communities. The International Rescue Committee (IRC) is the Recipient Agency responsible for overall management of the program and on-the-ground implementation. Management Sciences for Health (MSH) is primarily responsible for support to improved performance of public health services and management systems at District and sub-District levels. JHPIEGO, an affiliate of Johns Hopkins University, supports improved access to and quality of primary health care services. In addition to overall program management, IRC focuses on increased community participation in health services and healthier behaviors at household and community levels. The Population Council provides support to overall monitoring and evaluation functions within the project. 
The target population of PRIDE is over 1.5 million earthquake-affected people living in Bagh and Mansehra districts of northern Pakistan. PRIDE achieves its aims by serving the needs of this target population at several levels, assisting communities, providers and administrators in establishing a quality primary healthcare system in which all can take pride. This is a system that motivates and supports all who participate in it, while specifically addressing the health needs of the most vulnerable: women, children, the elderly, and families ravaged by the earthquake. The levels of intervention are outlined below:

- At the district level: PRIDE builds and institutes local capacity, building the managerial practices of health administrators.

- At the primary healthcare facility and provider level: PRIDE ensures accessible and essential primary healthcare services, improving the clinical practices of health providers.

- At the community level: PRIDE empowers communities to actively plan, access, and monitor health services, improving the health practices of communities.

- At the household level: PRIDE promotes healthy behaviors and improved health outcomes.

The PRIDE program is contributing to the achievement of USAID/Pakistan "Strategic Objective 7: Improved Health of Vulnerable Population." All PRIDE activities support the broad goal of this USAID strategic objective of improving the primary healthcare system in selected earthquake-hit districts.

To ensure that the success of PRIDE is properly ascertained and that the appropriate lessons are learned, PRIDE developed a Performance Management Plan. Included in this plan is the establishment of baseline measures for a set of indicators to be used for the evaluation of the success of the project. The plan calls for a baseline household survey, which was carried out in Bagh and Mansehra districts. There are two baseline household survey reports, one for each district. This report, Knowledge, Practice and Coverage (KPC) Survey: Baseline Report. Bagh District, which was written by Population Council staff involved in the survey, presents data for Bagh district and its tehsils (Haveli, Dhirkot, and Bagh). 


\section{Survey Objectives}

The KPC survey objectives include reference to PRIDE indicators; note that PRIDE key indicators, which are referred to in the survey objectives, are shown in Table 10.1 (Chapter 10) and are highlighted throughout this report. The KPC survey objectives are:

1. To obtain district data to measure Intermediate Results 2 and 3 indicators.

2. To obtain district data necessary to measure PRIDE indicators for household-level health practices of communities.

3. To obtain PRIDE indicators, such as infant mortality rate (IMR) and child mortality rate (CMR).

4. To obtain information on maternal and child health, and related issues. ${ }^{1}$

5. To obtain information required for the detailed design of the PRIDE project intervention. $^{2}$

\section{Methodology}

\section{Study Population}

PRIDE is primarily a district-level project, intended to improve the health of the entire population, particularly women and children, during the project period. To this end, the study has covered community residents - notably children, mothers and prospective mothers - in order to understand and measure general knowledge and practice of specific health behaviors and coverage of different, as well as relevant events (e.g., pregnancies, deliveries).

Hence, the study population for the baseline includes all married women of reproductive age (15-49 years) living in Bagh district, and more specifically women who have experienced a pregnancy during the last three years, and their children during the same period.

\footnotetext{
${ }^{1}$ This information may be of use to district health departments for planning and management.

${ }^{2}$ This includes information on: behavior change communication, public/private partnerships, and health systems strengthening.
} 


\section{Sample}

\section{Design and size}

The baseline household KPC survey was carried out in urban and rural areas all over Bagh district. Sampling of the population was carried out to provide data representative of the district, in addition to estimates for the entire project area. The number of blocks and villages selected in urban and rural areas, as well as the respective number of households selected, are shown in Table 1.1.

Table 1.1: Number of blocks/villages and households selected, by residence

\begin{tabular}{lrr} 
Residence & $\begin{array}{r}\text { Number of } \\
\text { blocks/villages }\end{array}$ & $\begin{array}{r}\text { Number of } \\
\text { households }\end{array}$ \\
Urban & 3 & 75 \\
\hline Rural & 56 & 1,398 \\
Total & 59 & 1,473
\end{tabular}

The sampling method used in the survey was a multistage stratified cluster sampling. The main focus, as described above, was on women of reproductive age and their children. Data on the health facilities available in these women's communities and on these women's household conditions were also collected.

The sample size was primarily based on the need to collect indicators based on the most recent pregnancy during the past 3 years for determination of practices surrounding pregnancy, childbirth, postpartum and child feeding and vaccination practices. For this purpose, a sample size of about 1,000 households would have been sufficient. However, an additional important indicator was under-5 mortality, for which the denominator would be births. A representative sample of 3,000 households for the two districts combined (1,500 for each district) was selected to be able to detect a 12 percent decline in the combined childhood mortality rate with 95 percent confidence. Among these households, all currently married women were interviewed.

\section{Urban sample}

The required number of enumeration blocks was selected with probability proportional to size (number of census circles) by adopting a multistage stratified sampling design. Firstly, the "enumeration circle," that is the smallest unit available in the 1998 Population District Census Reports as demarcated by the Population 
Census Organization, was selected. The maps of these circles, obtained from the Population Census Organization, were divided into blocks of approximately 250-300 households, depending on the number of households in each circle. Later, a block was randomly selected. The enumeration teams then carried out the listing of each block before selecting the sampled households. A fixed number of households (25 households) was drawn from each sample enumeration block by using the systematic random technique.

\section{Rural sample}

The 1998 Census list of villages was used as the sampling frame for the selection of the rural sample. Villages in rural areas have been treated as primary sampling units (PSUs). Sample PSUs were selected with probability proportional to size (number of households). Households within the sample PSUs were considered secondary sampling units. The listing of each village was then updated by the enumeration teams before selecting the sampled households. A fixed number of households (25 households) was drawn from each sample enumeration village by the systematic random technique.

\section{Questionnaires}

\section{Design}

Three different questionnaires - for women, households and communities - were developed by the Population Council based on a combination of current general demographic and health survey methodologies and the questionnaires developed by Population Council for the Safe Motherhood Applied Research and Training (SMART) project and the Pakistan Initiative for Mothers and Newborns (PAIMAN) baseline household survey. The questionnaires contained data sufficient to estimate those PRIDE indicators that were to be collected by the household KPC survey, as well as other relevant information.

\section{Pre-test}

PRIDE monitoring and evaluation partners and other interested stakeholders reviewed the KPC survey questionnaires, which were then pre-tested in urban and rural areas of Islamabad. The main objective of the pre-testing was to examine the suitability of questions and their effectiveness in eliciting adequate responses, to find out if there were any linguistic problems faced either by interviewers or respondents, and to determine the approximate time required to complete a questionnaire. 
In the pre-test, female interviewers were used and they were advised to note down their experiences with regard to each question. After making all of the revisions indicated by the pre-test, the questionnaires were finalized and translated into Urdu. A brief description of the three questionnaires follows.

\section{Household questionnaire}

The respondent for this questionnaire was either the head of each household or any available adult (male or female) of the household who was knowledgeable about household matters. The household questionnaire included information on the following indicators for the household:

- Age-sex composition.

- Socioeconomic conditions (e.g., household assets, source of drinking water and toilet facilities).

- Knowledge and practices regarding use of iodized salt and prevention of malaria.

\section{Women's questionnaire}

The respondents for this questionnaire were all married women of reproductive age in each household visited. The following information was collected about individual women through this questionnaire:

- Socioeconomic status.

- Fertility, pregnancy history and reproductive intentions.

- Attitude toward pregnancy, delivery and postpartum.

- Knowledge, attitude and practice of contraceptive methods.

- Child vaccination and health.

- Knowledge about symptoms and treatment of tuberculosis.

- Health seeking behavior.

\section{Community questionnaire}

The respondents for this questionnaire were three to four influential members of the community. The community questionnaire was designed to collect information regarding involvement of the community in health planning, designing and management at the local level. 


\section{Fieldwork}

\section{Hiring}

To be sensitive to cultural issues, it was decided to use female interviewers to interview females and male interviewers to interview males. Based on the constitution of each team, hiring of the required number of female and male interviewers was done. In recruiting interviewers, priority was given to those with knowledge of the local language and experience in similar work.

\section{Training}

Training of interviewers is key to the quality of data collection. To ensure high quality and uniformity in each interviewer's understanding of the definitions and concepts behind the language of the questions, training of the interviewers was conducted only in Islamabad.

The trained staff of the Population Council imparted training on the questionnaires and survey procedures. The training was conducted in different sessions for ten days. During the training, interviewers also visited a few communities to conduct interviews in order to practice how to ask the questions.

It is important that interviewers understand the methodology for sampling households; therefore, training on these aspects (e.g., the importance of the criteria for selecting primary sampling units, mapping and listing procedure, sample selection and field operation procedures, and selection of the particular households and respondents) was done by the sampling experts.

Training was also carried out for team leaders and those responsible for reviewing completed questionnaires once they were sent to the office (see quality assurance).

\section{Field teams}

There were three teams deployed in Bagh district with a team leader in each team. Each team consisted of four female interviewers and a male interviewer. The work plan of each team was prepared in a prescribed format indicating the name of the team members and the sample area name with enumeration dates. This system helped in monitoring the fieldwork by the Population Council monitoring teams and PRIDE partners. 


\section{Quality assurance}

To ensure the quality of the data, Population Council provided extensive monitoring of the field teams. Experienced Population Council field staff were used for this purpose. While supervising the fieldwork, the Population Council supervisory staff provided on-the-spot guidance to interviewers if any part of the questionnaire was not clear; this supervision helped to ensure completeness of each questionnaire. In addition, the team leaders, who were given editing instructions, conducted preliminary editing of completed questionnaires during the enumeration period. These instructions emphasized the completeness of each questionnaire, with correct identification of each eligible respondent and completeness of household composition. Extensive training of the editing staff responsible for reviewing the completed questionnaires in Islamabad was also imparted.

\section{Data processing}

Data processing started in the field with the checking of each questionnaire. Each team leader conducted on-the-spot editing of all questionnaires filled in by the interviewers, as they were trained to do.

On receipt of the questionnaires at the Islamabad office, a special team of experienced and well-trained staff edited the completed questionnaires. After having been edited and coded, questionnaires were dispatched to the data entry center.

Population Council was responsible for data entry using data entry (CSPro) and edit programs. Data entry was carried out concurrently with fieldwork; that is, data were entered as soon as they were received from the field, and errors were immediately returned for correction. After data entry and editing, a clean dataset was produced.

\section{Data analysis}

Data were analyzed using SPSS for Windows. Once basic data tables were prepared, they were shared with PRIDE partners and other district-level stakeholders. 


\section{Chapter 2}

\section{Characteristics of Households}

This chapter presents the post-earthquake socioeconomic and demographic information of the population in Bagh district. Information was collected on some of the demographic and socioeconomic characteristics, such as the source of drinking water, sanitation facilities and possession of household durable goods. The information on the characteristics of the households is essential for the interpretation of survey findings. The definition of the household used for this survey was "person or a group of persons, related or unrelated, who live together in the same dwelling unit and share a common source of food."

\section{Household Sample}

The number of households that were sampled, and in which interviews were conducted, is presented by tehsil in Table 2.1. A total of 9,941 individuals were members of these households.

Table 2.1: Number of households sampled and interviewed, and household members, by tehsil and district

\begin{tabular}{lrrrrrr} 
& \multicolumn{9}{c}{ Households } & & \\
Tehsil & Sampled & & Interviewed & Household members \\
\cline { 2 - 6 } Bagh & $N$ & $\%$ & $N$ & $\%$ & $N$ & $\%$ \\
\cline { 2 - 6 } Dhirkot & 700 & 46.7 & 700 & 47.5 & 4,674 & 47.0 \\
\hline Haveli & 425 & 28.3 & 425 & 28.9 & 2,828 & 28.4 \\
Total & 375 & 25.0 & 348 & 23.6 & 2,439 & 24.5 \\
\hline & 1,500 & 100.0 & 1,473 & 100.0 & 9,941 & 100.0
\end{tabular}




\section{Demographic Characteristics}

\section{Age and sex}

The age and sex distribution of all household members is presented in Table 2.2. Age and sex are important demographic variables and are the primary basis of demographic analysis. They are also important variables in the study of reproductive health, mortality and fertility.

There were 9,941 individuals living in the 1,473 district households where interviews took place: 48 percent males and 52 percent females. When stratified by sex, those in the age groups 20-40 years consisted of more males than females; one reason for this may be economic activity migration of most of the males from this age group. There were also more males ( 9 percent) than females ( 6 percent) in the 60 plus age group. The largest age group, by a small amount, was 10-14 years (14 percent).

In Table 2.2, the age-sex distribution shows that more than half of the population in Bagh district was less than 20 years of age, which can be attributed to a high fertility rate in the district. The male population of Bagh district appears to be slightly less than the female population, resulting in a sex ratio of 91 males for every 100 females.

Table 2.2: Percentage distribution of household population by age and sex

\begin{tabular}{lrrrrrr} 
Age & Male & \multicolumn{3}{c}{ Female } & \multicolumn{2}{c}{ Total } \\
\cline { 2 - 7 }$<5$ & $N$ & $\%$ & $N$ & $\%$ & $N$ & $\%$ \\
\cline { 2 - 7 } $5-9$ & 659 & 13.9 & 663 & 12.8 & 1,322 & 13.3 \\
\hline $10-14$ & 632 & 13.3 & 619 & 11.9 & 1,251 & 12.6 \\
\hline $15-19$ & 728 & 15.3 & 648 & 12.5 & 1,376 & 13.8 \\
\hline $20-24$ & 616 & 13.0 & 657 & 12.6 & 1,273 & 12.8 \\
\hline $25-29$ & 375 & 7.9 & 590 & 11.4 & 965 & 9.7 \\
\hline $30-34$ & 277 & 5.8 & 441 & 8.5 & 718 & 7.2 \\
\hline $35-39$ & 201 & 4.2 & 306 & 5.9 & 507 & 5.1 \\
\hline $40-44$ & 212 & 4.5 & 260 & 5.0 & 472 & 4.7 \\
\hline $45-49$ & 176 & 3.7 & 209 & 4.0 & 385 & 3.9 \\
\hline $50-54$ & 157 & 3.3 & 187 & 3.6 & 344 & 3.5 \\
\hline $55-59$ & 143 & 3.0 & 171 & 3.3 & 314 & 3.2 \\
\hline $60+$ & 122 & 2.6 & 130 & 2.5 & 252 & 2.5 \\
\hline Total & 447 & 9.4 & 315 & 6.1 & 762 & 7.7 \\
& 4,745 & 100.0 & 5,196 & 100.0 & 9,941 & 100.0
\end{tabular}




\section{Marital status}

The marital status of all household members above 14 years of age is given in Table 2.3. Overall, two-fifths (41 percent) of the male population, compared to one-third of the females (32 percent) in the sample, had never been married. The percentage of married women under the age of 20 is considerably higher than the percentage of married men within the same age group ( 9 and 1 percent, respectively), indicating that females tend to marry at an earlier age than males. Also, more women than men were widowed/divorced/separated at each age than men, largely because of higher mortality among husbands (usually older).

Table 2.3: Percentage of household population (ages 15 years and over) according to age, sex and marital status

\begin{tabular}{lrrrrrr} 
& \multicolumn{2}{c}{ Males } & \multicolumn{3}{c}{ Females } \\
\cline { 2 - 8 } Age & $\begin{array}{c}\text { Never } \\
\text { married }\end{array}$ & $\begin{array}{c}\text { Currently } \\
\text { married }\end{array}$ & $\begin{array}{c}\text { Widow } \\
\text { divorced/ } \\
\text { separated }\end{array}$ & $\begin{array}{c}\text { Never } \\
\text { married }\end{array}$ & $\begin{array}{c}\text { Currently } \\
\text { married }\end{array}$ & $\begin{array}{r}\text { divorced/ } \\
\text { separated }\end{array}$ \\
\hline $20-24$ & 98.9 & 1.1 & 0.0 & 90.6 & 9.4 & 0.0 \\
\hline $25-29$ & 81.8 & 18.0 & 0.3 & 56.6 & 42.8 & 0.7 \\
\hline $30-34$ & 47.1 & 51.5 & 1.5 & 21.1 & 76.4 & 2.5 \\
\hline $35-39$ & 20.4 & 76.1 & 3.5 & 4.2 & 92.2 & 3.6 \\
\hline $40-44$ & 6.2 & 90.0 & 3.8 & 3.9 & 92.3 & 3.9 \\
\hline $45-49$ & 1.7 & 90.3 & 8.0 & 1.9 & 92.3 & 5.7 \\
\hline $50-54$ & 1.3 & 94.9 & 3.8 & 1.6 & 88.8 & 9.6 \\
\hline $55-59$ & 0.7 & 93.0 & 6.3 & 0.6 & 87.1 & 12.3 \\
\hline $60-64$ & 1.6 & 91.0 & 7.4 & 0.0 & 68.5 & 31.5 \\
\hline 65 and older & 1.4 & 85.0 & 13.6 & 1.5 & 62.6 & 35.9 \\
\hline Total & 0.7 & 71.5 & 27.9 & 1.1 & 36.0 & 62.9 \\
\hline & 40.7 & 53.4 & 5.9 & 32.2 & 58.9 & 8.8
\end{tabular}

Figure 2.1 shows the distribution of the household population ages 15 years and over by marital status and sex. Marital status is classified as 'never married,' 'currently married,' and 'widowed/divorced/separated' (labeled as 'formerly married'). Fiftythree percent of males and 59 percent of females were currently married; 6 percent of males were formerly married compared to 9 percent of females. 
Figure 2.1: Marital status of household population (ages 15 years and over), by sex

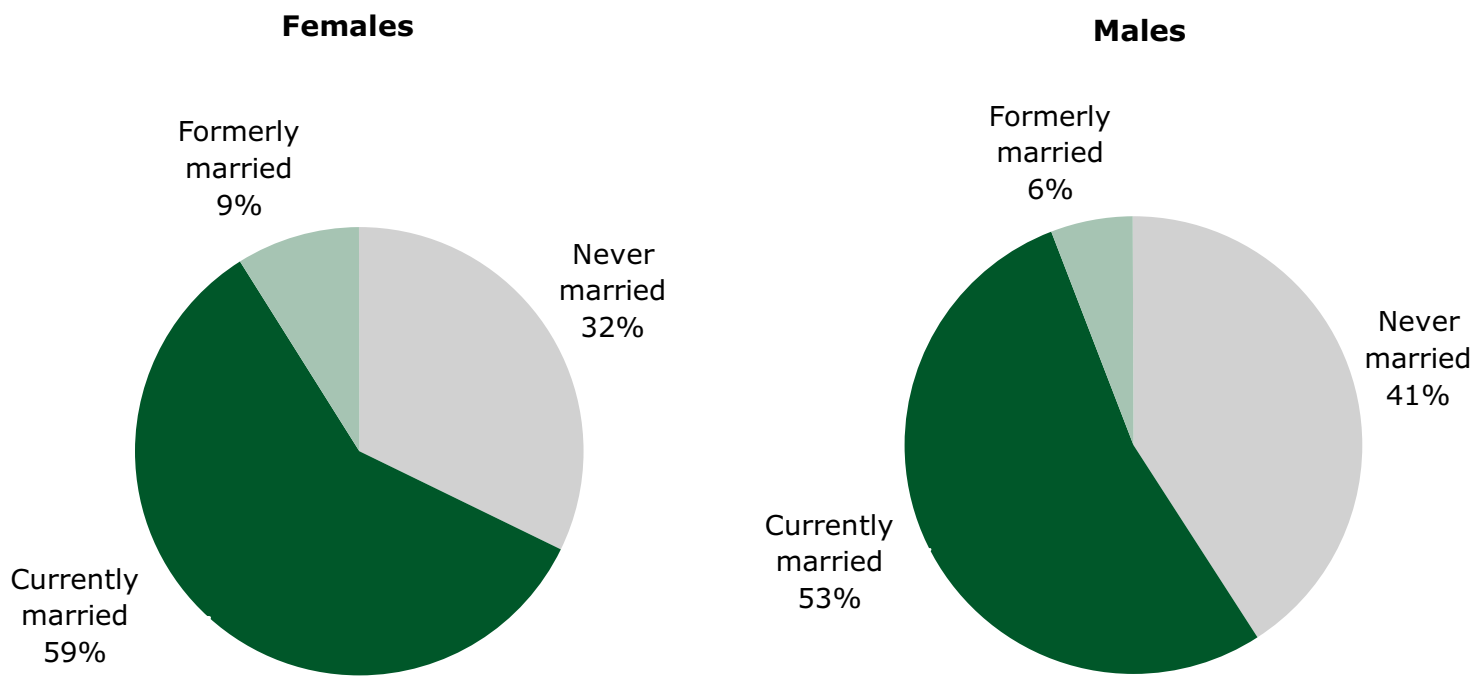

\section{Education}

Since education is the most important indicator for social development, a question on the educational level of all individuals aged five years and older was included. The results are shown in Table 2.4. The level of education attained by the females in Bagh district was consistently lower than the level of education attained by the males. Overall, 23 percent of males had no schooling at all compared to 43 percent of the females. For 6-10 years of schooling, males were ahead of females for all age groups.

In lower age groups, a slightly higher percentage of girls had 11 and more years of schooling than boys, indicating the increasing trend of girls getting into higher studies in Bagh district. 
Table 2.4: Household population ages 5 years and above according to sex, age and schooling

\begin{tabular}{|c|c|c|c|c|c|}
\hline \multirow[b]{2}{*}{ Sex and age } & \multicolumn{4}{|c|}{ Years of schooling } & \multirow[b]{2}{*}{ Total } \\
\hline & $\begin{array}{c}\text { No } \\
\text { schooling }\end{array}$ & $\begin{array}{c}1-5 \\
\text { years }\end{array}$ & $\begin{array}{c}6-10 \\
\text { years }\end{array}$ & $\begin{array}{l}11 \text { and } \\
\text { more years }\end{array}$ & \\
\hline Males & $\%$ & $\%$ & $\%$ & $\%$ & N \\
\hline $5-9$ & 63.8 & 36.2 & 0.0 & 0.0 & 619 \\
\hline $10-14$ & 9.5 & 63.6 & 26.9 & 0.0 & 728 \\
\hline $15-19$ & 3.7 & 20.0 & 68.1 & 8.1 & 614 \\
\hline $20-24$ & 6.7 & 15.5 & 57.2 & 20.6 & 374 \\
\hline $25-29$ & 8.4 & 12.0 & 62.4 & 17.2 & 274 \\
\hline $30-34$ & 8.0 & 15.9 & 52.7 & 23.4 & 201 \\
\hline $35-39$ & 10.0 & 24.2 & 43.1 & 22.7 & 211 \\
\hline $40-44$ & 22.7 & 21.0 & 43.2 & 13.1 & 176 \\
\hline $45-49$ & 18.5 & 26.1 & 35.0 & 20.4 & 157 \\
\hline $50-54$ & 27.5 & 23.2 & 38.7 & 10.6 & 142 \\
\hline $55-59$ & 32.0 & 30.3 & 32.0 & 5.7 & 122 \\
\hline $60-64$ & 36.1 & 35.4 & 22.2 & 6.3 & 144 \\
\hline 65 and older & 49.3 & 30.5 & 17.4 & 2.7 & 298 \\
\hline Total & 22.6 & 31.4 & 37.1 & 8.9 & 4,060 \\
\hline \multicolumn{6}{|l|}{ Females } \\
\hline $5-9$ & 65.2 & 34.8 & 0.0 & 0.0 & 607 \\
\hline $10-14$ & 11.4 & 63.8 & 24.7 & 0.0 & 647 \\
\hline $15-19$ & 15.9 & 20.9 & 52.7 & 10.5 & 656 \\
\hline $20-24$ & 15.9 & 20.5 & 41.7 & 21.9 & 585 \\
\hline $25-29$ & 26.4 & 18.9 & 40.1 & 14.6 & 439 \\
\hline $30-34$ & 43.3 & 19.0 & 29.5 & 8.2 & 305 \\
\hline $35-39$ & 59.6 & 18.5 & 15.0 & 6.9 & 260 \\
\hline $40-44$ & 74.8 & 12.1 & 10.2 & 2.9 & 206 \\
\hline $45-49$ & 83.4 & 9.6 & 5.3 & 1.6 & 187 \\
\hline $50-54$ & 90.4 & 6.0 & 3.0 & 0.6 & 167 \\
\hline $55-59$ & 90.8 & 7.7 & 0.8 & 0.8 & 130 \\
\hline $60-64$ & 93.9 & 4.6 & 0.8 & 0.8 & 131 \\
\hline 65 and older & 95.4 & 4.6 & 0.0 & 0.0 & 173 \\
\hline Total & 43.1 & 25.5 & 24.3 & 7.0 & 4,493 \\
\hline
\end{tabular}

Figure 2.2 presents the educational attainment of all males and females ages five years and more in Bagh district. Among males, the largest group was of those who had 6-10 years of schooling (37 percent); among females, the largest group was of those who had had no schooling at all (43 percent). 
Figure 2.2: Years of schooling for males and females ages 5 years and over (percent)

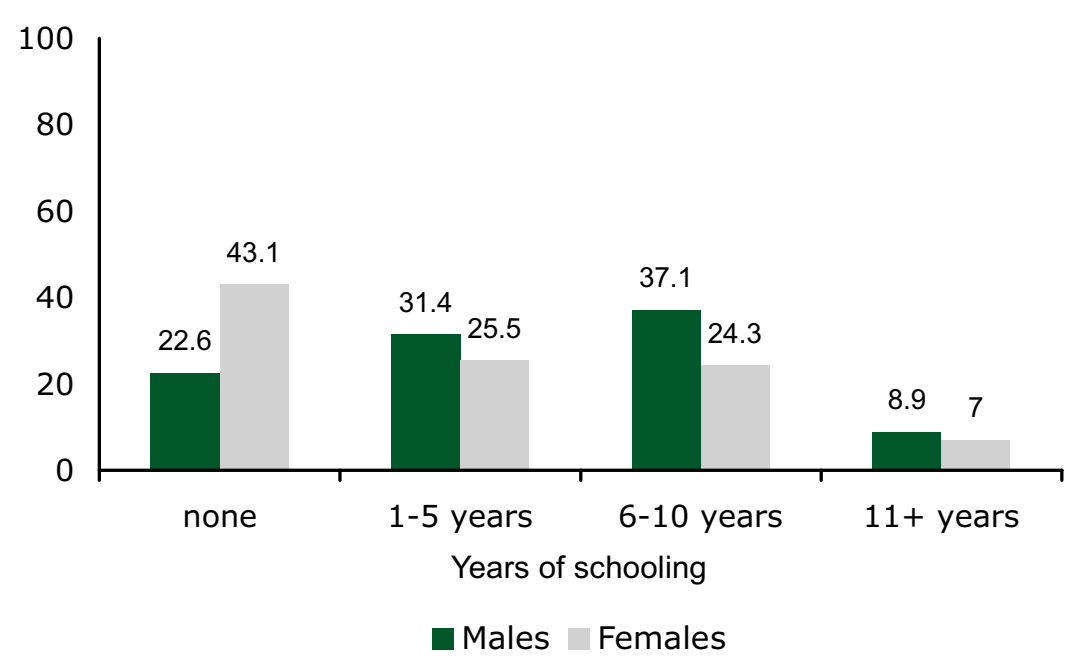

\section{Household Living Conditions}

\section{Drinking Water}

In order to obtain a clear understanding of the living conditions and the level of hygiene of the households, it was necessary to record the source of drinking water available to respondents and their families. Also, to create a clearer picture of the level of awareness of water purification, information was gathered from households on both their main source of water and what method they used to make the water suitable for drinking.

In Bagh district overall, the most common source of drinking water was spring water with more than two-thirds (68 percent) of the population bringing drinking water from this source. The second most common source in Bagh tehsils was tap water inside the houses (17 percent). More than one-fifth (22 percent) of the households in Bagh tehsil were using tap water inside their households; fewer in Haveli and Dhirkot were doing so (17 and 9 percent, respectively). 
Table 2.5: Source of drinking water, by tehsil and district

\begin{tabular}{lrrrrrrrr} 
& \multicolumn{9}{c}{ Tehsil } \\
\cline { 2 - 10 } Source & \multicolumn{2}{c}{ Bagh } & \multicolumn{2}{c}{ Dhirkot } & \multicolumn{2}{c}{ Haveli } & \multicolumn{2}{c}{ Total } \\
\cline { 2 - 10 } Govt. supply (tap water inside) & $N$ & $\%$ & $N$ & $\%$ & $N$ & $\%$ & $N$ & $\%$ \\
\hline Govt. supply (communal) & 144 & 21.7 & 38 & 9.0 & 57 & 16.5 & 239 & 16.7 \\
\hline Well (inside and outside) & 61 & 9.2 & 14 & 3.3 & 21 & 6.1 & 96 & 6.7 \\
\hline Springs & 43 & 6.5 & 32 & 7.6 & 2 & 0.6 & 77 & 5.4 \\
\hline Other & 388 & 58.4 & 326 & 77.3 & 254 & 73.4 & 968 & 67.6 \\
Total & 28 & 4.2 & 12 & 2.8 & 12 & 3.5 & 52 & 3.6 \\
& 664 & 100 & 422 & 100 & 346 & 100 & 1,432 & 100
\end{tabular}

Figure 2.3 shows the overall sources of drinking water in Bagh district, indicating spring water and tap water as the main sources.

Figure 2.3: Sources of drinking water for Bagh district

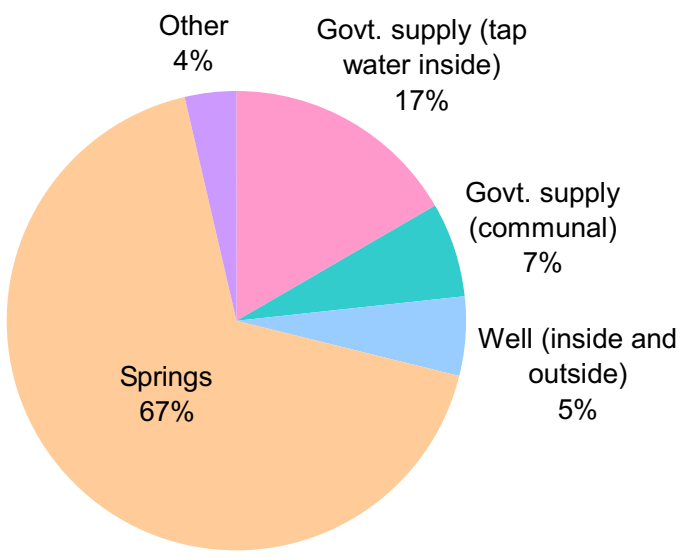

\section{Time to get water}

The women were also asked to indicate how much time it took them to get drinking water. Just over one-quarter ( 27 percent) of the households had drinking water facilities available within their premises; others had to travel some distance to get water. When comparing the tehsils, Dhirkot had the lowest percentage of households having some water facility available within their premises (14 percent). Table 2.6 shows the time taken to get water from the source. One out of every 5 households (20 percent) in Bagh district had to travel more than half an hour to get to the source of drinking water. 
Table 2.6: Time taken to get water, by tehsil and district

\begin{tabular}{|c|c|c|c|c|c|c|c|c|}
\hline \multirow{3}{*}{ Minutes } & \multicolumn{6}{|c|}{ Tehsil } & & \\
\hline & \multicolumn{2}{|c|}{ Bagh } & \multicolumn{2}{|c|}{ Dhirkot } & \multicolumn{2}{|c|}{ Haveli } & \multicolumn{2}{|c|}{ Total } \\
\hline & $N$ & $\%$ & $N$ & $\%$ & $N$ & $\%$ & $N$ & $\%$ \\
\hline 0 (on premises) & 206 & 31.0 & 59 & 14.0 & 124 & 35.9 & 389 & 27.2 \\
\hline $0-10$ & 116 & 17.4 & 96 & 22.7 & 54 & 15.7 & 266 & 18.6 \\
\hline $11-30$ & 216 & 32.5 & 174 & 41.2 & 99 & 28.7 & 489 & 34.1 \\
\hline $31-60$ & 93 & 14.0 & 70 & 16.6 & 52 & 15.1 & 215 & 15.0 \\
\hline $60+$ & 34 & 5.1 & 23 & 5.5 & 16 & 4.6 & 73 & 5.1 \\
\hline Total & 665 & 100.0 & 422 & 100.0 & 345 & 100.0 & 1,432 & 100.0 \\
\hline
\end{tabular}

\section{Treatment of drinking water}

A question was also included asking what methods, if any, were used by individual households to treat drinking water to make it safe (potable). Ninety-six percent of the households said they did not treat the water they drank.. Of those who reported treating water, 69 percent said that they boiled the water before drinking, 14 percent reported straining water through cloth and 9 percent used some other method of making water safer to drink.

Table 2.7: Treatment of drinking water to make it safer, by tehsil and district

\begin{tabular}{|c|c|c|c|c|c|c|c|c|}
\hline \multirow{3}{*}{ Response } & \multicolumn{6}{|c|}{ Tehsil } & \multirow{2}{*}{\multicolumn{2}{|c|}{ Total }} \\
\hline & Bagl & & Dhi & & $\mathrm{Ha}$ & & & \\
\hline & $N$ & $\%$ & $N$ & $\%$ & $N$ & $\%$ & $\Lambda$ & $\%$ \\
\hline
\end{tabular}

Drinking water is treated to make it safer

\begin{tabular}{lrrrrrrrr}
\hline Yes & 37 & 5.5 & 14 & 3.3 & 14 & 4.0 & 65 & 4.5 \\
\hline No & 630 & 94.5 & 410 & 96.7 & 334 & 96.0 & 1,374 & 95.5 \\
\hline Total & 667 & 100.0 & 424 & 100.0 & 348 & 100.0 & 1,439 & 100.0 \\
\hline
\end{tabular}

Ways of making water safer to drink

\begin{tabular}{lrrrrrrrr}
\hline Boil & 25 & 67.6 & 12 & 85.7 & 8 & 57.1 & 45 & 69.2 \\
\hline Add bleach/chlorine & 4 & 10.8 & 1 & 7.1 & 0 & 0.0 & 5 & 7.7 \\
\hline Strain through a cloth & 4 & 10.8 & 1 & 7.1 & 4 & 28.6 & 9 & 13.8 \\
\hline Use water filter & 1 & 2.7 & 1 & 7.1 & 0 & 0.0 & 2 & 3.1 \\
\hline Let it stand and settle & 0 & 0.0 & 0 & 0.0 & 1 & 7.1 & 1 & 1.5 \\
\hline Other & 5 & 13.5 & 0 & 0.0 & 1 & 7.1 & 6 & 9.2 \\
Total & 37 & na & 14 & na & 14 & na & 65 & na
\end{tabular}

na = Not applicable; respondents could give more than one response 


\section{Toilet Facilities}

Sanitation also affects the health of the household. The type of toilet facility a family has access to reflects their living condition and the type of sanitary conditions prevalent in the household. This is important for children, especially newborns, and pregnant mothers, as they are particularly vulnerable to diseases associated with unhygienic toilet facilities.

Overall, nearly half of the households (47 percent) reported that they used flush systems connected to septic tanks, and more than two-fifths (43 percent) said that they used open fields for the call of nature. Differences were seen between the tehsils. In Bagh tehsil, flush systems connected to septic tanks were used most frequently (53 percent); more than one-third (35 percent) said that they used open fields. In Haveli and Dhirkot, the majority of households did not have any toilet facility and used open fields for this purpose (55 and 46 percent, respectively); 41 percent in each of these tehsils used flush systems connected to septic tanks.

Table 2.8: Type of toilet facility used by household members, by tehsil and district

\begin{tabular}{lrrrrrrrr} 
& \multicolumn{9}{c}{ Tehsil } \\
\cline { 2 - 10 } Toilet facility & \multicolumn{1}{c}{ Bagh } & \multicolumn{1}{c}{ Dhirkot } & Haveli & \multicolumn{2}{c}{ Total } \\
\cline { 2 - 10 } Flush connected to septic tank & $N$ & $\%$ & $N$ & $\%$ & $N$ & $\%$ & $N$ & $\%$ \\
\cline { 2 - 10 } Flush connected to open drain & 351 & 52.9 & 175 & 41.4 & 143 & 41.4 & 669 & 46.7 \\
\hline Pit latrine & 23 & 3.5 & 4 & 0.9 & 5 & 1.4 & 32 & 2.2 \\
\hline In fields & 51 & 7.7 & 50 & 11.8 & 5 & 1.4 & 106 & 7.4 \\
\hline Other & 235 & 35.4 & 193 & 45.6 & 189 & 54.8 & 617 & 43.1 \\
\hline Total & 4 & 0.6 & 1 & 0.2 & 3 & 0.9 & 8 & 0.6 \\
& 664 & 100.0 & 423 & 100.0 & 345 & 100.0 & 1,432 & 100.0
\end{tabular}

\section{Cooking Fuel}

The fuel used for cooking is also a socioeconomic and health indicator, as wood fires, especially indoor fires, are linked to respiratory illnesses. "The fuel used for cooking affects the health of household members, specially the children, because they are more likely to catch diseases more quickly than elders and children are more vulnerable to this environment" (Mahmood 2003). More than 9 out of every 10 respondents reported that they used wood as their main fuel for cooking, although this was higher in Haveli and Dhirkot (more than 94 percent in each) than in Bagh (89 percent). One out of every 11 households in Bagh tehsil reported using cylinder gas; fewer households in Dhirkot and Haveli did so (3 percent in each). 
Table 2.9: Type of fuel used for cooking, by tehsil and district

\begin{tabular}{|c|c|c|c|c|c|c|c|c|}
\hline \multirow{3}{*}{ Fuel } & \multicolumn{6}{|c|}{ Tehsil } & \multirow{2}{*}{\multicolumn{2}{|c|}{ Total }} \\
\hline & \multicolumn{2}{|c|}{ Bagh } & \multicolumn{2}{|c|}{ Dhirkot } & \multicolumn{2}{|c|}{ Haveli } & & \\
\hline & $N$ & $\%$ & $N$ & $\%$ & $N$ & $\%$ & $N$ & $\%$ \\
\hline Cylinder gas & 59 & 8.9 & 14 & 3.3 & 10 & 2.9 & 83 & 5.8 \\
\hline Wood & 592 & 89.2 & 399 & 94.1 & 331 & 95.4 & 1,322 & 92.1 \\
\hline Straw/shrubs/grass & 6 & 0.9 & 11 & 2.6 & 5 & 1.4 & 22 & 1.5 \\
\hline Others & 7 & 1.1 & 0 & 0.0 & 1 & 0.3 & 8 & 0.6 \\
\hline Total & 664 & 100.0 & 424 & 100.0 & 347 & 100.0 & 1,435 & 100.0 \\
\hline
\end{tabular}

\section{Household Commodities}

Ownership of various household commodities is a significant indicator of socioeconomic status and of living conditions. It also provides valuable information on sources of information for households, for example, television, radio, and telephones. This information also helps maximize the efficiency and outreach of social services and public health campaigns. Since the areas concerned are predominantly rural, with many households depending on their own livestock, these were also included in the list of possessions.

Table 2.10 shows the detailed household possession of commodities in Bagh district; Figure 2.4 shows a comparison of household ownership of selected household goods.

When comparing ownership of selected household items in the three tehsils, households in Bagh and Dhirkot tehsils generally had more household commodities than those in Haveli. Ninety-eight percent of households in Dhirkot had electricity compared to 96 percent in Bagh and just 55 percent in Haveli. Also, very few households in Haveli had televisions (12 percent) compared to Dhirkot and Bagh (45 and 40 percent, respectively). Seven out of 10 households in all tehsils said they had radios. This suggests that in Bagh district radio is the better source of communicating information about health, especially in Haveli where radio reaches a much wider audience than television (69 versus 12 percent). Only 10 percent of households in Haveli had a telephone, whether land line or mobile, compared to 67 percent in Bagh tehsil and 73 percent in Dhirkot.

Eight percent of the households in Dhirkot had a jeep or car, more than in Bagh tehsil (6 percent) or Haveli (3 percent). Five percent of households in Bagh tehsil had 
personal computers; this was somewhat lower in Dhirkot and Haveli (4 and 3 percent, respectively).

Table 2.10: Ownership of household commodities / animals, by tehsil and district

\begin{tabular}{|c|c|c|c|c|c|c|c|c|}
\hline \multirow{3}{*}{ Commodity } & \multicolumn{6}{|c|}{ Tehsil } & \multirow{2}{*}{\multicolumn{2}{|c|}{ Total }} \\
\hline & \multicolumn{2}{|c|}{ Bagh } & \multicolumn{2}{|c|}{ Dhirkot } & \multicolumn{2}{|c|}{ Haveli } & & \\
\hline & $N$ & $\%$ & $N$ & $\%$ & $N$ & $\%$ & $N$ & $\%$ \\
\hline Electricity & 638 & 95.9 & 415 & 97.9 & 191 & 54.9 & 1,244 & 86.6 \\
\hline Radio & 479 & 72.0 & 278 & 65.6 & 241 & 69.3 & 998 & 69.5 \\
\hline Television & 266 & 40.0 & 189 & 44.7 & 43 & 12.4 & 498 & 34.7 \\
\hline Refrigerator & 128 & 19.3 & 77 & 18.2 & 6 & 1.7 & 211 & 14.7 \\
\hline Mobile/land telephone & 448 & 67.4 & 310 & 73.1 & 35 & 10.1 & 793 & 55.2 \\
\hline $\begin{array}{l}\text { Room cooler/air } \\
\text { conditioner }\end{array}$ & 24 & 3.6 & 7 & 1.7 & 2 & 0.6 & 33 & 2.3 \\
\hline Washing machine & 120 & 18.0 & 108 & 25.5 & 22 & 6.3 & 250 & 17.4 \\
\hline Water pump & 20 & 3.0 & 6 & 1.4 & 3 & 0.9 & 29 & 2.0 \\
\hline Bicycle/motorcycle & 16 & 2.4 & 15 & 3.5 & 9 & 2.6 & 40 & 2.8 \\
\hline Jeep/car & 38 & 5.7 & 34 & 8.0 & 11 & 3.2 & 83 & 5.8 \\
\hline Tractor & 15 & 2.3 & 6 & 1.4 & 4 & 1.1 & 25 & 1.7 \\
\hline Bed & 355 & 53.4 & 234 & 55.2 & 176 & 50.6 & 765 & 53.2 \\
\hline Chairs & 431 & 64.8 & 355 & 83.7 & 183 & 52.6 & 969 & 67.4 \\
\hline Almirah/ cabinet & 205 & 30.8 & 162 & 38.2 & 124 & 35.6 & 491 & 34.2 \\
\hline Clock & 278 & 41.9 & 227 & 53.5 & 160 & 46.0 & 665 & 46.3 \\
\hline Sofa & 174 & 26.2 & 145 & 34.2 & 41 & 11.8 & 360 & 25.1 \\
\hline Sewing machine & 218 & 32.8 & 165 & 38.9 & 82 & 23.6 & 465 & 32.4 \\
\hline Camera & 107 & 16.1 & 55 & 13.0 & 39 & 11.2 & 201 & 14.0 \\
\hline Personal computer & 33 & 5.0 & 16 & 3.8 & 9 & 2.6 & 58 & 4.0 \\
\hline Camel and/or horse & 2 & 0.3 & 0 & 0.0 & 10 & 2.9 & 12 & 0.8 \\
\hline Oxen & 28 & 4.2 & 38 & 9.0 & 100 & 28.8 & 166 & 11.6 \\
\hline Buffalo and/or cow & 320 & 48.2 & 226 & 53.3 & 286 & 82.2 & 832 & 57.9 \\
\hline Goat and/or sheep & 257 & 38.7 & 301 & 71.0 & 121 & 34.8 & 679 & 47.3 \\
\hline Donkey and/or mule & 11 & 1.7 & 3 & 0.7 & 14 & 4.0 & 28 & 2.0 \\
\hline Chicken and/or ducks & 440 & 66.4 & 268 & 63.2 & 241 & 69.7 & 949 & 66.2 \\
\hline
\end{tabular}


Figure 2.4: Ownership of selected household goods, by tehsil (percent)

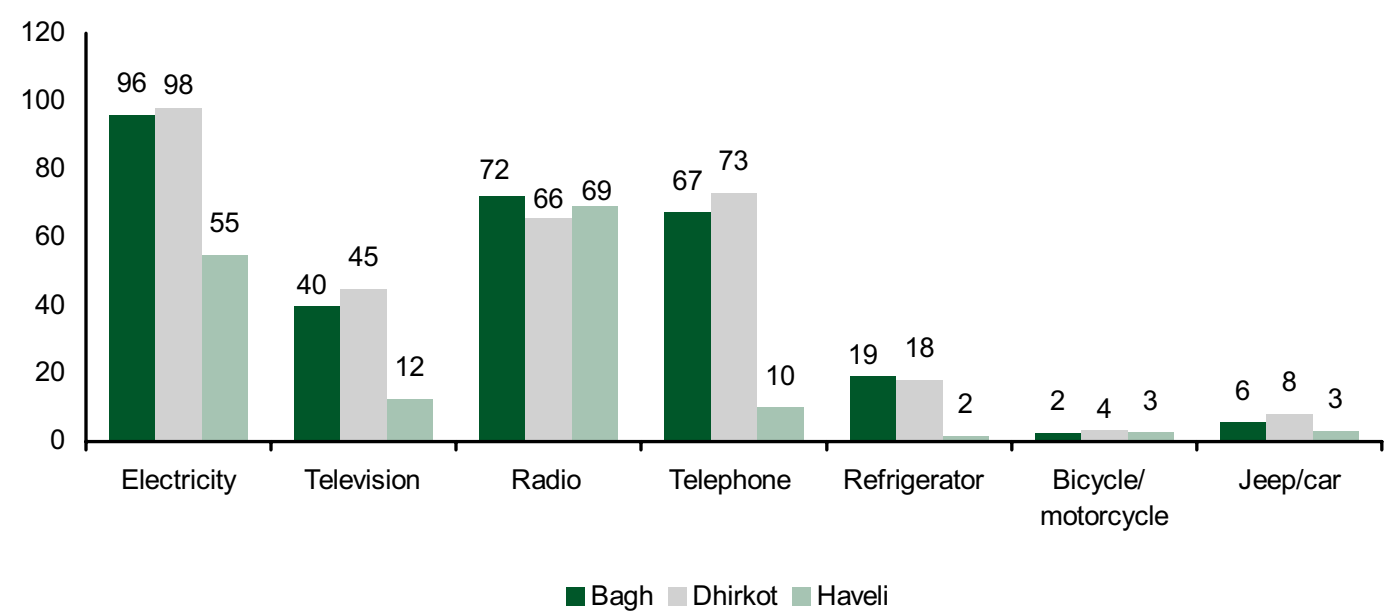

The livestock possessed by a household affects its susceptibility to disease through the transmission of infectious agents to children and mothers. Figure 2.5 gives a comparison of livestock possession of the households in the three tehsils, showing that more households in Haveli tended to have livestock, except for goats/sheep, which was almost double in Dhirkot (71 percent) than other tehsils. Chicken, buffalo/cow and goat/sheep were the main livestock in this district.

Figure 2.5: Ownership of livestock, by tehsil (percent)

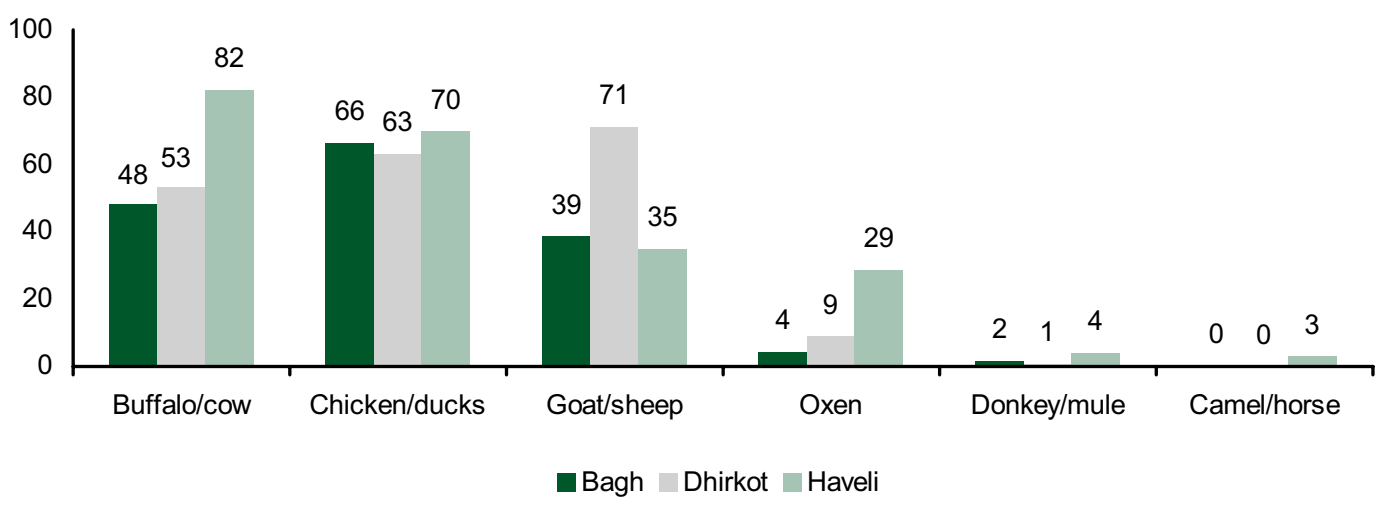




\section{lodine Deficiency}

In areas where there is little iodine in the diet, typically remote inland areas, iodine deficiency gives rise to goiter, as well as cretinism, which results in developmental delays and other health problems. Table salt mixed with a minute amount of sodium/potasium iodide is used to help reduce the chance of iodine deficiency in humans.

Iodine deficiency is a major health problem in Pakistan: "Around 50 million people across the country suffer from it" (IRIN 2007). In the PRIDE KPC survey, information was collected from the households on the type of salt they used and on their awareness of iodine deficiency and its manifestations.

\section{Use of iodized salt}

Overall in Bagh district, a majority (70 percent) of households reported that they used iodized salt; this was lower in Haveli, where almost half of the households said they used salt without iodine. Use of iodized salt was highest in Bagh tehsil, where

\section{PRIDE INDICATOR:}

Households that used iodized salt in their cooking: 70.3 percent. eight out of every ten households were using this type of salt. The use of rock salt is negligible in this district.

Table 2.11: Type of salt usually used, by tehsil and district

\begin{tabular}{lrrrrrrrrr} 
& \multicolumn{9}{c}{ Tehsil } \\
\cline { 2 - 11 } Type of salt & \multicolumn{1}{c}{ Bagh } & \multicolumn{1}{c}{ Dhirkot } & Haveli & \multicolumn{2}{c}{ Total } \\
& $N$ & $\%$ & $N$ & $\%$ & $N$ & $\%$ & $N$ & $\%$ \\
\cline { 2 - 10 } Powder salt (without iodine) & 140 & 21.2 & 106 & 25.0 & 169 & 48.7 & 415 & 29.0 \\
\hline Powder salt (with iodine) & 517 & 78.5 & 314 & 74.1 & 174 & 50.1 & 1,005 & 70.3 \\
\hline Rock salt & 2 & 0.3 & 4 & 0.9 & 4 & 1.2 & 10 & 0.7 \\
Total & 659 & 100 & 424 & 100 & 347 & 100 & 1,430 & 100
\end{tabular}

\section{Awareness and knowledge}

Those who were not using iodized salt were then asked if they had heard about it. Among the non-users, awareness was higher in Dhirkot, where 67 percent of the households said they had heard about iodized salt, compared to Haveli and Bagh, where 49 and 37 percent, respectively, had heard about it. 
Figure 2.6: Awareness of iodized salt among non-users, by tehsil (percent)

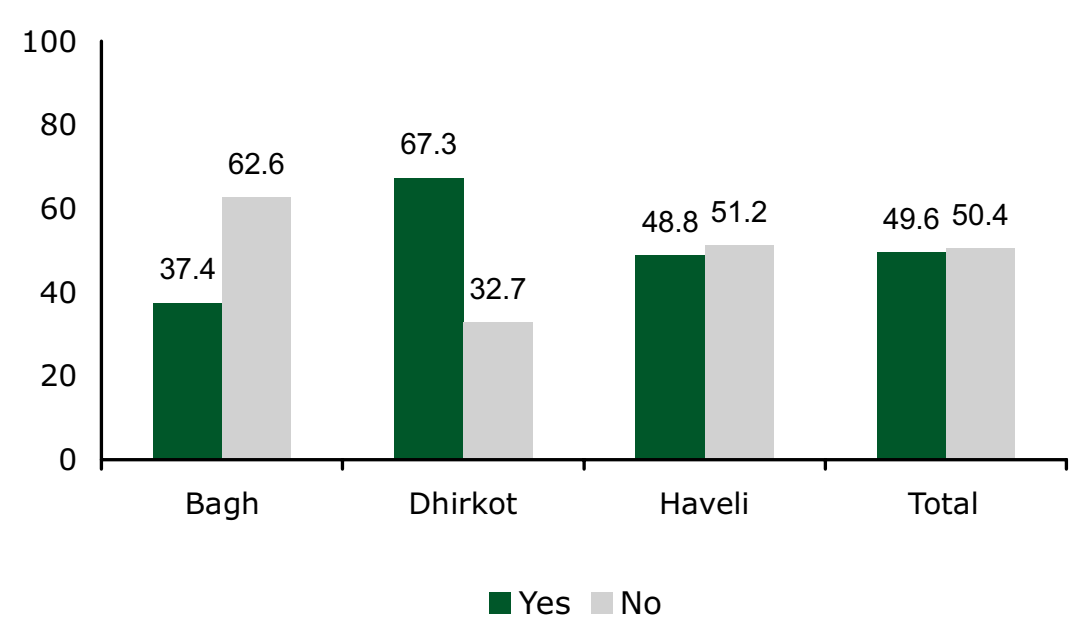

Households that were not using iodized salt but had heard about it were asked about their source of knowledge. The primary source of information was media (radio, television and newspapers) (37 percent), followed by shopkeepers (30 percent), and neighbors (15 percent). Table 2.12 shows all sources mentioned.

Table 2.12: Source of knowledge about iodized salt, by tehsil and district

\begin{tabular}{|c|c|c|c|c|c|c|c|c|}
\hline \multirow{3}{*}{ Source } & \multicolumn{6}{|c|}{ Tehsil } & \multirow{2}{*}{\multicolumn{2}{|c|}{ Total }} \\
\hline & \multicolumn{2}{|c|}{ Bagh } & \multicolumn{2}{|c|}{ Dhirkot } & \multicolumn{2}{|c|}{ Haveli } & & \\
\hline & $N$ & $\%$ & $N$ & $\%$ & $N$ & $\%$ & $N$ & $\%$ \\
\hline Health worker/doctor & 6 & 10.7 & 6 & 8.5 & 5 & 5.9 & 17 & 8.0 \\
\hline Radio/TV/newspapers & 24 & 42.9 & 31 & 43.7 & 23 & 27.1 & 78 & 36.8 \\
\hline Neighbor & 11 & 19.6 & 6 & 8.5 & 14 & 16.5 & 31 & 14.6 \\
\hline Own child & 4 & 7.1 & 7 & 9.9 & 8 & 9.4 & 19 & 9.0 \\
\hline Shopkeeper & 9 & 16.1 & 18 & 25.4 & 37 & 43.5 & 64 & 30.2 \\
\hline$\underline{\text { Relatives }}$ & 4 & 7.1 & 1 & 1.4 & 3 & 3.5 & 8 & 3.8 \\
\hline From salt pack & 6 & 10.7 & 9 & 12.7 & 1 & 1.2 & 16 & 7.5 \\
\hline Other & 1 & 1.8 & 3 & 4.2 & 3 & 3.5 & 7 & 3.3 \\
\hline Total & 56 & na & 71 & na & 85 & na & 212 & na \\
\hline
\end{tabular}

na $=$ Not applicable, respondents could name more than one source.

"It is commonly believed that iodine deficiency shows itself only as goiter, but actually it can lead to slow mental development, retardation, and lethargy and reproductive problems, including miscarriages or stillbirths among women" (Zafar 2007). Table 2.13 and Figure 2.7 show the responses when respondents were asked to 
point out the ill effects of iodine deficiency in the body. A majority of respondents named goiter (64 percent), followed by mental retardation and physical weakness (10 and 11 percent, respectively), but only 5 percent mentioned cretinism. Differences between the tehsils in knowledge about iodine deficiency were observed.

More than one-third of the women (35 percent) described some other manifestations of iodine deficiency, which actually were misconceptions (for example, calcium deficiency, low and/or high blood pressure, joint related diseases, etc.). This clearly indicates that people were not clear about the effects of iodine deficiency.

Table 2.13: Knowledge about ill effects of iodine deficiency, by tehsil and district

\begin{tabular}{|c|c|c|c|c|c|c|c|c|}
\hline \multirow{3}{*}{ Outcome } & \multicolumn{6}{|c|}{ Tehsil } & \multirow{2}{*}{\multicolumn{2}{|c|}{ Total }} \\
\hline & \multicolumn{2}{|c|}{ Bagh } & \multicolumn{2}{|c|}{ Dhirkot } & \multicolumn{2}{|c|}{ Haveli } & & \\
\hline & $N$ & $\%$ & $N$ & $\%$ & $N$ & $\%$ & $N$ & $\%$ \\
\hline Goiter & 141 & 59.2 & 79 & 64.2 & 63 & 75.0 & 283 & 63.6 \\
\hline Cretinism & 15 & 6.3 & 7 & 5.7 & 2 & 2.4 & 24 & 5.4 \\
\hline Mental retardation & 28 & 11.8 & 18 & 14.6 & 0 & 0.0 & 46 & 10.3 \\
\hline Deafness & 8 & 3.4 & 4 & 3.3 & 0 & 0.0 & 12 & 2.7 \\
\hline Still birth & 5 & 2.1 & 1 & 0.8 & 0 & 0.0 & 6 & 1.3 \\
\hline Physical weakness & 27 & 11.3 & 16 & 13.0 & 5 & 6.0 & 48 & 10.8 \\
\hline Other & 92 & 38.7 & 43 & 35.0 & 21 & 25.0 & 156 & 35.1 \\
\hline Total & 238 & na & 123 & na & 84 & na & 445 & na \\
\hline
\end{tabular}

na $=$ Not applicable; respondents could name more than one outcome.

Figure 2.7: Reported manifestations of iodine deficiency, by tehsil (percent)

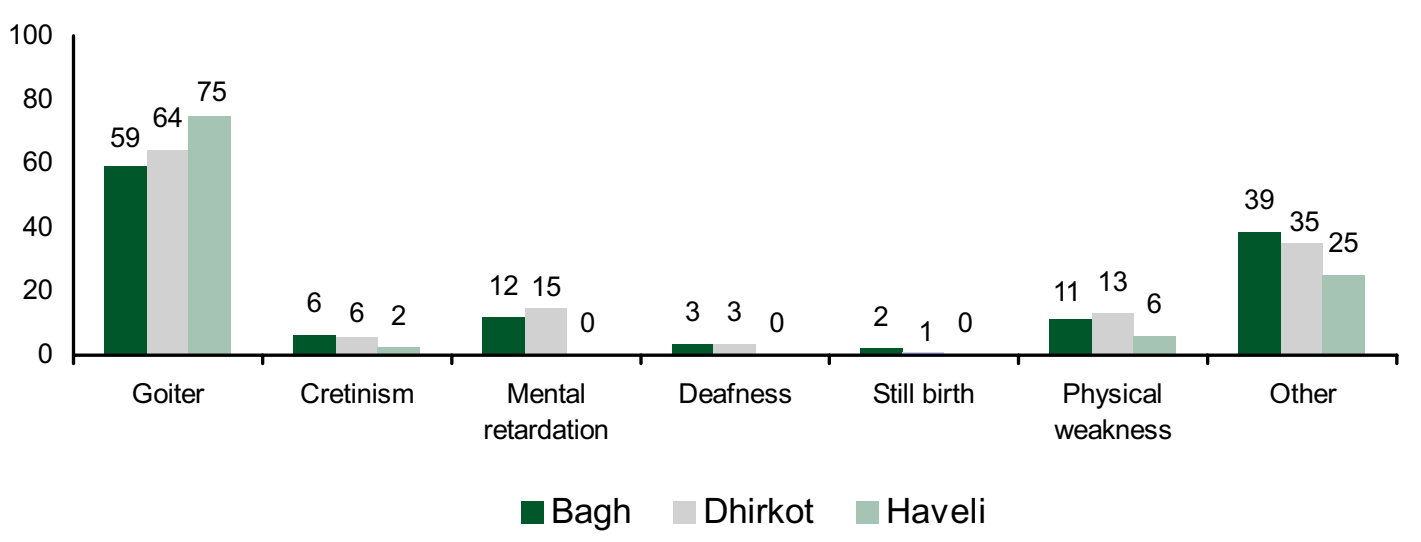


Responses about the effects of iodine deficiency in terms of correct and incorrect knowledge are given in Figure 2.8. Three out of every 10 respondent (29 percent) in Haveli had a wrong perception about the ill effects of iodine deficiency; in Dhirkot and Bagh tehsils, around two-fifths (38 and 42 percent, respectively) were not properly aware of the ill effects of iodine deficiency in the body.

Figure 2.8: Knowledge about ill effects of iodine deficiency, by tehsil (percent)

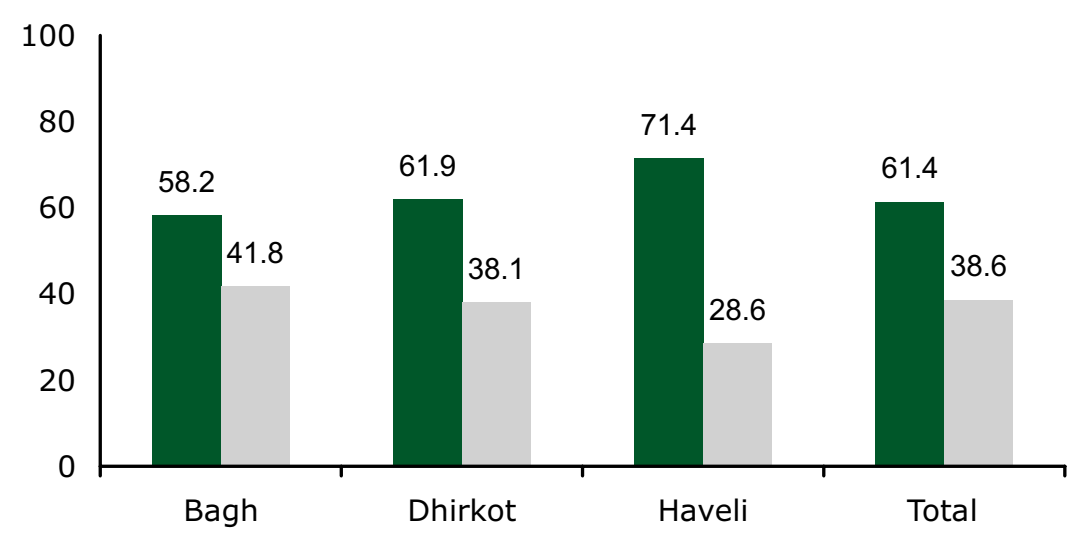

- Correct knowledge Wrong perception

\section{Malaria}

The prevention of malaria may be more cost-effective than treatment of this disease. The households were asked whether or not they did anything to avoid mosquito bites. The respondents were asked to indicate various measures they adopted to avoid mosquito bites.

\section{Awareness and prevention}

As shown in Figure 2.9, less than half (45 percent) of the households in Haveli said they took measures to avoid mosquito bites; 55 percent said they took no measures. The percentage in Bagh and Dhirkot tehsils who took measures to prevent bites was better (74 and 85 percent, respectively). Among those who adopted precautionary measures (see Table 2.14), the most common methods used were to give smoke by fire (39 percent), use of fans (30 percent), using spray (19 percent) and coils (16 percent). 
Figure 2.9: Action taken or not taken to prevent mosquito bites, by tehsil (percent)

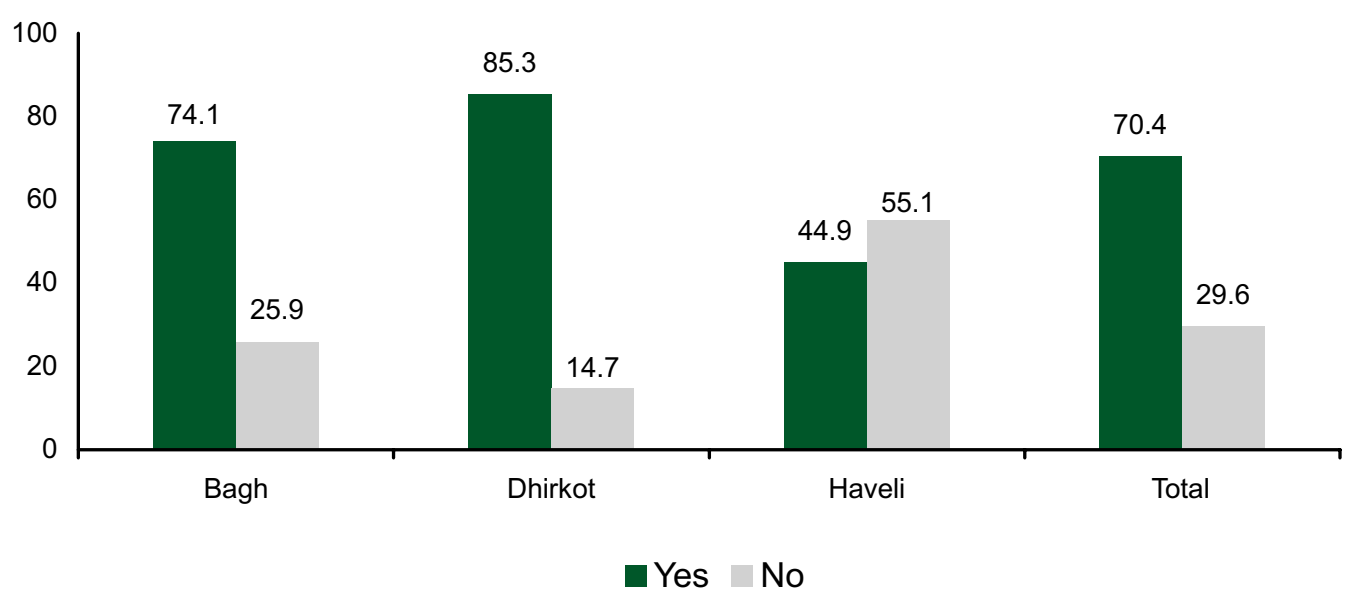

Table 2.14: Measures taken to avoid mosquito bites, by tehsil and district

\begin{tabular}{|c|c|c|c|c|c|c|c|c|}
\hline \multirow{3}{*}{ Measure } & \multicolumn{6}{|c|}{ Tehsil } & \multirow{2}{*}{\multicolumn{2}{|c|}{ Total }} \\
\hline & \multicolumn{2}{|c|}{ Bagh } & \multicolumn{2}{|c|}{ Dhirkot } & \multicolumn{2}{|c|}{ Haveli } & & \\
\hline & $N$ & $\%$ & $N$ & $\%$ & $N$ & $\%$ & $N$ & $\%$ \\
\hline Coil & 101 & 20.5 & 40 & 11.1 & 24 & 15.3 & 165 & 16.3 \\
\hline Mat & 74 & 15.0 & 25 & 6.9 & 8 & 5.1 & 107 & 10.6 \\
\hline Spray & 117 & 23.7 & 26 & 7.2 & 51 & 32.5 & 194 & 19.2 \\
\hline Mosquito net & 37 & 7.5 & 24 & 6.6 & 29 & 18.5 & 90 & 8.9 \\
\hline Give smoke by fire & 179 & 36.3 & 157 & 43.5 & 55 & 35.0 & 391 & 38.7 \\
\hline Fan & 120 & 24.3 & 180 & 49.9 & 7 & 4.5 & 307 & 30.4 \\
\hline Other & 21 & 4.3 & 8 & 2.2 & 3 & 1.9 & 32 & 3.2 \\
\hline Total & 493 & na & 361 & na & 157 & na & 1,011 & na \\
\hline
\end{tabular}

na $=$ Not applicable; respondents could name more than one measure.

Mosquito nets help keep mosquitoes away from people, and thus greatly reduce the infection and transmission of malaria; this is especially true in rural areas where the structure of the households does not allow for the use of coils, mats, sprays and other indoor treatments to avoid mosquitoes. For families with low socioeconomic status, nets can also be used exclusively by mothers and newborns, who are more vulnerable to malaria infections.

Overall in Bagh district, one-tenth (10 percent) of the households had mosquito nets, of those who had mosquito nets, 1 out of every 6 households (17 percent) indicated 
that no one slept under a mosquito net during the previous night. This indicates that ownership and use of mosquito nets in Bagh district is negligible. Those who possessed mosquito nets were not in the habit of using them for protection against mosquito bites. Clearly, community health education is needed to promote better health practices. 


\section{Chapter 3}

\section{Characteristics of Married Women of Reproductive Age}

This chapter explores the background characteristics of 1,483 ever-married women of reproductive age (ages 15-49 years) who were interviewed as part of the KPC baseline survey. Table 3.1 shows the number of women interviewed by tehsil. Like the socioeconomic condition of the household, information on basic background characteristics of the respondents is essential for the interpretation of the results. For this purpose, questions about a woman's age, her age at marriage, mother tongue, education (for both husband and wife), and husband's occupation were included in the survey.

Table 3.1: Ever-married women of reproductive age interviewed for the KPC baseline survey, by tehsil and district

\begin{tabular}{lcc} 
& Ever-married women of reproductive age \\
\cline { 2 - 3 } Tehsil & Number & Percent \\
Bagh & 727 & 49.0 \\
\hline Dhirkot & 422 & 28.5 \\
\hline Haveli & 334 & 22.5 \\
Total & 1,483 & 100.0
\end{tabular}

\section{Demographic Characteristics}

\section{Age}

Table 3.2 gives an overview of the age distribution of the respondents. Of the 1,483 eligible women interviewed, a large proportion (57 percent) belonged to the middle order age group of 25-39 years. The age group 25-29 represents more than one-fifth (22 percent) of the respondents. A higher proportion of married women in Haveli were in the age group 15-19 years (5 percent) than in Dhirkot (under 2 percent), perhaps indicating earlier marriages in Haveli (though numbers are small). 
The second part of the table shows respondent's age at marriage by tehsil. Age at marriage is important because poor women who get married at an early age, and also get pregnant early, have a higher risk of infant mortality because they have inadequate access to maternal and child health services (Singh and Samara 1996). The results show that the overall teenage ( $<20$ years of age) marriage rate for the district was 66 percent, which is also the same for Mansehra district covered under this survey; however, differences among tehsils were noticed. In Haveli, almost threequarters of the women (73 percent) were married during their teen years, while in Bagh tehsil this proportion was 68 percent compared to 58 percent in Dhirkot. Figures for Haveli indicate the early marriage trends in this area compared to others. Overall, only a small proportion of the women (7 percent) were married at the age of 25 or older. Slightly more than a quarter ( 27 percent) of the women were married when they were 20-24 years of age.

Table 3.2 and Figure 3.1 show the mean age at marriage. The average age at marriage of women in Bagh district is 18.4 years, ranging from 18.9 in Dhirkot to 18.0 in Haveli.

Table 3.2: Age, age at marriage and mean age at marriage of eligible women, by tehsil and district

\begin{tabular}{|c|c|c|c|c|c|c|c|c|}
\hline \multirow{3}{*}{ Age } & \multicolumn{6}{|c|}{ Tehsil } & & \\
\hline & \multicolumn{2}{|c|}{ Bagh } & \multicolumn{2}{|c|}{ Dhirkot } & \multicolumn{2}{|c|}{ Haveli } & \multicolumn{2}{|c|}{ Total } \\
\hline & $N$ & $\%$ & $N$ & $\%$ & $N$ & $\%$ & $N$ & $\%$ \\
\hline $15-19$ & 25 & 3.4 & 7 & 1.7 & 18 & 5.4 & 50 & 3.4 \\
\hline $20-24$ & 103 & 14.2 & 53 & 12.6 & 67 & 20.1 & 223 & 15.0 \\
\hline $25-29$ & 180 & 24.8 & 96 & 22.7 & 49 & 14.7 & 325 & 21.9 \\
\hline $30-34$ & 138 & 19.0 & 83 & 19.7 & 60 & 18.0 & 281 & 18.9 \\
\hline $35-39$ & 111 & 15.3 & 76 & 18.0 & 49 & 14.7 & 236 & 15.9 \\
\hline $40-44$ & 93 & 12.8 & 51 & 12.1 & 56 & 16.8 & 200 & 13.5 \\
\hline $45-49$ & 77 & 10.6 & 56 & 13.3 & 35 & 10.5 & 168 & 11.3 \\
\hline Total & 727 & 100.0 & 422 & 100.0 & 334 & 100.0 & 1,483 & 100.0 \\
\hline \multicolumn{9}{|l|}{ Age at marriage } \\
\hline$<15$ & 93 & 12.8 & 45 & 10.7 & 44 & 13.2 & 182 & 12.3 \\
\hline $15-19$ & 402 & 55.3 & 200 & 47.4 & 200 & 59.9 & 802 & 54.1 \\
\hline $20-24$ & 184 & 25.3 & 142 & 33.6 & 74 & 22.2 & 400 & 27.0 \\
\hline $25+$ & 48 & 6.6 & 35 & 8.3 & 16 & 4.8 & 99 & 6.7 \\
\hline Total & 727 & 100.0 & 422 & 100.0 & 334 & 100.0 & 1,483 & 100.0 \\
\hline Mean age at marriage & 727 & 18.3 & 422 & 18.9 & 334 & 18.0 & 1,483 & 18.4 \\
\hline
\end{tabular}


Figure 3.1: Age at marriage (by age group) of eligible women in Bagh district

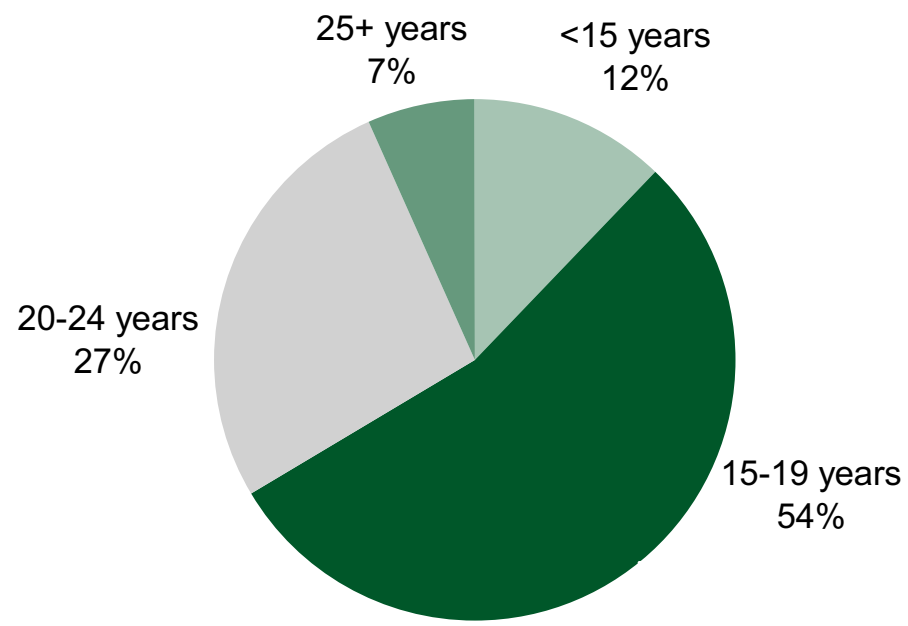

\section{Marital Status}

The married women of reproductive age who were interviewed were required to be either currently married or to have been married at some point in the past. Table 3.3 reveals that about 96 percent of these women were currently married, 3 percent were widowed and less than 1 percent were divorced and separated. The same pattern can be seen in the three tehsils of Bagh district. The proportion of widows in Haveli was higher (4 percent), which might be due to the vast number of male deaths in Haveli during the October 2005 earthquake.

Table 3.3: Marital status of eligible women, by tehsil and district

\begin{tabular}{|c|c|c|c|c|c|c|c|c|}
\hline \multirow[b]{2}{*}{ Marital status } & \multicolumn{6}{|c|}{ Tehsil } & \multirow{2}{*}{\multicolumn{2}{|c|}{ Total }} \\
\hline & $\mathrm{Ba} \xi$ & & Dhir & & $\mathrm{Ha}$ & & & \\
\hline & $N$ & $\%$ & $N$ & $\%$ & $N$ & $\%$ & N & $\%$ \\
\hline Married & 697 & 95.9 & 405 & 96.0 & 319 & 95.5 & 1,421 & 95.8 \\
\hline Widowed & 21 & 2.9 & 13 & 3.1 & 13 & 3.9 & 47 & 3.2 \\
\hline Divorced & 4 & 0.6 & 3 & 0.7 & 2 & 0.6 & 9 & 0.6 \\
\hline Separated & 5 & 0.7 & 1 & 0.2 & 0 & 0.0 & 6 & 0.4 \\
\hline Total & 727 & 100.0 & 422 & 100.0 & 334 & 100.0 & 1,483 & 100.0 \\
\hline
\end{tabular}

\section{Education}

The level of education obtained by a woman is an absolute indicator for her status in society as well as her independent decision making power. "The higher level of education she has obtained, the better she is expected to be concerned about her 
health and that of her family" (Caldwell 1986). The women were asked about their own level of education and that of their husbands.

A vast disparity can be seen between tehsils in women's education (see Table 3.4). Haveli had widespread illiteracy among women: 65 percent did not attend school and only 5 percent had gone beyond the secondary level. Though similar to Haveli, the situation in Bagh tehsil was better: 44 percent had no education and 10 percent had completed more than ten years of schooling. In Dhirkot, 39 percent of the women had never been to school and 24 percent had only primary-level education.

The higher education level of husbands is also an indicator of a better socioeconomic status of families, and can have positive and recurring affect on the health of families. Information on the education of husbands is also shown in Table 3.4. Education among husbands of women of Bagh district was recorded with good results: 88 percent had completed some level of education. Overall in Bagh district, secondarylevel education among husbands was prominent at 30 percent. Among tehsils, Haveli had 19 percent illiterate husbands, Dhirkot had 11 percent and Bagh tehsil had 10 percent.

Table 3.4: Education level of eligible women and their husbands, by tehsil and district

\begin{tabular}{|c|c|c|c|c|c|c|c|c|}
\hline \multirow{3}{*}{ Variable } & \multicolumn{6}{|c|}{ Tehsil } & & \\
\hline & \multicolumn{2}{|c|}{ Bagh } & \multicolumn{2}{|c|}{ Dhirkot } & \multicolumn{2}{|c|}{ Haveli } & \multicolumn{2}{|c|}{ Total } \\
\hline & $N$ & $\%$ & $N$ & $\%$ & $N$ & $\%$ & $N$ & $\%$ \\
\hline \multicolumn{9}{|l|}{ Women } \\
\hline No education & 321 & 44.2 & 165 & 39.1 & 217 & 65.0 & 703 & 47.4 \\
\hline Primary & 139 & 19.1 & 102 & 24.2 & 50 & 15.0 & 291 & 19.6 \\
\hline Middle & 105 & 14.4 & 63 & 14.9 & 19 & 5.7 & 187 & 12.6 \\
\hline Secondary & 87 & 12.0 & 67 & 15.9 & 31 & 9.3 & 185 & 12.5 \\
\hline Secondary + & 75 & 10.3 & 25 & 5.9 & 17 & 5.1 & 117 & 7.9 \\
\hline Total & 727 & 100.0 & 422 & 100.0 & 334 & 100.0 & 1,483 & 100.0 \\
\hline \multicolumn{9}{|l|}{ Husbands } \\
\hline No education & 70 & 9.6 & 45 & 10.7 & 62 & 18.6 & 177 & 12.0 \\
\hline Primary & 142 & 19.6 & 92 & 21.9 & 70 & 21.0 & 304 & 20.5 \\
\hline Middle & 158 & 21.8 & 87 & 20.7 & 65 & 19.5 & 310 & 20.9 \\
\hline Secondary & 216 & 29.8 & 132 & 31.4 & 93 & 27.8 & 441 & 29.8 \\
\hline Secondary + & 140 & 19.3 & 65 & 15.4 & 44 & 13.2 & 249 & 16.8 \\
\hline Total & 726 & 100.0 & 421 & 100.0 & 334 & 100.0 & 1,481 & 100.0 \\
\hline
\end{tabular}




\section{Language}

Table 3.5 and Figure 3.2 show that the main language (mother tongue) of the women in Bagh district was Pahari (87 percent). Ninety-nine percent of the women in Dhirkot spoke Pahari as their main language; in Haveli and Bagh, Pahari was the main language for 59 and 95 percent, respectively. Gojri was the main language of 33 percent of the women in Haveli. Overall in Bagh district, other languages than Kashmiri, Pahari, and Gojri were also being spoken by 3 percent of the women.

Table 3.5: Mother tongue of eligible women, by tehsil and district

\begin{tabular}{|c|c|c|c|c|c|c|c|c|}
\hline \multirow{2}{*}{ Mother tongue } & \multicolumn{6}{|c|}{ Tehsil } & \multirow{2}{*}{\multicolumn{2}{|c|}{ Total }} \\
\hline & \multicolumn{2}{|c|}{ Bagh } & \multicolumn{2}{|c|}{ Dhirkot } & \multicolumn{2}{|c|}{ Haveli } & & \\
\hline & $N$ & $\%$ & $N$ & $\%$ & $N$ & $\%$ & $N$ & $\%$ \\
\hline Kashmiri & 12 & 1.7 & 1 & 0.2 & 15 & 4.5 & 28 & 1.9 \\
\hline Pahari & 687 & 94.6 & 416 & 98.6 & 195 & 58.4 & 1,298 & 87.6 \\
\hline Gojri & 7 & 1.0 & 1 & 0.2 & 109 & 32.6 & 117 & 7.9 \\
\hline Other & 20 & 2.8 & 4 & 0.9 & 15 & 4.5 & 39 & 2.6 \\
\hline Total & 726 & 100.0 & 422 & 100.0 & 334 & 100.0 & 1,482 & 100.0 \\
\hline
\end{tabular}

Figure 3.2: Mother tongue of eligible women in Bagh district

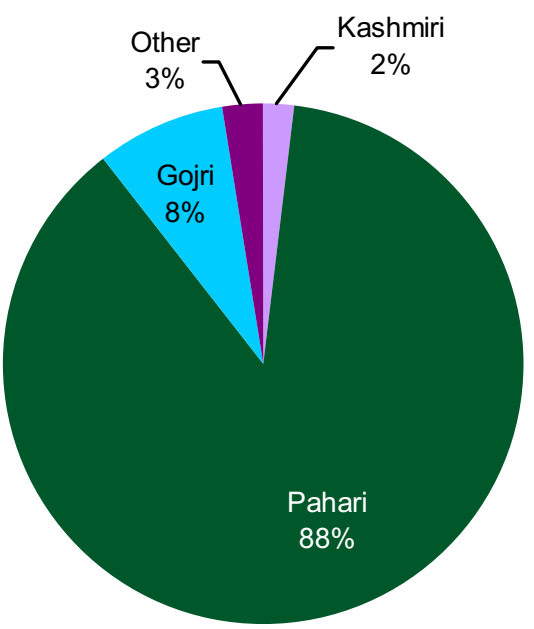

\section{Number of Children}

Fertility trends can be seen from the number of children ever born and the age of mothers. Table 3.5 illustrates the number of children ever born to women in Bagh district. Women at the end of their reproductive years generally have more children. In Bagh district, 80 percent of women ages 40-49 years had more than 5 live births, 
and 60 percent ages $45-49$ had given birth to 7 or more children, indicating a high fertility rate among this cohort. Eleven percent of the women ages 25-29 had at least 5 live births. On the other hand, 16 percent ages 25-29 and 30 percent ages 20-24 had not had a live birth yet.

Table 3.6 also gives the comparison of mean number of children ever born and living to the women of different age groups. Overall in Bagh district, the ratio of ever born to living children is $4: 3.5$.

Table 3.6: Eligible women according to age, by children ever born, number of women and mean number of children (ever born and living)

\begin{tabular}{|c|c|c|c|c|c|c|c|c|c|}
\hline \multirow[b]{3}{*}{ Age } & \multicolumn{5}{|c|}{ Children ever born } & \multirow{3}{*}{$\begin{array}{r}\text { Total } \\
(\%)\end{array}$} & \multirow{3}{*}{$\begin{array}{r}\text { Number } \\
\text { of } \\
\text { women }\end{array}$} & \multirow{2}{*}{\multicolumn{2}{|c|}{$\begin{array}{l}\text { Mean number of } \\
\text { children }\end{array}$}} \\
\hline & & & & & 7 or & & & & \\
\hline & 0 & $1-2$ & $3-4$ & $5-6$ & more & & & Ever born & Living \\
\hline $15-19$ & 62.0 & 36.0 & 2.0 & 0.0 & 0.0 & 100.0 & 50 & 0.5 & 0.4 \\
\hline $20-24$ & 30.0 & 55.2 & 13.0 & 1.8 & 0.0 & 100.0 & 223 & 1.3 & 1.1 \\
\hline $25-29$ & 16.3 & 37.8 & 34.8 & 10.2 & 0.9 & 100.0 & 325 & 2.4 & 2.1 \\
\hline $30-34$ & 5.3 & 19.9 & 32.7 & 29.9 & 12.1 & 100.0 & 281 & 4.0 & 3.5 \\
\hline $35-39$ & 5.1 & 10.2 & 29.2 & 28.4 & 27.1 & 100.0 & 236 & 5.0 & 4.3 \\
\hline $40-44$ & 4.5 & 4.0 & 14.0 & 22.0 & 55.5 & 100.0 & 200 & 6.6 & 5.7 \\
\hline $45-49$ & 3.6 & 3.6 & 10.7 & 22.6 & 59.5 & 100.0 & 168 & 6.9 & 6.0 \\
\hline Total & 13.0 & 24.1 & 23.6 & 18.2 & 21.0 & 100.0 & 1,483 & 4.0 & 3.5 \\
\hline
\end{tabular}

\section{Occupation of Husbands}

Employment is primary for any sustained earning for families. Overall in Bagh district, unemployment stands at about 14 percent. In Bagh tehsil, unemployment is relatively high (17 percent), which could be due to the heavy destruction of the infrastructure during the 2005 earthquake. The population of the district engages in a variety of professions, from unskilled labor to professional jobs at executive levels. Nine percent of the husbands were working abroad. Skilled labor accounted for more employment (20 percent) than any other type. Twelve percent of husbands were earning from business, both small and large scale. In Haveli, 11 percent of the husbands were associated with agriculture and livestock compared to only 2 percent in both Dhirkot and Bagh. 
Table 3.7: Occupation of eligible women's husbands, by tehsil and district

\begin{tabular}{lrrrrrrrr} 
& \multicolumn{9}{c}{ Tehsil } \\
\cline { 2 - 10 } Occupation & \multicolumn{1}{c}{ Bagh } & \multicolumn{2}{c}{ Dhirkot } & \multicolumn{2}{c}{ Haveli } & \multicolumn{2}{c}{ Total } \\
\cline { 2 - 10 } Agriculture/livestock/poultry & $N$ & $\%$ & $N$ & $\%$ & $N$ & $\%$ & \multicolumn{1}{c}{$\%$} \\
\hline Skilled labor & 13 & 1.8 & 8 & 1.9 & 36 & 10.8 & 57 & 3.8 \\
\hline Unskilled labor & 129 & 17.7 & 118 & 28.0 & 43 & 12.9 & 290 & 19.6 \\
\hline Employed non-executive level & 122 & 11.4 & 55 & 13.0 & 70 & 21.0 & 208 & 14.0 \\
\hline Employed executive level & 20 & 2.8 & 9 & 2.1 & 4 & 1.2 & 33 & 2.2 \\
\hline Professional & 34 & 4.7 & 20 & 4.7 & 14 & 4.2 & 68 & 4.6 \\
\hline In army & 19 & 2.6 & 17 & 4.0 & 29 & 8.7 & 65 & 4.4 \\
\hline Small scale business & 67 & 9.2 & 54 & 12.8 & 34 & 10.2 & 155 & 10.5 \\
\hline Large scale business & 20 & 2.8 & 4 & 0.9 & 1 & 0.3 & 25 & 1.7 \\
\hline Retired & 14 & 1.9 & 9 & 2.1 & 18 & 5.4 & 41 & 2.8 \\
\hline Abroad & 79 & 10.9 & 34 & 8.1 & 16 & 4.8 & 129 & 8.7 \\
\hline Unemployed & 122 & 16.8 & 52 & 12.3 & 30 & 9.0 & 204 & 13.8 \\
\hline Other & 5 & 0.7 & 2 & 0.5 & 2 & 0.6 & 9 & 0.6 \\
Total & 727 & 100.0 & 422 & 100.0 & 334 & 100.0 & 1,483 & 100.0
\end{tabular}





\section{Chapter 4}

\section{Contraceptive Knowledge and Use}

The contraceptive prevalence rate (CPR) is one of the main indicators of the PRIDE KPC baseline survey. A section of the women's questionnaire focused on women's knowledge and use of family planning methods. Though these questions were asked from all ever-married women ages 15-49 years, the results presented in this chapter are only from the 1,421 women who were currently married.

\section{Knowledge of Methods}

Lack of knowledge of contraceptive methods can be a major obstacle to their use. The women, currently married ages 15-49 years, were asked to name the ways or methods that a couple can use to delay or avoid pregnancy. Figure 4.1 shows knowledge of specific contraceptives in Bagh district. More than 94 percent of the women knew about pills and injectables as family planning methods. Knowledge of female sterilization and IUDs was also high (92 and 90 percent, respectively). More than three-fourths (77 percent) knew about condoms. The least known methods were male sterilization and implants (28 and 25 percent, respectively). Knowledge of traditional methods (withdrawal and rhythm) was not as high as that for modern FP methods. 
Figure 4.1: Currently married women's knowledge of specific contraceptive methods (percent)

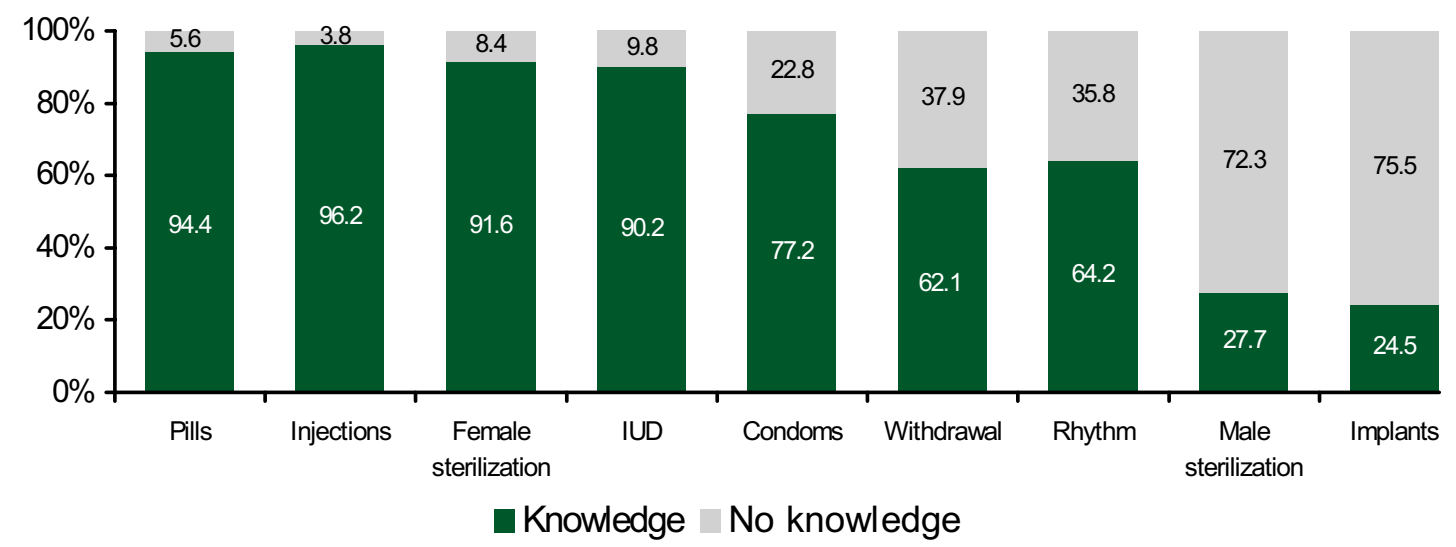

\section{Use of Methods}

\section{Ever Used}

Women who have ever used any contraceptive method, regardless of their current use status are considered ever users of contraceptive methods. KPC survey findings show that the total ever use of contraceptives in Bagh district was 62 percent. Table 4.1 shows ever use of contraceptives by tehsil for currently married women. In Bagh tehsil, the most common modern methods ever used were condoms ( 29 percent), followed by injectables and pills (19 and 14 percent, respectively). This pattern is the same in Dhirkot: ever use of condoms was 32 percent, followed by injectables and pills (16 and 12 percent, respectively). In Haveli, the order is slightly changed but the main three modern methods ever used were the same: injectables (15 percent), condoms (13 percent) and pills (10 percent). Among traditional methods, use of rhythm was higher in Dhirkot and Haveli (40 and 38 percent, respectively), but in Bagh tehsil 32 percent of the women had ever used withdrawal. 
Table 4.1: Contraceptive methods ever used by currently married women, by tehsil and district

\begin{tabular}{lrrrrr} 
& \multicolumn{3}{c}{ Tehsil } & & \\
\cline { 2 - 6 } Method & Bagh & Dhirkot & Haveli & Total \\
Female sterilization & $\%$ & $\%$ & $\%$ & $\%$ & $N$ \\
\cline { 2 - 6 } Pills & 4.9 & 6.9 & 1.9 & 4.8 & 68 \\
\hline IUD & 13.7 & 11.7 & 10.4 & 12.4 & 175 \\
\hline Injectables & 8.1 & 4.5 & 6.0 & 6.6 & 93 \\
\hline Implants & 18.9 & 16.3 & 14.8 & 17.2 & 244 \\
\hline Condoms & 0.0 & 0.5 & 0.0 & 0.1 & 2 \\
\hline Rhythm & 29.4 & 31.6 & 13.2 & 26.4 & 374 \\
\hline Withdrawal & 25.3 & 38.9 & 38.2 & 32.1 & 455 \\
\hline Other & 31.5 & 35.7 & 23.8 & 31.0 & 438 \\
\hline Overall ever use & 0.3 & 0.2 & 0.6 & 0.4 & 5 \\
(N) & 62.2 & 66.2 & 54.2 & 61.5 & 874 \\
na $=$ Not applicable; respondents could name more than one method. & $(405)$ & $(319)$ & na & $(1,421)$ \\
& & & & &
\end{tabular}

Figure 4.2 shows the overall ever-use status of contraceptives used by currently married women in Bagh district. The traditional methods were the highest ever-used methods among all methods, with rhythm used by 32 percent and withdrawal by 31 percent. Among the modern methods, the most ever-used method was condoms (26 percent), followed by injectables and pills (17 and 12 percent, respectively). 
Figure 4.2: Ever use of specific contraceptive methods by currently married women (percent)

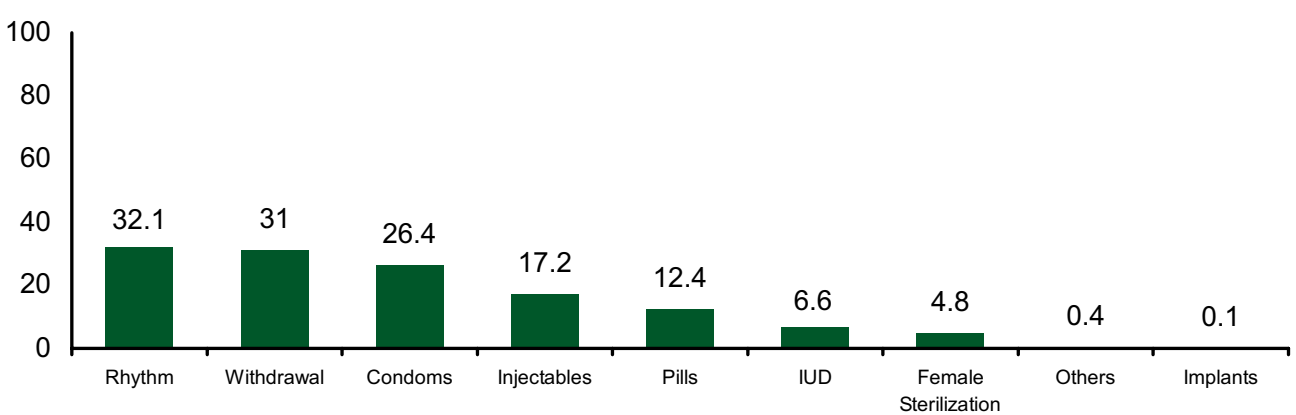

\section{Current Use}

Contraceptive prevalence is defined as the proportion of currently married women ages 15-49 years using any method of family planning at the time of the survey. Table 4.2 shows the percentage distribution of married women currently using specific family planning methods.

The overall CPR of Bagh district was recorded as 29 percent, reflecting that 1 out of every 3 women was currently using some family planning method. Tehsil differences were noted. The CPR was lowest in Haveli (19 percent), next highest in Bagh (29 percent)

\section{PRIDE INDICATOR:}

Contraceptive prevalence rate for modern methods among currently married women: 18.4 percent.

and highest for Dhirkot (37 percent). Overall, modern methods of contraception seem to be more popular than traditional ones (18 percent modern versus 11 percent traditional). Among the modern methods, condoms (7 percent) and female sterilization (5 percent) were more common. Male sterilization was not reported by any respondent, and only 1 reported using implants (though this woman had consulted a health facility outside of Bagh district), indicating that these two types of contraception were not available in the district.

Condom was the most widely used family planning method in Dhirkot and Bagh. In Haveli, injectable was the most popular modern method, followed by condoms. 
Table 4.2: Percent of current use of contraceptive methods by currently married women, by tehsil and district

\begin{tabular}{lrrrr} 
& \multicolumn{3}{c}{ Tehsil } & \\
\cline { 2 - 4 } Method & Bagh & Dhirkot & Haveli & Total \\
\hline Any method & 29.4 & 37.0 & 18.8 & 29.2 \\
\hline Any modern method & 19.2 & 23.2 & 10.7 & 18.4 \\
\hline Female sterilization & 10.2 & 13.8 & 8.2 & 10.8 \\
\hline Male sterilization & 4.9 & 6.9 & 1.9 & 4.8 \\
\hline Pills & 0.0 & 0.0 & 0.0 & 0.0 \\
\hline IUD & 0.4 & 0.0 & 0.0 & 0.2 \\
\hline Injectable & 2.3 & 2.2 & 2.2 & 2.3 \\
\hline Implants & 3.4 & 5.2 & 3.8 & 4.0 \\
\hline Condom & 0.0 & 0.2 & 0.0 & 0.1 \\
\hline Rhythm & 8.2 & 8.6 & 2.8 & 7.1 \\
\hline Withdrawal & 3.6 & 5.2 & 5.0 & 4.4 \\
\hline Other & 6.6 & 8.4 & 3.1 & 6.3 \\
\hline Not currently using & 0.0 & 0.2 & 0.0 & 0.1 \\
\hline (N) & 70.6 & 63.0 & 81.2 & 70.8 \\
\hline
\end{tabular}

\section{Source of Methods}

The women who were currently using any FP method were then asked to indicate their last source of supply. Table 4.3 depicts the sources mentioned. In Bagh district, government hospitals were the main source of supply for more than one-quarter of the women (28 percent). Differences among private facilities were quite obvious among the tehsils. In both Bagh and Dhirkot tehsils, private facilities were a common source for contraceptive supplies (30 and 23 percent, respectively). In Haveli, only 15 percent of the women had received their method of contraception from private facilities.

Lady health workers were the main source of supply for 11 to 12 percent of the women in Dhirkot and Bagh tehsils. In Haveli, only 6 percent indicated lady health workers were their source, which was a sign of low coverage by the LHW program in this tehsil. Grocery shops (not pharmacy/chemist) were the main source of supply for more than 12 percent of the women, and were the main source for condom users. 
Table 4.3: Percent of currently married women who were current contraceptive users according to the source of their last supply, by tehsil and district

\begin{tabular}{|c|c|c|c|c|c|}
\hline \multirow[b]{2}{*}{ Source } & \multicolumn{3}{|c|}{ Tehsil } & \multirow[b]{2}{*}{ Total } & \\
\hline & Bagh & Dhirkot & Haveli & & \\
\hline & $\%$ & $\%$ & $\%$ & $\%$ & $N$ \\
\hline Govt. hospital/RHSC & 29.5 & 26.3 & 24.2 & 27.7 & 72 \\
\hline Rural health centre, $\mathrm{MCH}$ & 3.8 & 23.2 & 0.0 & 10.4 & 27 \\
\hline Family welfare center & 0.8 & 1.1 & 6.1 & 1.5 & 4 \\
\hline Mobile service camp & 0.0 & 0.0 & 6.1 & 0.8 & 2 \\
\hline Lady health worker & 12.1 & 10.5 & 6.1 & 10.8 & 28 \\
\hline Lady health visitor & 1.5 & 1.1 & 12.1 & 2.7 & 7 \\
\hline Basic health unit & 0.0 & 2.1 & 9.1 & 1.9 & 5 \\
\hline Other public & 9.8 & 11.6 & 12.1 & 10.8 & 28 \\
\hline Private facilities & 29.5 & 23.2 & 15.2 & 25.4 & 66 \\
\hline Others & 0.8 & 0.0 & 3.0 & 0.8 & 2 \\
\hline Don't know & 12.1 & 1.1 & 6.1 & 7.3 & 19 \\
\hline Total & 100.0 & 100.0 & 100.0 & 100.0 & 260 \\
\hline$(\mathrm{N})$ & (132) & (95) & (33) & 100.0 & (260) \\
\hline
\end{tabular}

\section{Emergency Contraception}

Emergency contraception (EC) refers to contraceptive measures that, if taken after sex, may prevent pregnancy. As its name implies, EC is intended for occasional use when primary means of contraception fail. Overall in Bagh district, many women (81 percent) were unaware of the use of emergency contraception to avoid pregnancy. Less than 2 percent in Dhirkot and Bagh ever used emergency contraception. In Haveli, none had ever used emergency contraception. 
Figure 4.3: Currently married women's knowledge and ever use of emergency contraception, by tehsil and district (percent)

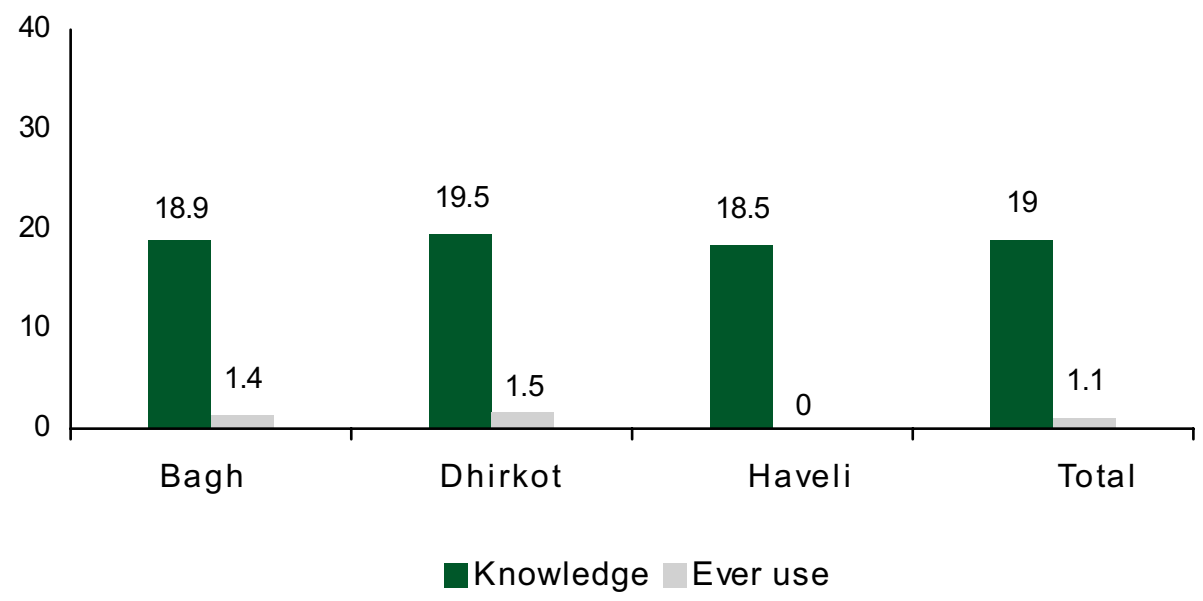

\section{Quality of Care Components}

Since the ethics of quality of care require some protocols to be followed while giving advice to a couple about the type of contraceptive they want to use, women who were currently using any modern family planning method were asked whether they were told about side effects or problems they might have with their specific contraceptive method and if they were they told what to do in case of experiencing any side effects. A question was also included to learn if the women had been given a briefing by service providers about all contraceptive methods, whether they were available or not. Figure 4.4 shows the outcomes of all of these questions.

Of the women currently using any modern family planning method, only 37 percent in the district were told about side effects, and in Dhirkot and Haveli tehsils, the percents were lower (29 and 27 percent, respectively). Overall in Bagh district, 2 out of every 5 women (40 percent) were briefed about all other FP methods. 
Figure 4.4: Quality of care components at ANC visits for currently married women (\%)

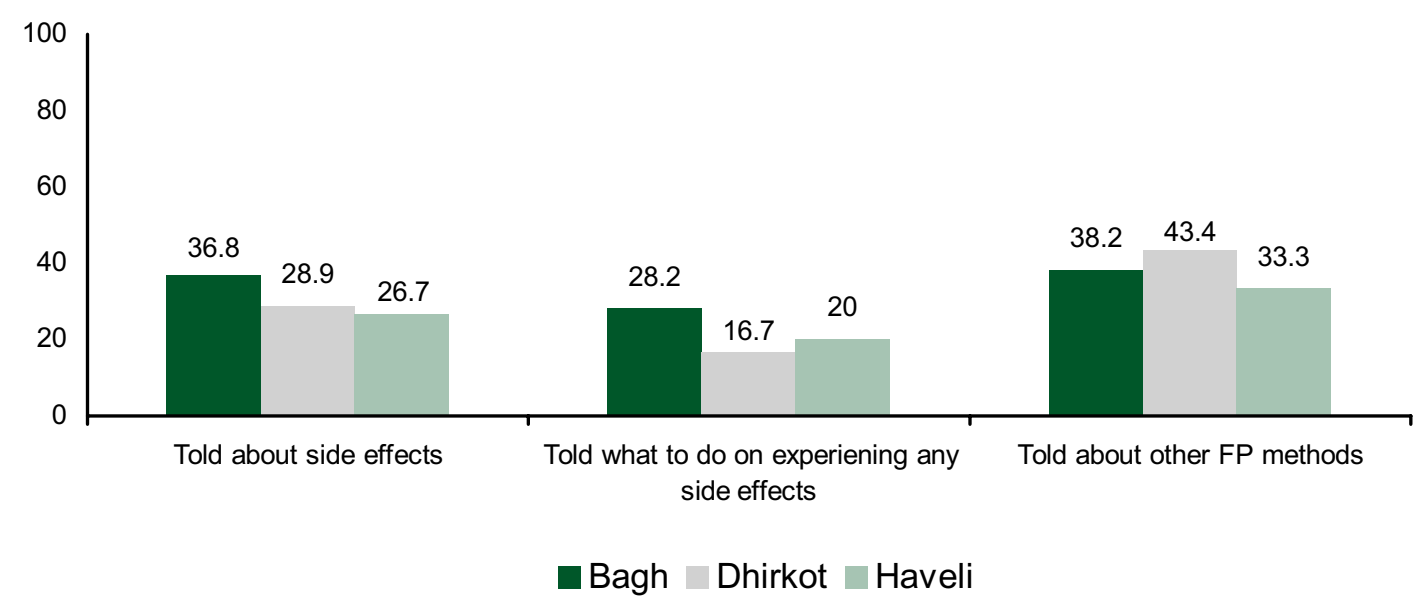

\section{Intentions for Future Use}

Non-users of family planning were asked if they would like to use any method in the future; their answers are presented in Figure 4.5. More than two-thirds of the women in Dhirkot and Haveli (68 percent each) said that they would like to use a FP method in the future; in Bagh tehsil, slightly fewer women (63 percent) were interested in future use. These figures indicate that there is opportunity for family planning activities in Bagh district. Not many women were unsure about their intentions -these percents ranged from 5 to 7 percent over the three tehsils. Those who did not intend to use a family planning method in the future ranged from about 25 percent in Dhirkot and in Haveli to 32 percent in Bagh tehsil. 
Figure 4.5: Currently married women who were non-users of FP according to their future intention to use a contraceptive method, by tehsil (percent)

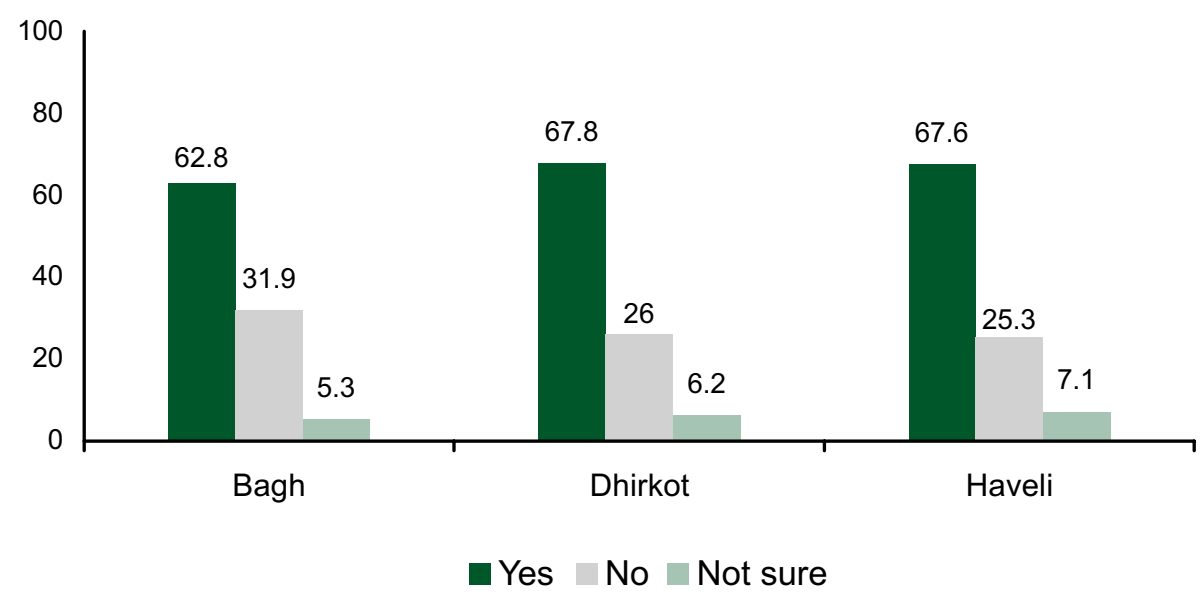

\section{Unmet Need}

The concept of "unmet need for family planning" joins together fertility preferences and contraceptive behavior. Women are said to have unmet need if they wish to avoid getting pregnant (because they want to delay their next child or want to stop childbearing altogether) but are not practicing any form of contraception.

Figure 4.6 depicts the contraceptive need among the currently married women by their status of being currently pregnant or not. The category 'not in need' in the figure includes currently married women who want to have a birth soon or are infecund, in other words they do not need to use any contraceptive method. The KPC survey findings show that in Bagh district the total unmet need was 42 percent, with 26 percent of the women having unmet need for limiting and 16 percent having unmet need for spacing. 
Figure 4.6: Currently married women who were pregnant or non-pregnant, by their contraceptive need (percent)

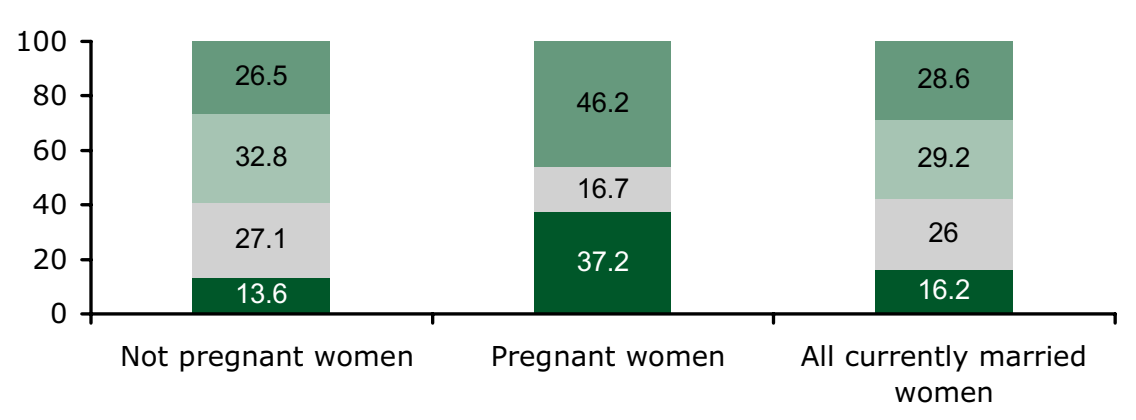

$\square$ Unmet need for spacing $\square$ Unmet need for limiting $\square$ Users $\square$ Not in need 


\section{Chapter 5}

\section{Pregnancy, Delivery and Postnatal Care}

This chapter explores attitudes and practices regarding pregnancy, delivery and postnatal care. The information was collected from 703 women of reproductive age (15-49 years) who had a live birth during the three years preceding the survey.

\section{Antenatal Care}

In this survey, antenatal care (ANC) was defined according to the type of provider, the number of visits made, stage of pregnancy at the time of the first ANC visit and the services provided during this check-up, including whether or not tetanus toxoid injections were received.

Respondents were asked if they had any ANC visit during their last pregnancy and those who had ANC visits were then asked to indicate the number of visits (see Table 5.1). KPC survey findings show that of the 703 women, 30 percent (209 women) had no antenatal visits and 70 percent (494 women) had one

\section{PRIDE INDICATOR:}

Women who delivered in the past three years and had 4 or more antenatal consultations during their last pregnancy: 28.6 percent.

or more visits. More than one-forth of the women (29 percent) had 4 or more visits during their last pregnancy. In Bagh and Dhirkot tehsils, one-fifth of the women had no antenatal visits compared to about one-half of the women in Haveli. 
Table 5.1: Eligible women according to the number of antenatal visits they had, by tehsil and district

\begin{tabular}{|c|c|c|c|c|c|c|c|c|}
\hline \multirow{3}{*}{ Number of visits } & \multicolumn{6}{|c|}{ Tehsil } & \multirow{2}{*}{\multicolumn{2}{|c|}{ Total }} \\
\hline & \multicolumn{2}{|c|}{ Bagh } & \multicolumn{2}{|c|}{ Dhirkot } & \multicolumn{2}{|c|}{ Haveli } & & \\
\hline & $N$ & $\%$ & $N$ & $\%$ & $N$ & $\%$ & $N$ & $\%$ \\
\hline No ANC visit & 65 & 20.1 & 41 & 21.6 & 103 & 54.5 & 209 & 29.7 \\
\hline At least 1 ANC visit & 259 & 79.9 & 149 & 78.4 & 86 & 45.5 & 494 & 70.3 \\
\hline Total & 324 & 100.0 & 190 & 100.0 & 189 & 100.0 & 703 & 100.0 \\
\hline At least 2 ANC visit & 226 & 69.8 & 121 & 63.7 & 63 & 33.3 & 410 & 58.3 \\
\hline At least 3 ANC visit & 188 & 58.0 & 92 & 48.4 & 39 & 20.6 & 319 & 45.4 \\
\hline 4+ ANC visit & 127 & 39.2 & 57 & 30.0 & 17 & 9.0 & 201 & 28.6 \\
\hline
\end{tabular}

\section{Location}

For the 494 women who had one or more antenatal visits, Table 5.2 shows the locations where they received antenatal care. Multiple responses were obtained. Overall in Bagh district, government hospital and basic health unit (BHU) were the most visited facilities (63 percent) for ANC followed by private clinic/hospital and private doctor's office combined (52 percent). Less than 2 percent had check-ups at home.

Table 5.2: Eligible women according to the location where antenatal care was given, by tehsil and district

\begin{tabular}{|c|c|c|c|c|c|c|c|c|}
\hline \multirow{3}{*}{ Location } & \multicolumn{6}{|c|}{ Tehsil } & & \\
\hline & \multicolumn{2}{|c|}{ Bagh } & \multicolumn{2}{|c|}{ Dhirkot } & \multicolumn{2}{|c|}{ Haveli } & \multicolumn{2}{|c|}{ Total } \\
\hline & $N$ & $\%$ & $\mathrm{~N}$ & $\%$ & $\mathrm{~N}$ & $\%$ & $N$ & $\%$ \\
\hline Your home & 0 & 0.0 & 0 & 0.0 & 1 & 1.2 & 1 & 0.2 \\
\hline Other home & 3 & 1.2 & 1 & 0.7 & 2 & 2.4 & 6 & 1.2 \\
\hline Govt. facility & 139 & 54.3 & 107 & 73.3 & 58 & 69.0 & 304 & 62.6 \\
\hline Pvt. hospital/clinic & 154 & 60.2 & 62 & 42.5 & 30 & 35.7 & 246 & 50.6 \\
\hline Pvt. doctor & 3 & 1.2 & 5 & 3.4 & 0 & 0.0 & 8 & 1.6 \\
\hline Homeopath & 1 & 0.4 & 0 & 0.0 & 0 & 0.0 & 1 & 0.2 \\
\hline Dispenser/compounder & 4 & 1.6 & 1 & 0.7 & 0 & 0.0 & 5 & 1.0 \\
\hline Other private medical & 5 & 2.0 & 1 & 0.7 & 3 & 3.6 & 9 & 1.9 \\
\hline Total & 256 & na & 146 & na & 84 & na & 486 & na \\
\hline
\end{tabular}

na $=$ Not applicable; respondents could name more than one location if they had more than one visit. 


\section{Provider}

When the 494 women who had had antenatal care were asked about the provider of care at their antenatal visits, they reported seeing a doctor 83 percent of the time, followed by nurse/midwife/LHV (21 percent) and dai/TBA ( 2 percent).

Table 5.3: Providers of antenatal care, by tehsil and district

\begin{tabular}{|c|c|c|c|c|c|c|c|c|}
\hline \multirow{3}{*}{ Provider } & \multicolumn{6}{|c|}{ Tehsil } & \multirow{2}{*}{\multicolumn{2}{|c|}{ Total }} \\
\hline & \multicolumn{2}{|c|}{ Bagh } & \multicolumn{2}{|c|}{ Dhirkot } & \multicolumn{2}{|c|}{ Haveli } & & \\
\hline & $N$ & $\%$ & $N$ & $\%$ & $N$ & $\%$ & $N$ & $\%$ \\
\hline Doctor & 223 & 86.4 & 117 & 78.5 & 66 & 77.6 & 406 & 82.5 \\
\hline Nurse/midwife/LHV & 46 & 17.8 & 40 & 26.8 & 16 & 18.8 & 102 & 20.7 \\
\hline Dai-TBA & 4 & 1.6 & 3 & 2.0 & 3 & 3.5 & 10 & 2.0 \\
\hline Lady health worker & 5 & 1.9 & 1 & 0.7 & 0 & 0.0 & 6 & 1.2 \\
\hline Hakim & 0 & 0.0 & 1 & 0.7 & 0 & 0.0 & 1 & 0.2 \\
\hline Dispenser/compounder & 3 & 1.2 & 2 & 1.3 & 1 & 1.2 & 6 & 1.2 \\
\hline Others & 1 & 0.4 & 0 & 0.0 & 2 & 2.4 & 3 & 0.6 \\
\hline Total & 258 & na & 149 & na & 85 & na & 492 & na \\
\hline
\end{tabular}

\section{Components of Antenatal Care}

Details regarding services provided during antenatal visits were obtained from those who had antenatal visits. Measuring blood pressure during antenatal visits was recorded highest, followed by performing or referring for ultrasound and urine test. Blood testing and measuring weight remained the lowest among the services provided. A comparison by tehsil reflects the service package during antenatal visits remained highest in Bagh tehsil. One of the reasons for the high package of antenatal services in Bagh tehsil could be attributed to relief and rehabilitation work initiated by several local and international non-governmental organizations after the 2005 earthquake. 
Figure 5.1: Services performed during antenatal check-up, by tehsil and district (\%)

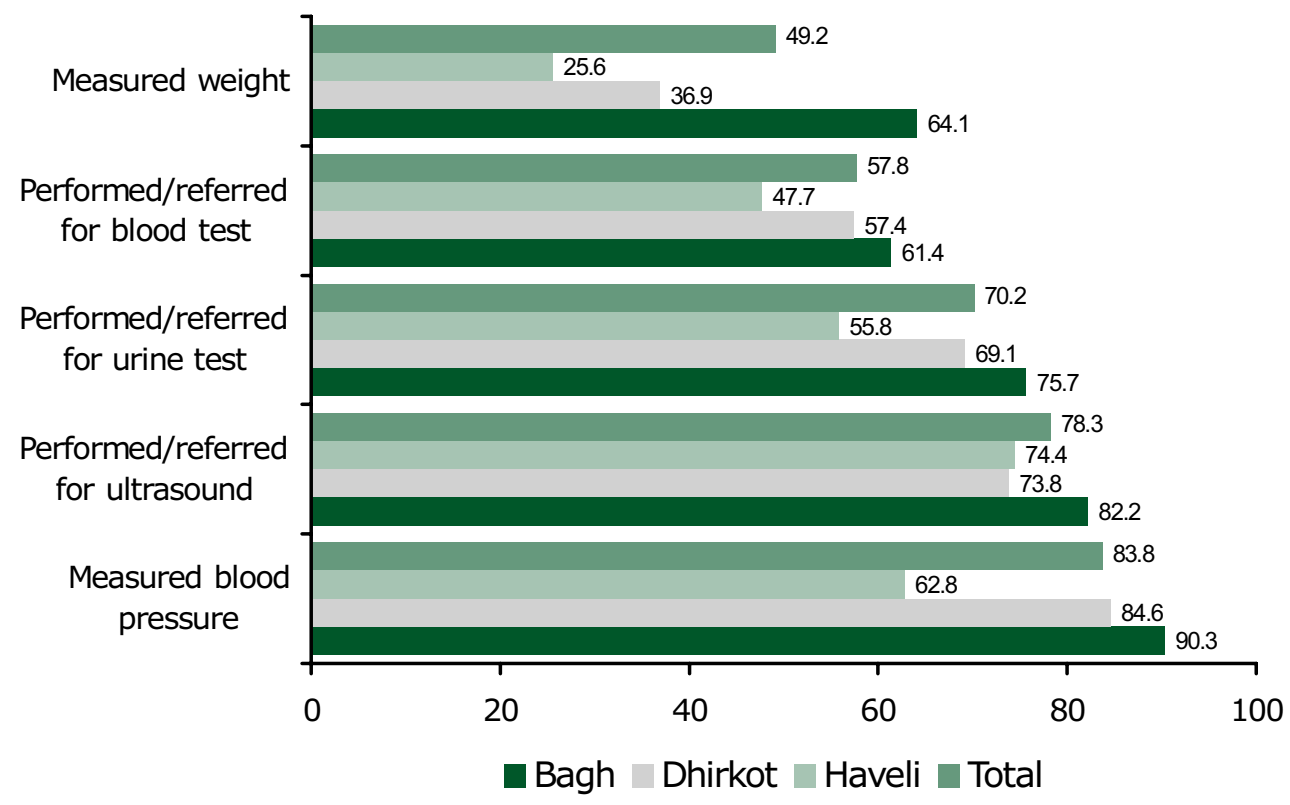

Women who had antenatal check-ups (494 women) were asked to indicate the reason they had their first antenatal check-up to assess whether the visit was made for treatment of a problem that they had experienced during pregnancy or to have a routine medical check-up to ensure that the journey through pregnancy was completed in a safe manner. The chart below indicates that more than 45 percent of the women had their first antenatal visit due to problems during their pregnancy and 55 percent had gone for a routine antenatal check-up without having a medical problem. 
Figure 5.2: First antenatal care visit according to the reason for the visit, by tehsil and district (percent)

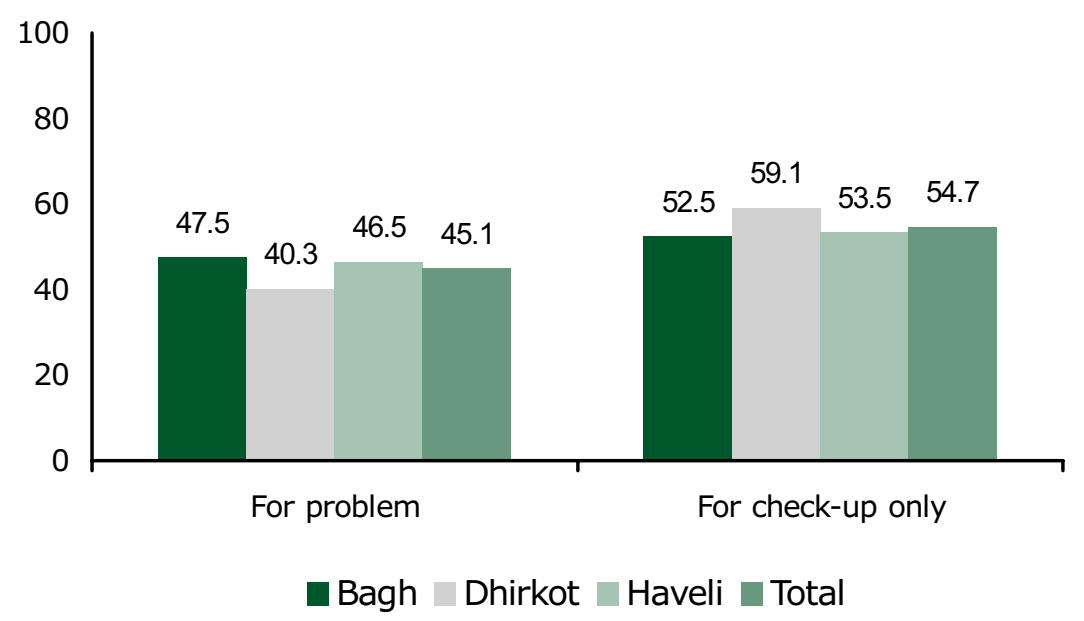

Women who made more than one ANC visit were more likely to make those visits for regular checkups than those who only made one visit. Among 703 women who had a live birth during the three years preceding the survey, about one-third (32 percent) had their check-up due to some problem faced during pregnancy, while about two-fifths (38 percent) went for a regular check-up. Out of the women who made more than four ANC visits, 13 percent made their first visit for some problem, while 16 percent went for a regular ANC check-up. Table 5.4 gives detailed information about the number of ANC visits and the reasons for them.

Table 5.4: Women who had a live birth in the last 3 years according to number of ANC visits, by reason for first ANC visit

\begin{tabular}{lrrrrrr} 
& \multicolumn{3}{c}{ Reason for first ANC visit } & \multicolumn{2}{c}{} \\
\cline { 2 - 7 } Number of visits & Curative & \multicolumn{2}{c}{ Preventive } & \multicolumn{2}{c}{ Total } \\
\cline { 2 - 8 } No ANC visit & $N$ & $\%$ & $N$ & $\%$ & $N$ & $\%$ \\
\hline At least 1 ANC visit & na & na & na & na & 209 & 29.7 \\
\hline Total & 224 & 31.9 & 270 & 38.4 & 494 & 70.3 \\
\hline At least 2 ANC visits & 189 & 26.9 & 221 & 31.4 & 410 & 58.3 \\
\hline At least 3 ANC visits & 139 & 19.8 & 180 & 25.6 & 319 & 45.4 \\
\hline 4+ ANC visits & 88 & 12.5 & 113 & 16.1 & 201 & 28.6 \\
\hline
\end{tabular}




\section{Reasons for Not Having Antenatal Care}

Respondents who never had an antenatal visit during their last pregnancy were asked to indicate reasons for not having antenatal care. Multiple responses were received. Almost half of the women (48 percent) who never had an antenatal visit stated that antenatal visits were not necessary. This attitude needs to be addressed at the community level through health education campaigns.

Around one-fifth (23 percent) of the women indicated that the facility was too far away to get to for a check-up. Ten percent of the women had transport problems. Some 6 percent of the women responded that one or more family members would not allow them to have an antenatal check-up. About the same number of women indicated that they did not have time for an ANC check-up or that no one was able to accompany them ( 6 and 8 percent, respectively). The behavior change communication (BCC) strategy of the project has great potential to address these aspects of social attitude. More than one-tenth (12 percent) highlighted the fact that the cost of antenatal check-ups was very high.

Table 5.5: Eligible women according to reason for not having antenatal visits, by tehsil and district

\begin{tabular}{lrrrrrrrrr} 
& \multicolumn{9}{c}{ Tehsil } \\
\cline { 2 - 8 } Reason & Bagh & \multicolumn{1}{c}{ Dhirkot } & \multicolumn{1}{c}{ Haveli } & \multicolumn{2}{c}{ Total } \\
\cline { 2 - 8 } Not necessary & $N$ & $\%$ & $N$ & $\%$ & $N$ & $\%$ & $N$ & $\%$ \\
\hline Facility too far & 53.1 & 34 & 53.7 & 22 & 41.7 & 43 & 47.6 & 99 \\
\hline Costs too much & 7.8 & 5 & 29.3 & 12 & 29.1 & 30 & 22.6 & 47 \\
\hline Not transport & 21.9 & 14 & 2.4 & 1 & 8.7 & 9 & 11.5 & 24 \\
\hline Feels shy & 4.7 & 3 & 7.3 & 3 & 14.6 & 15 & 10.1 & 21 \\
\hline No one to go with & 10.9 & 7 & 14.6 & 6 & 3.9 & 4 & 8.2 & 17 \\
\hline Not allowed to go & 10.9 & 7 & 12.2 & 5 & 3.9 & 4 & 7.7 & 16 \\
\hline No time to go & 10.9 & 7 & 2.4 & 1 & 4.9 & 5 & 6.3 & 13 \\
\hline Not customary & 9.4 & 6 & 4.9 & 2 & 4.9 & 5 & 6.3 & 13 \\
\hline Did not want to see male doctor & 1.6 & 1 & 0.0 & 0 & 8.7 & 9 & 4.8 & 10 \\
\hline Service not good & 1.6 & 1 & 2.4 & 1 & 6.8 & 7 & 4.3 & 9 \\
\hline Others & 1.6 & 1 & 4.9 & 2 & 2.9 & 3 & 2.9 & 6 \\
\hline Did not know where to go & 0.0 & 0 & 2.4 & 1 & 1.9 & 2 & 1.4 & 3 \\
\hline Long waiting time & 1.6 & 1 & 0.0 & 0 & 1.9 & 2 & 1.4 & 3 \\
\hline Total & 0.0 & 0 & 0.0 & 0 & 1.0 & 1 & 0.5 & 1 \\
\hline
\end{tabular}

na $=$ Not applicable; respondents could name more than one reason. 


\section{Tetanus Toxoid Injections}

At least one tetanus toxoid injection (TT) was received by 50.2 percent of the women during their last pregnancy; 44 percent had two or more TT injections. Half of women had no TT injections during their last pregnancy. Among the tehsils,

\section{PRIDE INDICATOR:}

Percentage of women who received at least two tetanus toxoid injections: 44.2 percent. Haveli had the highest number of women not having TT injections during their last pregnancy (71 percent).

Figure 5.3: Tetanus toxoid injections received during last pregnancy, by tehsil and district (percent)

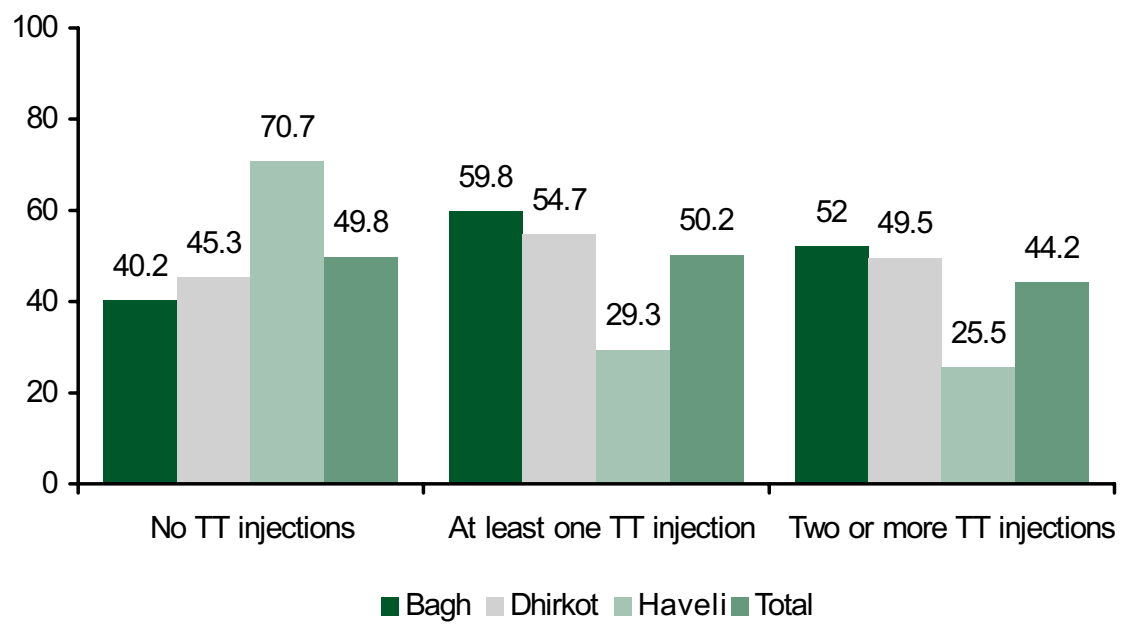

\section{Delivery/Childbirth}

\section{Place of Delivery}

Home-based delivery for the last birth was reported by 63 percent of respondents; 37 percent gave birth at a health facility. Haveli, with 87 percent of the women giving birth at home, ranked first in home deliveries. This high level of home-based deliveries could be attributed to local culture, non-affordability of health facilities in the tehsil, and difficulty in approaching these facilities. Sixty-one percent of the women in Dhirkot had home-based deliveries. In Bagh tehsil, 49 percent of the women had their last birth at a health facility. The reason for this could be due to better maternal services at health facilities provided by the government and NGOs after the 2005 earthquake than was available in the other tehsils. 
Figure 5.4: Place of last delivery, by tehsil and district (percent)

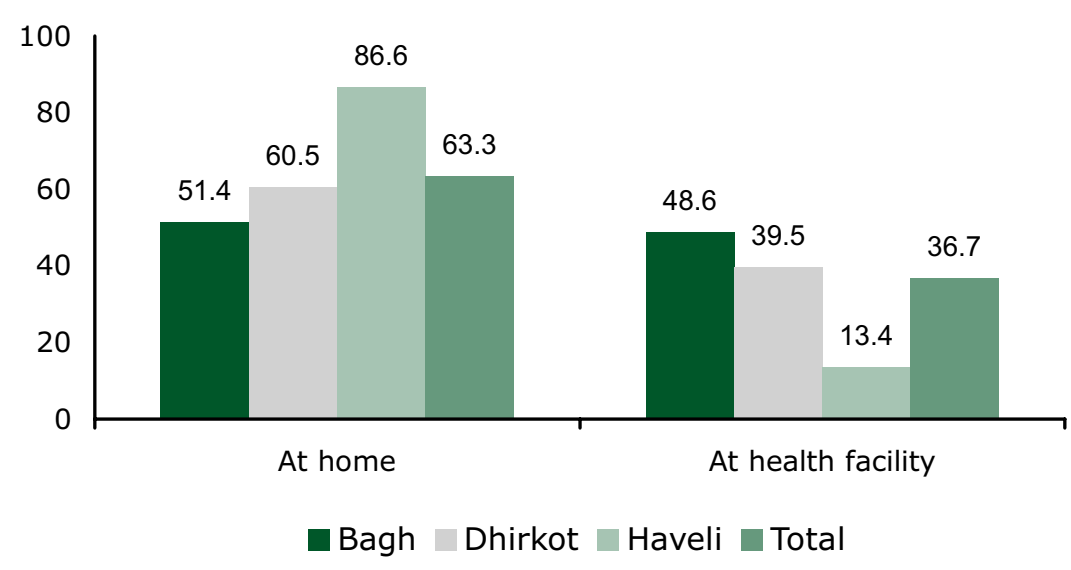

\section{Assistance During Delivery}

Table 5.5 shows the category of birth attendant who assisted women at their last delivery. Thirty-six percent of the women were delivered by trained birth attendants; 64 percent utilized the services of unskilled birth attendants. Relatives and friends (who were not dais), who were considered unskilled birth attendants, topped the list of those assisting women at their last delivery (35 percent). Twenty-six percent of the women were assisted by dai/TBA. Among skilled birth attendants, doctors delivered 26 percent of the women, and nurse/midwife/LHV accounted for 10 percent of deliveries.

A comparison by tehsil indicates that in Dhirkot and Haveli, relatives and friends had the greatest share in assisting women during childbirth (43 and 39 percent, respectively). This high level of participation of relatives and friends could be due to the joint

\section{PRIDE INDICATOR:}

Percentage of births attended by a skilled birth attendant:

36.3 percent. family system and trust in family members or difficulty in accessing trained birth attendants. In Bagh tehsil, doctors assisted at 36 percent of the births. Dais/TBAs were a great resource in Haveli, assisting at deliveries for 46 percent of the women. 
Table 5.6: Eligible women according to type of person attending at delivery and skill level, by tehsil and district

\begin{tabular}{|c|c|c|c|c|c|c|c|c|}
\hline \multirow{3}{*}{$\begin{array}{l}\text { Birth attendant } \\
\text { and skill level }\end{array}$} & \multicolumn{6}{|c|}{ Tehsil } & \multirow{2}{*}{\multicolumn{2}{|c|}{ Total }} \\
\hline & \multirow{2}{*}{$\begin{array}{l}\text { Bagh } \\
\qquad N\end{array}$} & \multicolumn{2}{|c|}{ Dhirkot } & \multicolumn{2}{|c|}{ Haveli } & & & \\
\hline & & $\%$ & $N$ & $\%$ & $N$ & $\%$ & $N$ & $\%$ \\
\hline Doctor & 115 & 35.5 & 50 & 26.3 & 20 & 10.6 & 185 & 26.3 \\
\hline Nurse/midwife/LHV & 36 & 11.1 & 31 & 16.3 & 3 & 1.6 & 70 & 10.0 \\
\hline Dai-TBA & 74 & 22.8 & 21 & 11.1 & 87 & 46.0 & 182 & 25.9 \\
\hline$\underline{\text { Relative/friend (not a dai) }}$ & 87 & 26.9 & 82 & 43.2 & 74 & 39.2 & 243 & 34.6 \\
\hline Other & 12 & 3.7 & 6 & 3.2 & 5 & 2.6 & 23 & 3.3 \\
\hline Total & 324 & 100.0 & 190 & 100.0 & 189 & 100.0 & 703 & 100.0 \\
\hline \multicolumn{9}{|c|}{ Delivered by skilled or unskilled attendant } \\
\hline Skilled birth attendant & 151 & 46.6 & 81 & 42.6 & 23 & 12.2 & 255 & 36.3 \\
\hline Unskilled birth attendant & 173 & 53.4 & 109 & 57.4 & 166 & 87.8 & 448 & 63.7 \\
\hline Total & 324 & 100.0 & 190 & 100.0 & 189 & 100.0 & 703 & 100.0 \\
\hline
\end{tabular}

\section{Problems During Delivery and Postpartum}

The women were asked to respond regarding medical problems they had experienced during their last delivery, including the postpartum period. Multiple responses were obtained from the women. Severe headache was mentioned by 37 percent of the women, and blurred vision and high fever were reported by 35 and 31 percent, respectively. Swelling of face and hands were reported by one-fifth of women. Vaginal discharge (foul smell) was reported by 7 percent. These figures are indicative of unhygienic practices and deliveries by unskilled practitioners. Heavy vaginal bleeding is one of the leading causes of maternal deaths and this was reported by 17 percent of women. 
Figure 5.5: Women who experienced a problem(s) during their last delivery and postpartum period, by type of problem experienced (percent)

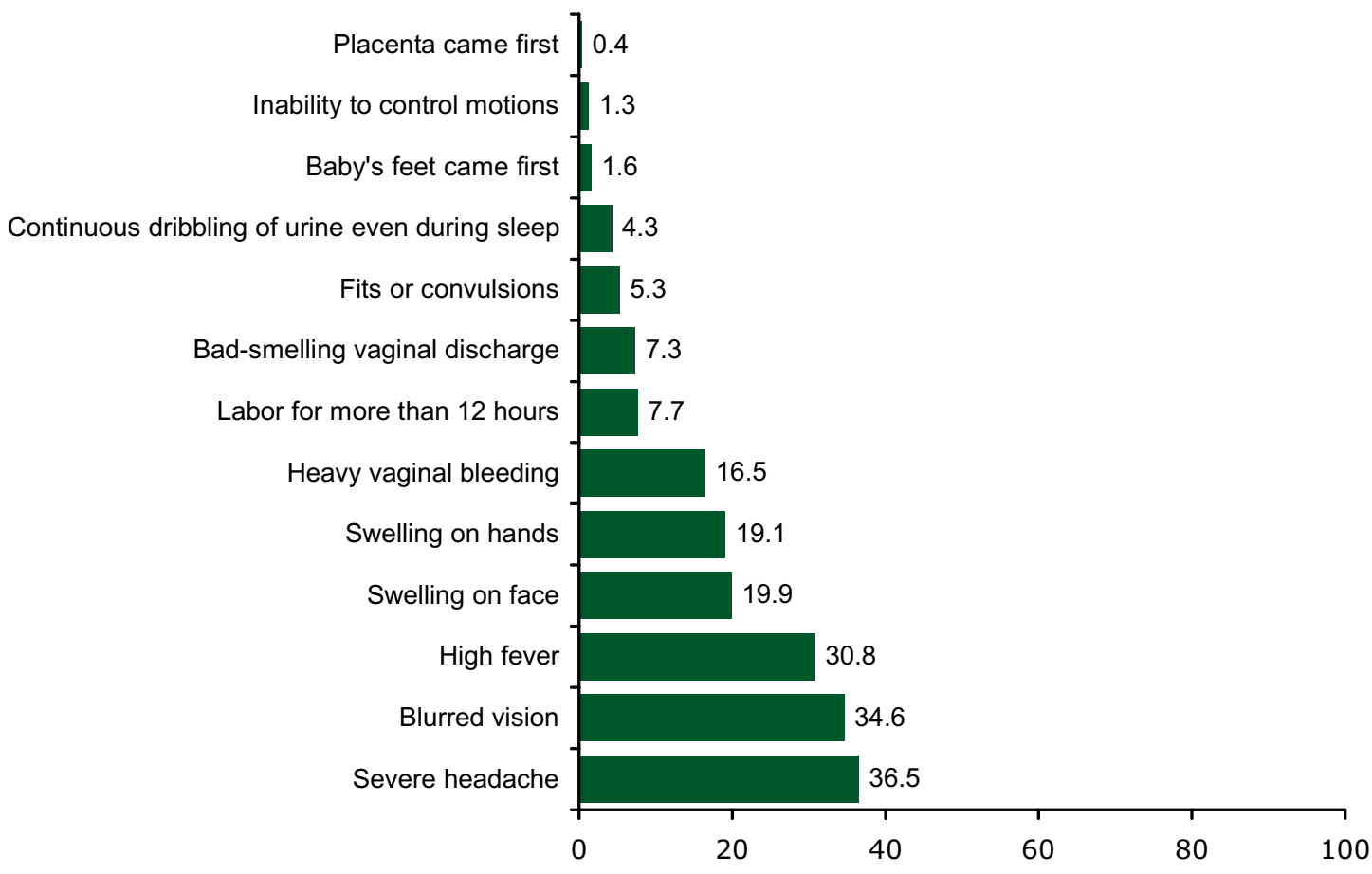

\section{Clean Delivery Practices}

The 461 women who had delivered their babies at home were asked questions about safe birth practices (see Figure 5.6). In Bagh tehsil, only 5 percent of the women were delivered using clean delivery kits compared to 16 percent in Haveli. The percentage of women who reported the use of a new blade to cut the umbilical cord was lower in Haveli (29 percent) compared to Bagh and Dhirkot tehsils (61 and 78 percent, respectively). The percent of women who reported the use of new/boiled thread to tie the cord was 10 percent in Dhirkot, followed by Bagh and Haveli tehsils ( 9 and 3 percent, respectively). 
Figure 5.6: Safe delivery practices used at home births, by tehsil and district (percent)

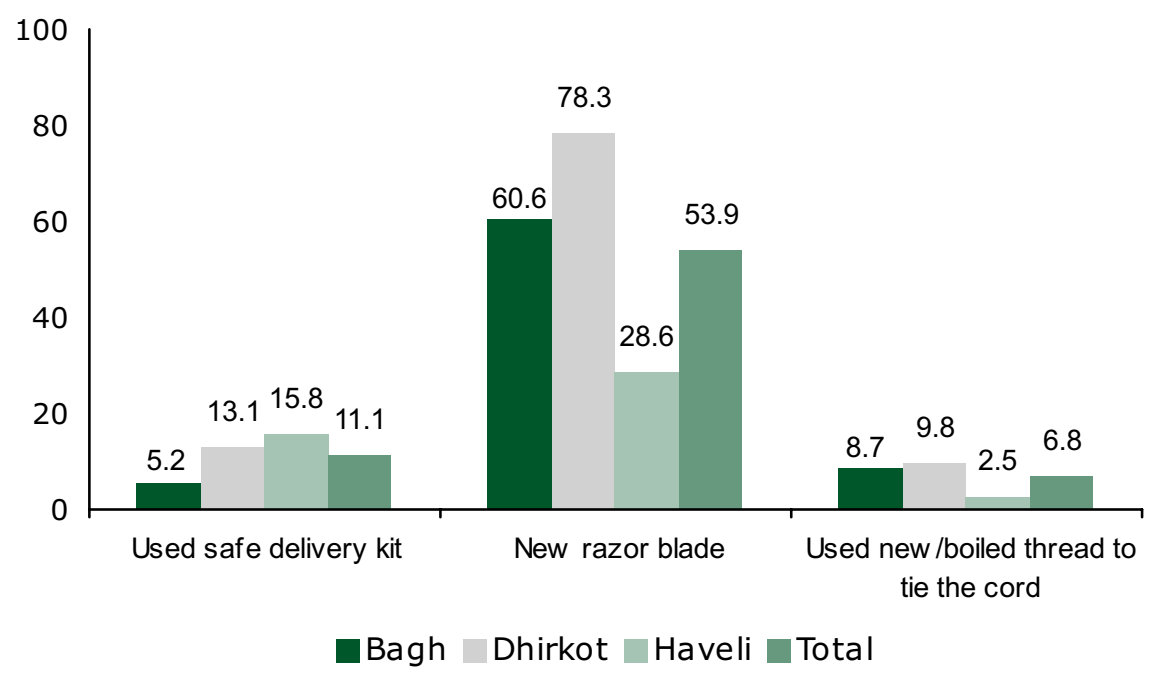

\section{Postpartum Care}

In the KPC survey, the postpartum period is defined as the 40 days after childbirth. The postpartum period is a critical time for both the mother and the newborn. Respondents were asked about the postpartum care they received

\section{PRIDE INDICATOR:}

Percentage of mothers who had at least one postnatal visit within 40 days of delivery: 24.6 percent. after their last delivery. Table 5.7 shows that many married women did not receive a postnatal check-up after their last delivery. In Bagh district, 75 percent had no postnatal check-up; this figure was highest in Haveli, where 83 percent received no postnatal care. Among those who went for postnatal care, the highest percent (61 percent) went within 24 hours after childbirth. 
Table 5.7: History of postnatal care, by tehsil and district

\begin{tabular}{|c|c|c|c|c|c|c|c|c|}
\hline \multirow{3}{*}{ History } & \multicolumn{6}{|c|}{ Tehsil } & \multirow{2}{*}{\multicolumn{2}{|c|}{ Total }} \\
\hline & \multicolumn{2}{|l|}{ Bagh } & \multicolumn{2}{|c|}{ Dhirkot } & \multicolumn{2}{|c|}{ Haveli } & & \\
\hline & $N$ & $\%$ & $N$ & $\%$ & $N$ & $\%$ & $N$ & $\%$ \\
\hline \multicolumn{9}{|c|}{ Had postnatal check-up } \\
\hline Yes & 91 & 28.1 & 49 & 25.8 & 33 & 17.5 & 173 & 24.6 \\
\hline No & 233 & 71.9 & 141 & 74.2 & 156 & 82.5 & 530 & 75.4 \\
\hline Total & 324 & 100.0 & 190 & 100.0 & 189 & 100.0 & 703 & 100.0 \\
\hline \multicolumn{9}{|c|}{ Number of days after delivery before first check-up } \\
\hline Same day & 61 & 67.0 & 34 & 69.4 & 10 & 30.3 & 105 & 60.7 \\
\hline Within 7 days & 7 & 7.7 & 5 & 10.2 & 10 & 30.3 & 22 & 12.7 \\
\hline Within 40 days & 23 & 25.3 & 10 & 20.4 & 13 & 39.4 & 46 & 26.6 \\
\hline Total & 91 & 100.0 & 49 & 100.0 & 33 & 100.0 & 173 & 100.0 \\
\hline
\end{tabular}

\section{Knowledge of Danger Signs in Newborns}

Respondents were asked an unprompted question about danger signs in the newborn that indicate the need for medical attention. Figure 5.7 depicts the percentage of respondents who believed that specific complications required medical attention. Overall, it is apparent that knowledge regarding the health of newborns was very poor in Bagh district. Differences between the tehsils in the knowledge of the respondents can be seen in the figure. The most widely recognized danger sign for newborns by tehsil: Haveli - unable to suckle/ poor sucking (22 percent); Dhirkot blue skin color and baby did not cry/weak cry (27 percent each); and Bagh - baby did not cry/weak cry and unable to suckle/ poor sucking (28 and 26 percent, respectively). 
Figure 5.7: Percentage of respondents who had knowledge about danger signs in newborns, by tehsil and district (percent)

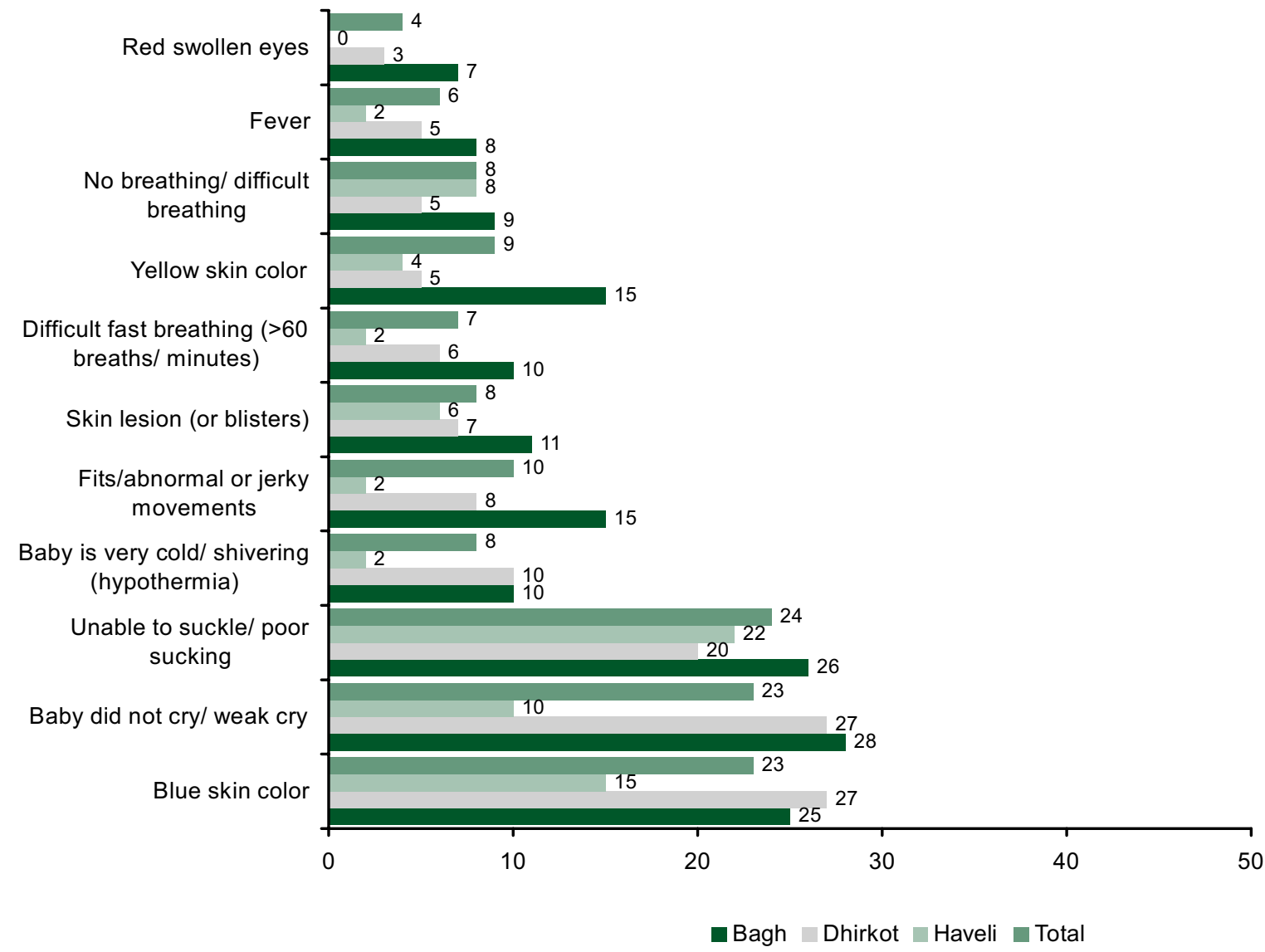

Figure 5.8 shows that the knowledge of newborn danger signs was the lowest in Haveli tehsil. No more than 15 percent of the women in Bagh district knew three or more danger signs in newborns. Thirty-six percent in Bagh tehsil could not identify one danger sign, compared to 40 percent in Dhirkot

\section{PRIDE INDICATOR:}

Percentage of mothers who knew at least 3 newborn danger signs that require immediate treatment: 15 percent. and 56 percent in Haveli. 
Figure 5.8: Women's knowledge of the number of danger signs in a newborn within one hour of birth, by tehsil and district (percent)

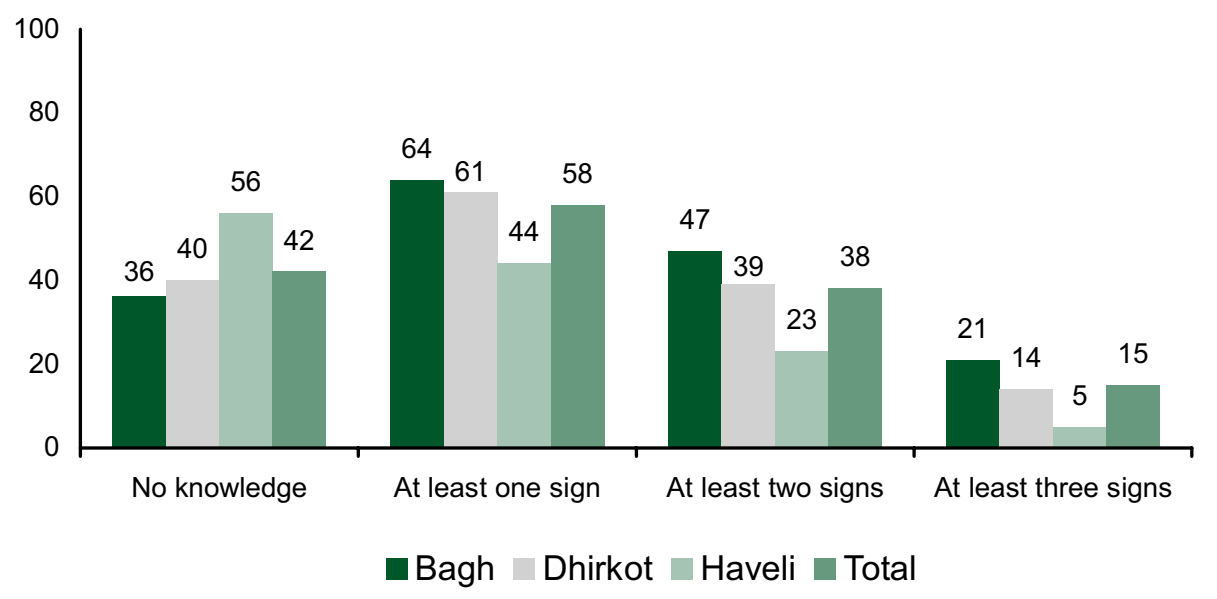




\section{Chapter 6}

\section{Child Health}

This chapter provides information from the married women of reproductive age who had a live birth in the three years preceding the KPC survey and whose child/children were alive and under the age of 36 months at that time. Information is presented by the age of the children (in months) according to the specific aspect of child health being discussed.

\section{Immunization}

A child is considered fully vaccinated if s/he has received a bacille Calmette-Guérin (BCG) vaccination against tuberculosis, three doses of DPT vaccine to prevent diphtheria, pertussis and tetanus, at least three doses of polio vaccine and one dose of measles vaccine. During the KPC survey, information was collected on vaccination among all 191 children ages 12-23 months. Measuring immunization coverage at the household level is not an easy task. Parents often do not have an immunization card with full information on the immunizations received; therefore, an immunization rate based on card information often underestimates the coverage rate. However, calculating the coverage rate using recall from parents, especially mothers, is problematic as they may confuse the vaccine injection with another type of injection, etc. Neither of these measures of immunization is ideal. Therefore, information on immunization is presented here using information collected both from immunization records and recall of the mothers.

\section{Full immunization}

Figure 6.1 presents the information on vaccination coverage for children aged 12-23 months who were fully vaccinated against six preventable childhood

PRIDE INDICATOR: Children ages 12-23 months who were fully immunized: 45.9 percent 
illnesses. The result is based both on health card information and mother's recall.

Overall, 46 percent of children ages 12-23 months were fully vaccinated with BCG, measles and three doses of DPT and polio. Full immunization of children was highest in Dhirkot (53 percent) and lowest in Bagh tehsil (40 percent).

Figure 6.1: Children ages 12-23 months who were fully immunized, based on records and recall, by tehsil and district (percent)

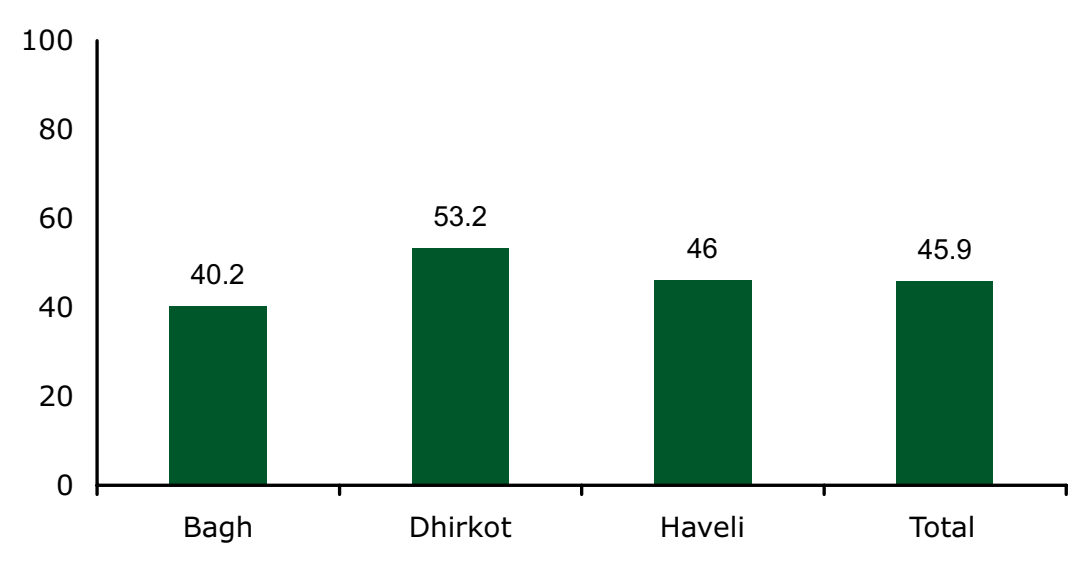

Figure 6.2 reflects the antigen-specific coverage rate by tehsil, as shown below:

BCG. Eight out of every 10 children (80 percent) had received the BCG vaccination at birth: highest in Dhirkot (84 percent) and equal in Bagh and Haveli tehsils (78 percent each).

Polio. Almost 99 percent of district children had received complete polio vaccinations (3 doses). Polio vaccination was equally high in all three tehsils.

DPT. The recommended three doses were received by 55 percent of district children. However, tehsil variations were observed in DPT vaccination rates: Dhirkot had the highest rate (60 percent), followed by Bagh (54 percent), and Haveli had the lowest vaccination rate (52 percent).

Measles. The total district vaccination rate for measles was recorded as 63 percent. Dhirkot tehsil had a much higher vaccination rate (73 percent) than Bagh or Haveli (about 58 percent each). 
Figure 6.2: Children ages 12-23 months according to immunizations received, by tehsil and district (percent)

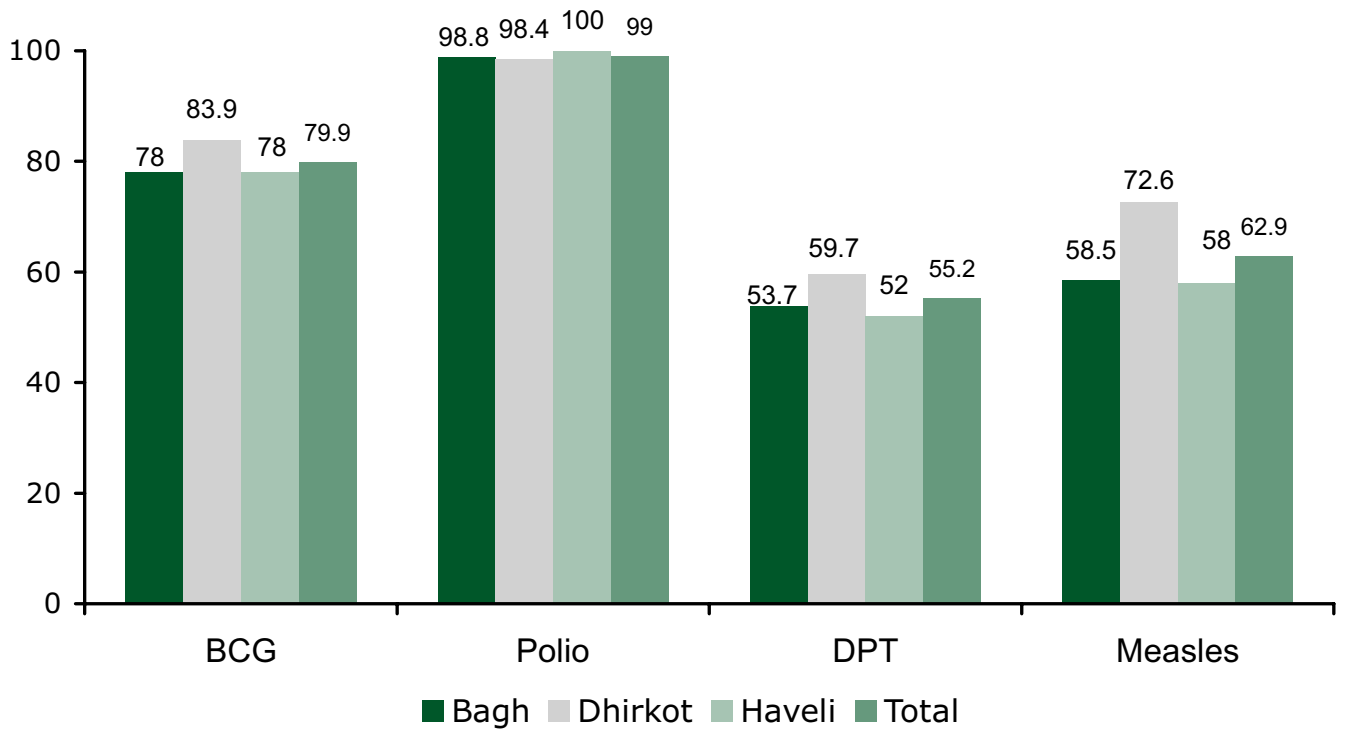

Respondents were asked if their child had received polio vaccine during national immunization campaigns. The responses by age of the child are presented in Table 6.1. Eighty-eight percent of the children under three years of age were immunized during national polio day campaigns.

Table 6.1: Children under age 3 who received polio vaccination during national immunization day campaigns

\begin{tabular}{lrrrrr} 
Age in months & \multicolumn{2}{c}{ Vaccinated } & \multicolumn{2}{c}{ Not vaccinated } & Total \\
\cline { 2 - 6 } $0-11$ & $N$ & $\%$ & $N$ & $\%$ & $N$ \\
\hline $12-23$ & 257 & 77.2 & 76 & 22.8 & 333 \\
\hline $24-35$ & 191 & 100.0 & 0 & 0.0 & 191 \\
Total & 111 & 99.1 & 1 & 0.9 & 112 \\
& 559 & 87.9 & 77 & 12.1 & 636
\end{tabular}

Information was also obtained about the availability of immunization cards/health cards for the children ages 12-23 months. Figure 6.3 shows that a total of 79 percent of the mothers claimed to have a vaccination card. However, a vaccination card was seen and confirmed with only 29 percent of mothers, while 51 percent could not show an immunization card. Some 20 percent of mothers responded that they had no immunization card for their children. 
Figure 6.3: Status of immunization cards of mothers of children ages 12-23 months, by tehsil and district (percent)

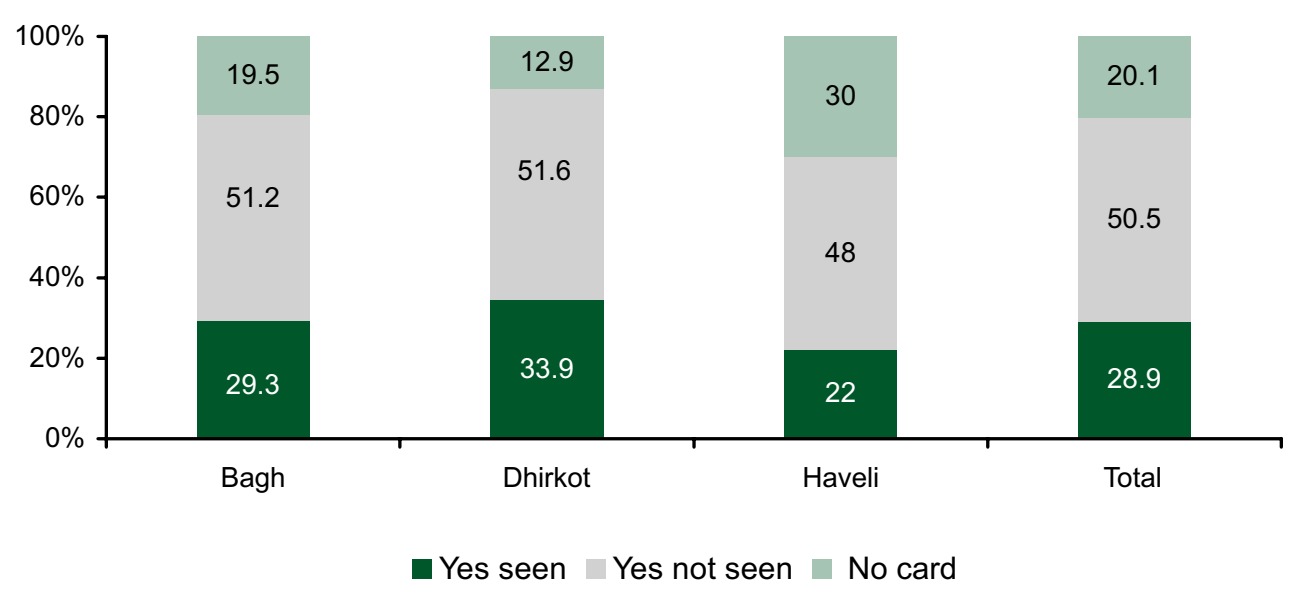

\section{Diarrhea}

Dehydration caused by severe diarrhea is one of the major causes of child mortality in Pakistan. Prompt medical attention is crucial to reduce child deaths from diarrhea. Information was obtained from mothers on their knowledge about diarrhea and the episodes of the illness in their children (ages 0-23 months).

In Figure 6.4, the results show that altogether more than one-third (34 percent) of the children had experienced diarrhea in the last two weeks. Haveli had experienced more diarrhea cases when compared to Bagh and Dhirkot tehsils. 
Figure 6.4: Children ages 0-23 months who had diarrhea during the last two weeks, by tehsil and district (percent)

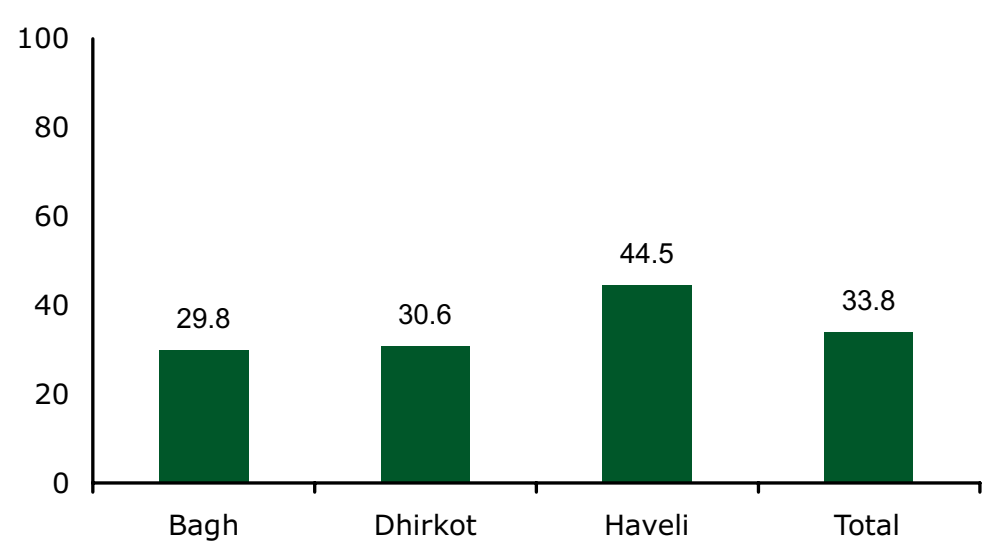

Among the children ages 0-23 months who had experienced diarrhea in the last two weeks, 48 percent had had diarrhea episodes during the last 24 hours. Dhirkot had the highest number of cases of diarrhea during the 24 hours prior to the survey team's visit.

Almost 59 percent of mothers of children ages 0-23 months who had had diarrhea in the last two weeks obtained advice or treatment for their children's diarrhea from either a government facility or private health practitioner. The treatment or advice seeking behavior was higher in Bagh (63 percent) than in Haveli and Dhirkot (57 and 55 percent, respectively) (see Figure 6.5). 
Figure 6.5: Mothers of children ages 0-23 months who sought advice or treatment from service providers for episodes of diarrhea, by tehsil and district (percent)

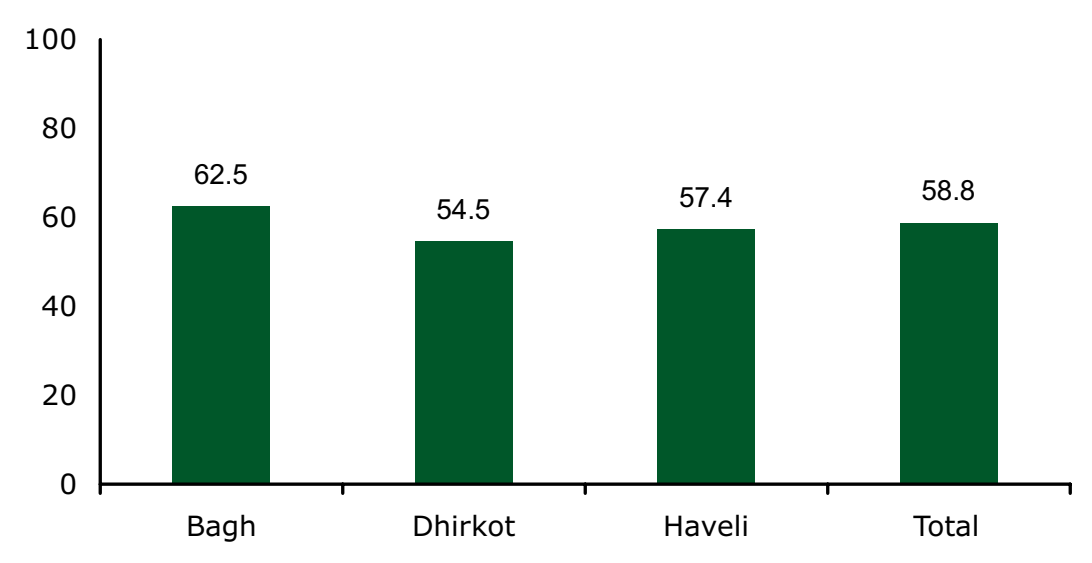

The use of oral rehydration therapy (ORT) promptly increases the intake of a child's fluids, which is a simple and effective response to diarrhea. Mothers reported during the survey that more than half of their children ages 0-23 months (54 percent) were treated with some form

PRIDE INDICATOR:

Children ages 0-23 months treated with oral rehydration therapy (ORT) during their last bout of diarrhea: 54.2 percent. of ORT (see Table 6.6). The use of ORT was highest in Haveli (67 percent) and lowest in Dhirkot (39 percent). 
Figure 6.6: Mothers according to whether or not they treated the last bout of diarrhea in their children ages 0-23 months with ORT, by tehsil and district (percent)

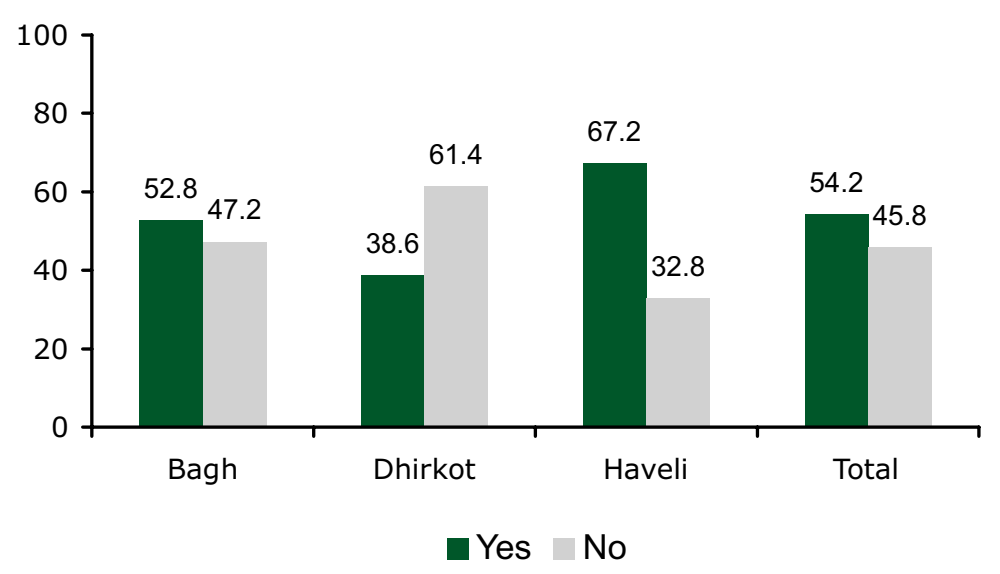

Mothers were asked if they recognized a single danger sign for diarrhea that requires immediate treatment at a health facility: four-fifths ( 80 percent)

\section{PRIDE INDICATOR:}

Mothers of children ages $0-23$ months who could cite at least one danger sign of diarrhea in their children: 80.2 percent.

specific signs named: severe dehydration (shortage

of water inside the body, shortage of vitamins, minerals and salt were grouped together to indicate severe dehydration) was mentioned by a majority of mothers as one of the danger sign of diarrhea followed by weakness, sunken eyes and unconsciousness. Mothers in Dhirkot had the highest (87 percent) knowledge of danger signs of diarrhea that require immediate treatment at a health facility. Mothers in Haveli and Bagh tehsils were somewhat less knowledgeable of danger signs (80 and 77 percent, respectively) 
Table 6.2: Danger signs of diarrhea requiring immediate treatment cited by mothers of children ages 0-23 months, by tehsil and district

\begin{tabular}{|c|c|c|c|c|c|c|c|c|}
\hline \multirow{3}{*}{ Sign } & \multicolumn{6}{|c|}{ Tehsil } & & \\
\hline & \multicolumn{2}{|c|}{ Bagh } & \multicolumn{2}{|c|}{ Dhirkot } & \multicolumn{2}{|c|}{ Haveli } & \multicolumn{2}{|c|}{ Total } \\
\hline & $N$ & $\%$ & $\mathrm{~N}$ & $\%$ & $N$ & $\%$ & $N$ & $\%$ \\
\hline $\begin{array}{l}\text { Can recognize at least one } \\
\text { danger sign of diarrhea }\end{array}$ & 184 & 76.7 & 125 & 86.8 & 109 & 79.6 & 418 & 80.2 \\
\hline Sunken eyes & 40 & 21.7 & 27 & 21.8 & 7 & 6.5 & 74 & 17.8 \\
\hline Severe dehydration & 134 & 72.8 & 88 & 71.0 & 56 & 51.9 & 278 & 66.8 \\
\hline Depress anterior fontanel & 5 & 2.7 & 3 & 2.4 & 2 & 1.9 & 10 & 2.4 \\
\hline Dry mouth and tongue & 16 & 8.7 & 6 & 4.8 & 2 & 1.9 & 24 & 5.8 \\
\hline No tears on weeping & 4 & 2.2 & 0 & 0.0 & 0 & 0.0 & 4 & 1.0 \\
\hline Dry skin & 7 & 3.8 & 3 & 2.4 & 2 & 1.9 & 12 & 2.9 \\
\hline Unconsciousness & 25 & 13.6 & 27 & 21.8 & 22 & 20.4 & 74 & 17.8 \\
\hline Restless & 34 & 18.5 & 16 & 12.9 & 10 & 9.3 & 60 & 14.4 \\
\hline Weakness & 39 & 21.2 & 44 & 35.5 & 36 & 33.3 & 119 & 28.6 \\
\hline $\begin{array}{l}\text { Change of color (e.g. } \\
\text { yellow skin color) }\end{array}$ & 7 & 3.8 & 11 & 8.9 & 11 & 10.2 & 29 & 7.0 \\
\hline Fever & 10 & 5.4 & 5 & 4.0 & 23 & 21.3 & 38 & 9.1 \\
\hline Baby cries & 2 & 1.1 & 4 & 3.2 & 2 & 1.9 & 8 & 1.9 \\
\hline Pain in abdomen & 4 & 2.2 & 4 & 3.2 & 2 & 1.9 & 10 & 2.4 \\
\hline Loss of appetite & 2 & 1.1 & 2 & 1.6 & 6 & 5.6 & 10 & 2.4 \\
\hline Vomiting & 0 & 0.0 & 9 & 7.3 & 4 & 3.7 & 13 & 3.1 \\
\hline Others & 3 & 1.6 & 3 & 2.4 & 4 & 3.7 & 10 & 2.4 \\
\hline Total & 184 & na & 124 & na & 108 & na & 416 & na \\
\hline
\end{tabular}

na $=$ Not applicable; respondents could name more than one sign/symptom.

\section{Pneumonia}

Mothers of children ages 0-23 months were asked whether they had heard about pneumonia: 91 percent of mothers had (see Figure 6.7). However, slight differences among tehsils were noted in the responses of mothers: Dhirkot was highest (95 percent) and Haveli was lowest (89 percent).

\section{PRIDE INDICATOR:}

Mothers of children ages 0-23 months who had heard about pneumonia: 91.4 percent. 
Figure 6.7: Mothers of children ages 0-23 months who had heard about pneumonia, by tehsil and district (percent)

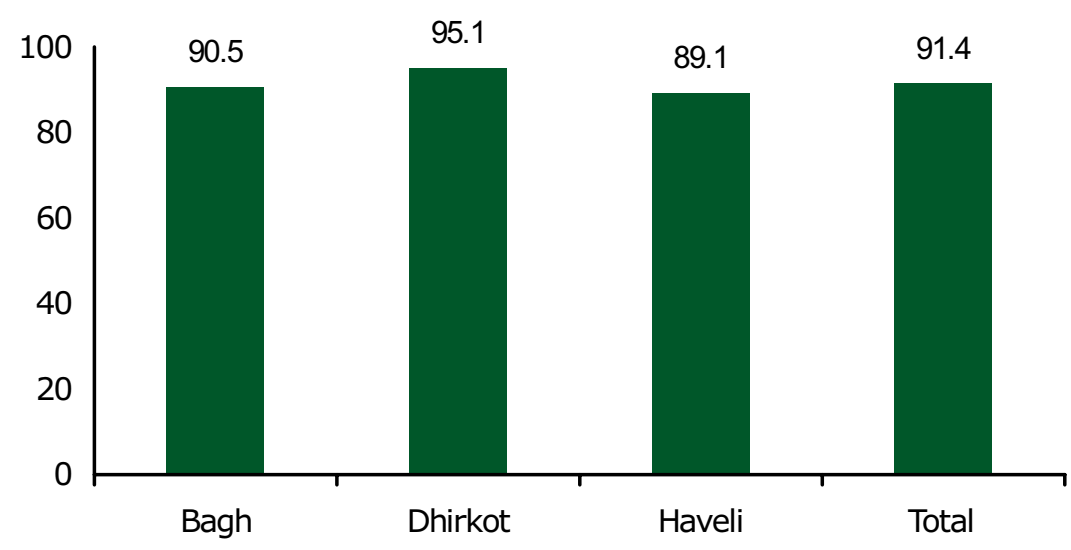

Mothers of children 0-23 months who had heard about pneumonia were also asked to identify symptoms of pneumonia in children. Table 6.3 shows these results for the 479 mothers who had heard about pneumonia and could name one or more signs. Overall, the most frequently mentioned signs/symptoms were high fever/ temperature (72 percent), followed by severe cough and rapid or difficult breathing (49 and 48 percent, respectively) and chest indrawing (28 percent). Not many mothers mentioned other signs. 
Table 6.3: Identification of signs/symptoms of pneumonia by mothers of children $0-23$ months, by tehsil and district

\begin{tabular}{|c|c|c|c|c|c|c|c|c|}
\hline \multirow{3}{*}{ Symptom } & \multicolumn{6}{|c|}{ Tehsil } & & \\
\hline & \multicolumn{2}{|c|}{ Bagh } & \multicolumn{2}{|c|}{ Dhirkot } & \multicolumn{2}{|c|}{ Haveli } & \multicolumn{2}{|c|}{ Total } \\
\hline & $N$ & $\%$ & $N$ & $\%$ & $N$ & $\%$ & $N$ & $\%$ \\
\hline Rapid or difficult breathing & 96 & 43.6 & 77 & 56.2 & 59 & 48.4 & 232 & 48.4 \\
\hline High fever/temperature & 175 & 79.5 & 97 & 70.8 & 71 & 58.2 & 343 & 71.6 \\
\hline Severe cough & 117 & 53.2 & 67 & 48.9 & 49 & 40.2 & 233 & 48.6 \\
\hline Blue skin color & 21 & 9.5 & 34 & 24.8 & 6 & 4.9 & 61 & 12.7 \\
\hline Fits & 4 & 1.8 & 0 & 0.0 & 3 & 2.5 & 7 & 1.5 \\
\hline Chest indrawing & 53 & 24.1 & 30 & 21.9 & 52 & 42.6 & 135 & 28.2 \\
\hline Pain & 16 & 7.3 & 14 & 10.2 & 19 & 15.6 & 49 & 10.2 \\
\hline Baby cries & 3 & 1.4 & 8 & 5.8 & 11 & 9.0 & 22 & 4.6 \\
\hline Wheezing/coughing/sputum production & 4 & 1.8 & 2 & 1.5 & 0 & 0.0 & 6 & 1.3 \\
\hline Loss of appetite & 5 & 2.3 & 1 & 0.7 & 2 & 1.6 & 8 & 1.7 \\
\hline Other & 23 & 10.5 & 14 & 10.2 & 15 & 12.3 & 52 & 10.9 \\
\hline Total & 220 & na & 137 & na & 122 & na & 479 & na \\
\hline
\end{tabular}

na $=$ Not applicable; respondents could name more than one symptom.

The mothers were asked about what should be done if their child had difficult and fast breathing. The responses are shown in Figure 6.8. Overall, a total of 83.5 percent said that the child should be immediately taken to a health facility. This response was highest in Haveli (88 percent) and lowest in Bagh tehsil (81 percent). Around 32 percent of mothers in the district mentioned that they should treat the child by themselves and 9 percent thought that the child should be kept warm if $\mathrm{s} /$ he developed rapid and

\section{PRIDE INDICATOR}

Mothers of children ages 0-23 months who cited rapid or difficult breathing as a cause for immediate treatment at a health facility: 83.5 percent. difficult breathing. 
Figure 6.8: Mothers of children ages 0-23 months according to what should be done if their child breathes fast with difficulty, by tehsil and district (percent)

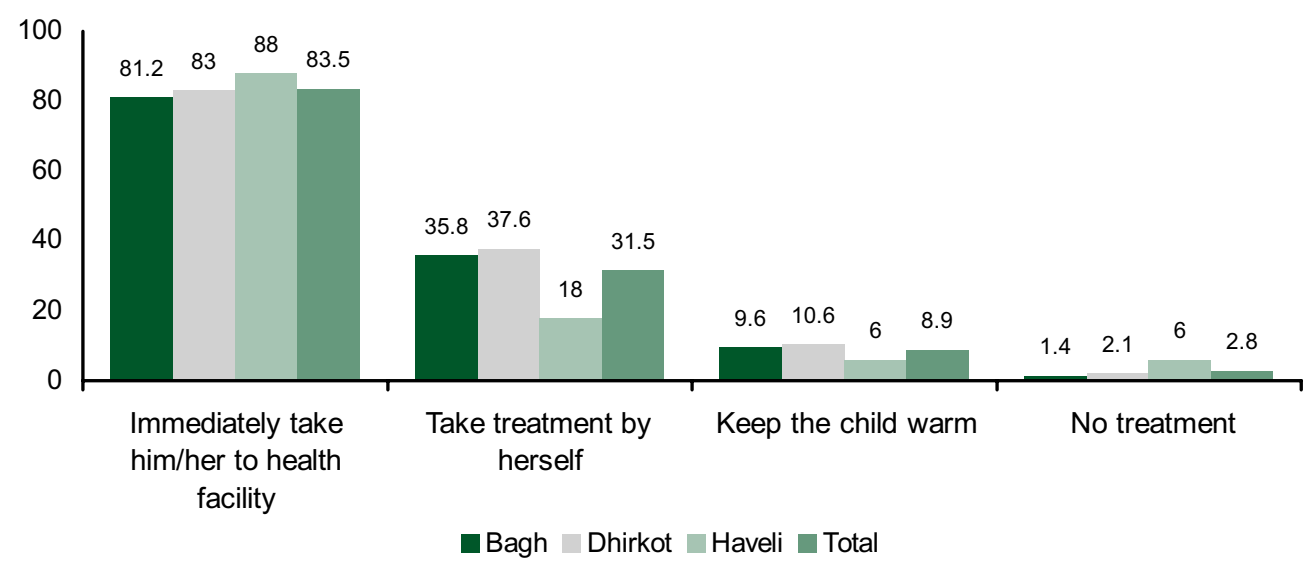

\section{Infant and Under-Five Mortality}

Sample size of the survey was not sufficient to estimate infant and under-five mortality for Bagh alone; mortality rates were estimated only for the two PRIDE project districts combined (Mansehra and Bagh) (see Chapter 1 on sample). Infant and under-five mortality estimates were calculated from information that was collected by the questionnaire for women. The information provided by the women for the live births that occurred during one year prior to the survey was used to estimate the infant and under-five mortality rates. The following definitions are used to estimate infant and under-five mortality:

Infant mortality: the probability of dying during the first year of life, per thousand live births in a year.

Under-five mortality: the probability of dying before the fifth birthday, per thousand live births in a year.

The reliability of infant and under-five mortality estimates derived from the birth information data is affected by a number of factors as given below:

- The completeness with which deaths of children are reported.

- The extent to which birth dates and ages at death are accurately reported by the women. 
- Omissions of either births or deaths are a more serious problem since they affect the level of the mortality estimates.

The KPC survey findings show that there were 676 live births in one year prior to the survey; 55 infants who died during the previous year before their first birthday; and 67 children who died during the

\section{PRIDE INDICATOR:}

Under 5 mortality rate: 99

deaths for every 1,000 live births. previous year aged less than 5 years. This gives an estimated infant mortality rate of 81 deaths per 1,000 live births, and an under-five mortality rate of 99 deaths per 1,000 live births in the two PRIDE project districts combined. 


\section{Chapter 7}

\section{Tuberculosis}

According to $\mathrm{WHO}$, one-third of the world's population is currently infected with tuberculosis (TB); every second this disease is infecting one more person in the world. This chapter presents the knowledge of respondents about TB.

\section{Awareness}

When respondents were asked if they had ever heard about tuberculosis, most reported that they had: 16 percent in Haveli and 6 percent in Bagh tehsil responded that they had not heard about it (Figure 7.1). More women had heard about TB in Dhirkot, where only 2 percent were unaware of this disease.

Figure 7.1: Ever-married women who had or had not heard about tuberculosis, by tehsil (percent)

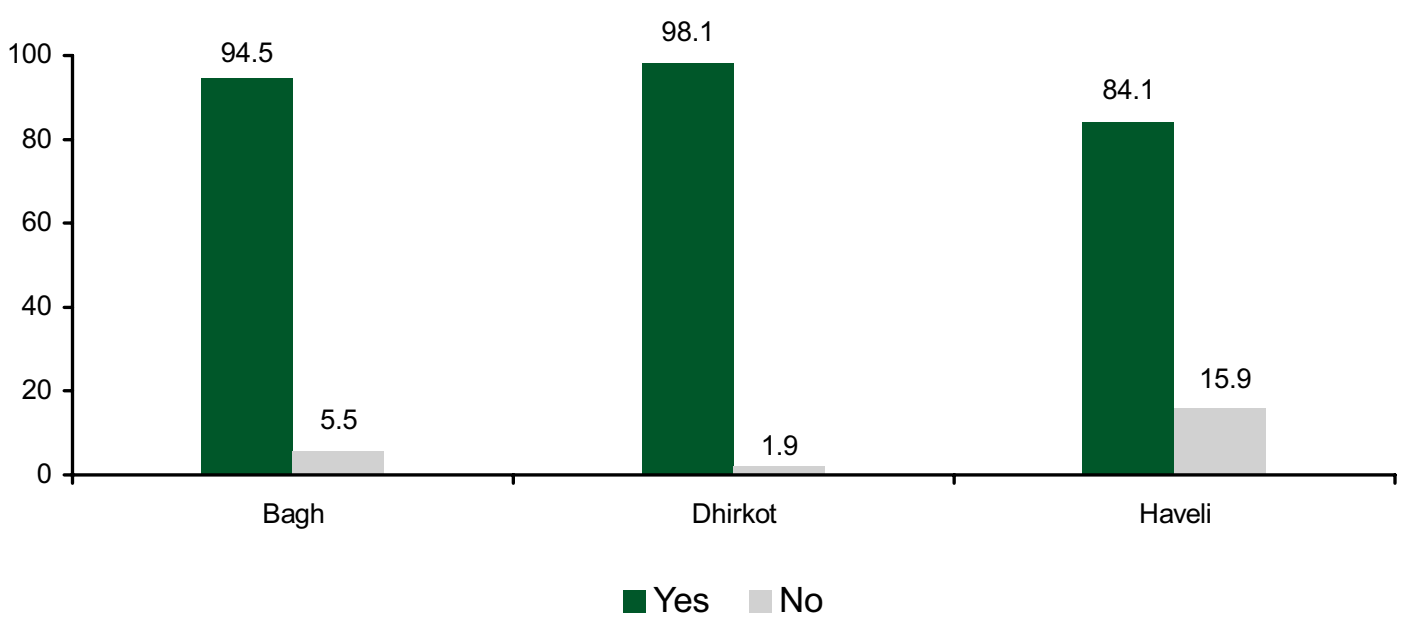




\section{Contagion}

"Tuberculosis (TB) is a contagious disease. Like the common cold it spreads through the air. When infectious people cough, sneeze, talk or spit, they propel TB germs into the air. A person needs only to inhale a small number of these to be infected" (WHO 2007).

Those who had heard of TB were further asked to name the ways TB can spread from one person to another. A majority of the women responded that TB could spread by sharing food and utensils (67 and 54 percent, respectively), and 39 percent said through the air by coughing and/or sneezing of a TB patient. About 12 percent of the women did not know a single way by which TB can spread from one person to another. "A person with active but untreated tuberculosis can infect 10-15 other people per year" (WHO 2007). About 15 percent of the women had an incorrect perceception of TB spreading through sexual contact.

Table 7.1: Ever-married women who knew about TB according to their knowledge about ways in which TB can be spread from person to person, by tehsil and district

\begin{tabular}{|c|c|c|c|c|c|c|c|c|}
\hline \multirow{4}{*}{$\begin{array}{l}\text { Mode of transmission } \\
\text { Through the air when coughing or } \\
\text { sneezing }\end{array}$} & \multicolumn{6}{|c|}{ Tehsil } & \multirow{2}{*}{\multicolumn{2}{|c|}{ Total }} \\
\hline & \multicolumn{2}{|c|}{ Bagh } & \multicolumn{2}{|c|}{ Dhirkot } & \multicolumn{2}{|c|}{ Haveli } & & \\
\hline & $N$ & $\%$ & $N$ & $\%$ & $N$ & $\%$ & $N$ & $\%$ \\
\hline & 275 & 40.2 & 166 & 40.1 & 95 & 33.8 & 536 & 38.9 \\
\hline Sharing utensils & 366 & 53.5 & 239 & 57.7 & 142 & 50.5 & 747 & 54.2 \\
\hline Touching person with $\mathrm{TB}$ & 45 & 6.6 & 9 & 2.2 & 23 & 8.2 & 77 & 5.6 \\
\hline Sharing food & 460 & 67.3 & 283 & 68.4 & 178 & 63.3 & 921 & 66.8 \\
\hline Sexual contact & 113 & 16.5 & 66 & 15.9 & 21 & 7.5 & 200 & 14.5 \\
\hline Sputum of TB patient & 24 & 3.5 & 47 & 11.4 & 5 & 1.8 & 76 & 5.5 \\
\hline Using bed of TB patient & 35 & 5.1 & 21 & 5.1 & 21 & 7.5 & 77 & 5.6 \\
\hline Using TB patient's possessions & 4 & 0.6 & 7 & 1.7 & 12 & 4.3 & 23 & 1.7 \\
\hline Biktaitlg with TB patient/ through & 9 & 1.3 & 2 & 0.5 & 1 & 0.4 & 12 & 0.9 \\
\hline Other & 18 & 2.6 & 10 & 2.4 & 1 & 0.4 & 29 & 2.1 \\
\hline Don't know & 65 & 9.5 & 43 & 10.4 & 61 & 21.7 & 169 & 12.3 \\
\hline Total & 684 & na & 414 & na & 281 & na & 1,379 & na \\
\hline
\end{tabular}




\section{Treatment}

Though TB is a curable disease, respondents did not know exactly how much time it takes for the treatment to completely get rid of it. First the respondents were asked whether they knew about treatment for TB. Almost 99 percent of the women in Bagh and Dhirkot, and almost 95 percent in Haveli, said they were aware that TB was a curable disease, while the rest wrongly believed that it was incurable.

Figure 7.2: Ever-married women according to whether or not they knew that TB was a treatable disease, by tehsil (percent)

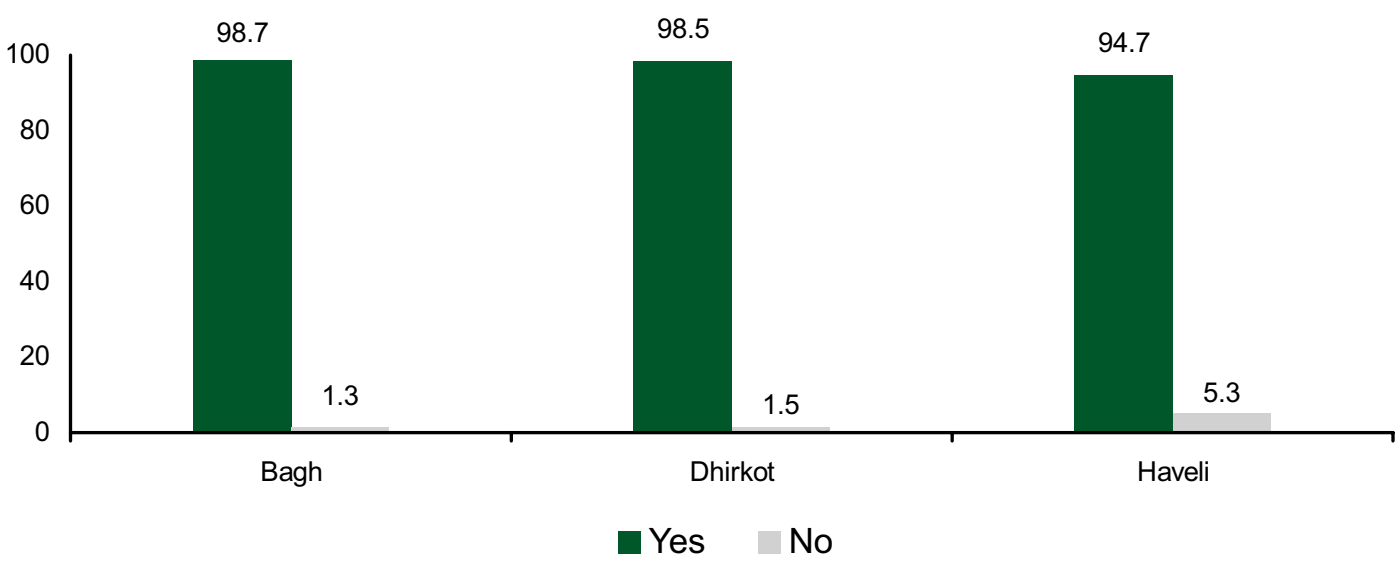

Of respondents who believed TB could be treated, around 42 percent correctly said that treatment takes 8 or more months. Twenty-one percent believed taking treatment for 4 to 7 months could fully cure TB. Twenty percent said they did not know about the duration of treatment.

Table 7.2: Ever-married women who believed TB to be treatable according to their beliefs about the duration of TB treatment, by tehsil and district

\begin{tabular}{lrrrrrrrr} 
Length of treatment & \multicolumn{9}{c}{ Tehsil } \\
in months & \multicolumn{1}{c}{ Bagh } & \multicolumn{2}{c}{ Dhirkot } & Haveli & \multicolumn{2}{c}{ Total } \\
\cline { 2 - 9 } 0 & $N$ & $\%$ & $N$ & $\%$ & $N$ & $\%$ & $N$ & $\%$ \\
\hline $0-3$ & 96 & 14.6 & 103 & 25.6 & 25 & 10 & 224 & 17.1 \\
\hline $4-7$ & 155 & 23.5 & 60 & 14.9 & 64 & 25.6 & 279 & 21.3 \\
\hline 8 or more & 291 & 44.2 & 173 & 42.9 & 85 & 34 & 549 & 41.8 \\
\hline Don't know & 117 & 17.8 & 67 & 16.6 & 76 & 30.4 & 260 & 19.8 \\
Total & 659 & 100.0 & 403 & 100.0 & 250 & 100.0 & 1,312 & 100.0
\end{tabular}




\section{Exposure in Family/Knowledge of Signs}

It is assumed that if some individual in a family has ever suffered from a particular disease the rest of the family would better know about the symptoms of that disease, and at the same time be at higher risk of getting infected by this disease. The respondents were asked if any person in their family had ever been diagnosed with TB: the highest percent was in Dhirkot, where 16 percent said yes, followed by 11 percent in Bagh tehsil and 8 percent in Haveli (see Table 7.3).

Table 7.3: Ever-married women according to whether or not anyone in their family ever suffered from TB, by tehsil and district

\begin{tabular}{|c|c|c|c|c|c|c|c|c|}
\hline \multirow{3}{*}{ Response } & \multicolumn{6}{|c|}{ Tehsil } & \multirow{2}{*}{\multicolumn{2}{|c|}{ Total }} \\
\hline & \multicolumn{2}{|c|}{ Bagh } & \multicolumn{2}{|c|}{ Dhirkot } & \multicolumn{2}{|c|}{ Haveli } & & \\
\hline & $N$ & $\%$ & $N$ & $\%$ & $N$ & $\%$ & $N$ & $\%$ \\
\hline Yes & 76 & 11.2 & 65 & 15.8 & 22 & 7.9 & 163 & 11.9 \\
\hline No & 605 & 88.8 & 347 & 84.2 & 255 & 92.1 & 1,207 & 88.1 \\
\hline Total & 681 & 100.0 & 412 & 100.0 & 277 & 100.0 & 1,370 & 100.0 \\
\hline
\end{tabular}

Respondents were further asked if they could identify TB symptoms. Overall, around 82 percent of those who had heard about TB said yes. Figure 7.3 shows the results by tehsil: more women in Haveli did not know any symptoms of TB (27 percent).

Figure 7.3: Ever-married women who reported whether or not they could identify at least one symptom of TB, by tehsil (percent)

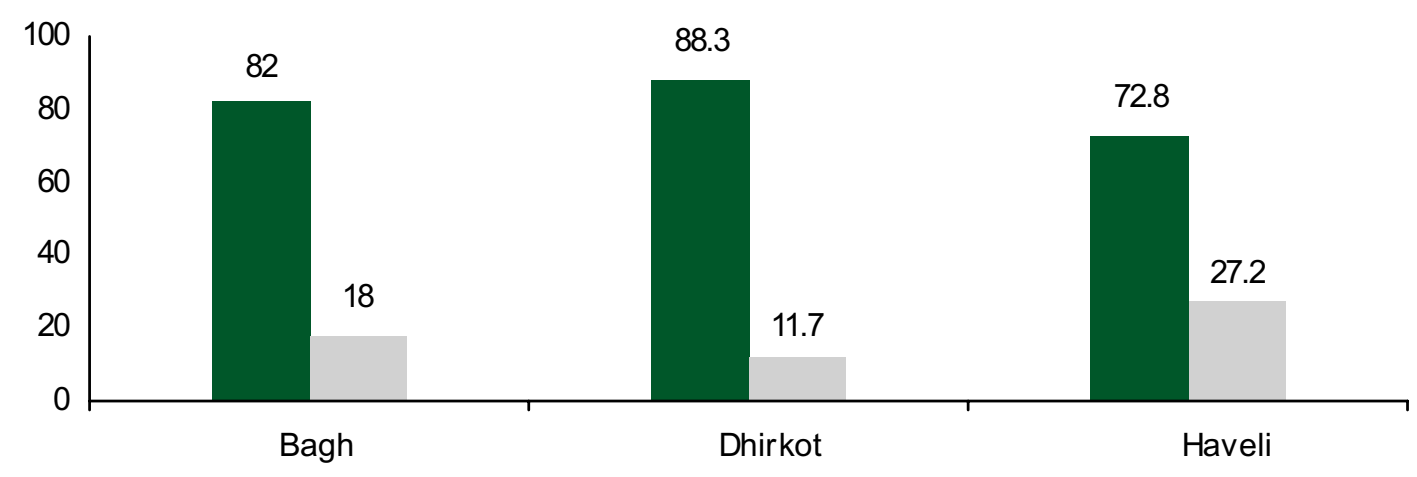

Yes No 
The main symptoms of TB include chest pain, coughing up blood, and a productive, prolonged cough for more than three weeks. Systemic symptoms include fever, chills, night sweats, appetite loss, weight loss, pallor, and often a tendency to fatigue very easily. When the women were asked to name the symptoms of TB, a vast majority named chronic cough (83 percent), followed by fever, loss of weight/weakness and sputum with blood (51, 48 and 30 percent, respectively).

Table 7.4: Ever-married women who cited symptoms of TB according to symptom, by tehsil and district

\begin{tabular}{|c|c|c|c|c|c|c|c|c|}
\hline \multirow{3}{*}{ Symptom } & \multicolumn{6}{|c|}{ Tehsil } & & \\
\hline & \multicolumn{2}{|c|}{ Bagh } & \multicolumn{2}{|c|}{ Dhirkot } & \multicolumn{2}{|c|}{ Haveli } & \multicolumn{2}{|c|}{ Total } \\
\hline & $N$ & $\%$ & $N$ & $\%$ & $N$ & $\%$ & $N$ & $\%$ \\
\hline Chronic cough & 462 & 84.8 & 319 & 88.4 & 134 & 66.0 & 915 & 82.5 \\
\hline Sputum with blood & 169 & 31.0 & 126 & 34.9 & 38 & 18.7 & 333 & 30.0 \\
\hline Loss of weight/weakness & 282 & 51.7 & 150 & 41.6 & 105 & 51.7 & 537 & 48.4 \\
\hline Fever & 232 & 42.6 & 237 & 65.7 & 100 & 49.3 & 569 & 51.3 \\
\hline Loss of appetite & 32 & 5.9 & 25 & 6.9 & 22 & 10.8 & 79 & 7.1 \\
\hline Pain in body/chest/ribs & 28 & 5.1 & 34 & 9.4 & 12 & 5.9 & 74 & 6.7 \\
\hline Change of complexion & 55 & 10.1 & 16 & 4.4 & 35 & 17.2 & 106 & 9.6 \\
\hline Problem in breathing & 13 & 2.4 & 18 & 5.0 & 7 & 3.4 & 38 & 3.4 \\
\hline Vomiting/motions & 9 & 1.7 & 2 & 0.6 & 6 & 3.0 & 17 & 1.5 \\
\hline Fatigue & 6 & 1.1 & 1 & 0.3 & 3 & 1.5 & 10 & 0.9 \\
\hline Other & 21 & 3.9 & 9 & 2.5 & 16 & 7.9 & 46 & 4.1 \\
\hline Total & 545 & na & 361 & na & 203 & na & 1,109 & na \\
\hline
\end{tabular}

na $=$ Not applicable; respondents could name more than one symptom. 



\section{Chapter 8}

\section{Community Involvement in Health}

The involvement of any community in local health planning and management is very important to improving the health delivery system and to ensuring that a better health services package is available, especially for women and children. Through participation in local health planning and management, communities can bridge the gap between the health facilities and the intended recipients of service (the community population), helping to ensure that facilities serve the health needs of the community.

\section{Presence of LHWs/CHWs}

In Bagh, 85 percent of the communities (50 out of 59 communities) reported the presence of a lady health worker or community health worker (LHW/CHW) in their respective areas.

\section{Health Committees}

The local influential community members who responded to questions about local health management came from 59 selected communities in Bagh district. These respondents were asked to indicate their involvement in the planning and management of local health facilities either individually or through an organized forum/committee.

Out of the 59 communities represented, 55 communities (93 percent) had no committee or forum working on health issues (Figure 8.1). However, four village health committees (VHCs) and community-based organizations (CBOs) (7 percent) were on record as working with the local health authority. These included three community-based organizations and one other non-profit, non-government 
organization. Bagh tehsil had one committee, Dhirkot had two and Haveli had one. All four of these committees/organizations were functional.

Figure 8.1: Percentage of 59 selected communities that have VHCs/CBOs

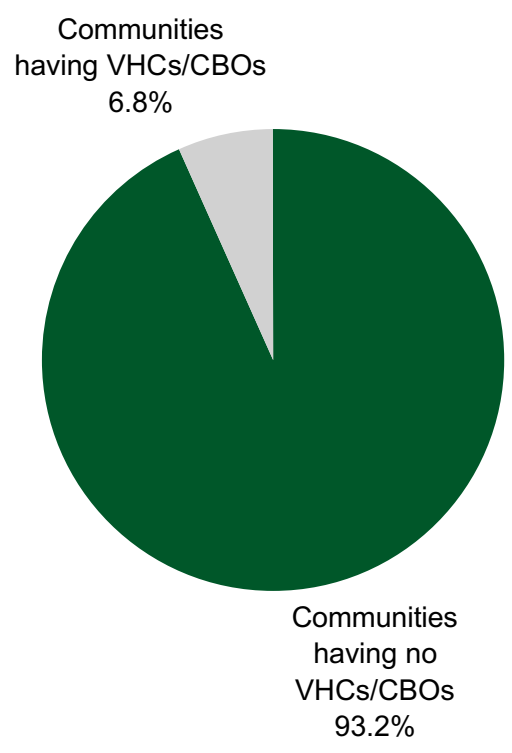

\section{Awareness and Activity Level}

The influential community members from the communities that had VHCs/CBOs were asked if they were aware of the terms of reference (TOR) of the village health committee in their community. All four from communities with VHCs reported that they were aware of the TOR of their respective committees.

When further probed about the frequency of the meetings of the four VHCs they reported being aware of, it was indicated that two committees met once a month, one met once a year and one did not meet.

In response to a question regarding VHC member's interaction with health department officers/staff, it was reported that all four committees had interacted with health managers (EDO-H and $\mathrm{ADHO}$ ) and service providers (MO BHU). During these meetings they were reported to have discussed issues related to the health of mothers and children, and to have given suggestions for improving health in their communities. 


\section{Chapter 9}

\section{Discussion of KPC Baseline Findings for Bagh District}

\section{Comparisons with Other Surveys}

The PRIDE indicators intended to be measured by the KPC survey have been estimated in various other household surveys in Pakistan, whether at national, provincial, or district levels. Estimates at district levels should be similar to the KPC findings, except for allowance for the passage of time. Unfortunately, survey data generally do not cover Azad Jammu and Kashmir (AJK), and therefore not Bagh district. However, estimates for Pakistan as a whole shed light on Bagh's place in relation to AJK and Pakistan; in the absence of other district-level data, they can also shed some light on the credibility of the estimates.

Table 9.1 shows national estimates from various sources for most of the PRIDE indicators for which household survey estimates are available, ${ }^{1}$ as well as selected general socio-economic indicators. Two sources of national data for which several PRIDE indicators are available are the 2006-2007 Demographic and Health Survey (DHS), and the 2005-2006 Pakistan Social and Living Standards Measurement Survey (PSLM). Selected other sources are given, especially where indicators are not available for the two prime sources.

\footnotetext{
${ }^{1}$ Alternative survey data are unavailable for two PRIDE indicators: recognition that rapid/difficult breathing of infants requires immediate treatment; and the proportion of mothers recognizing at least one danger sign of diarrhea.
} 
Table 9.1: Comparison of Bagh KPC indicators with selected national survey data

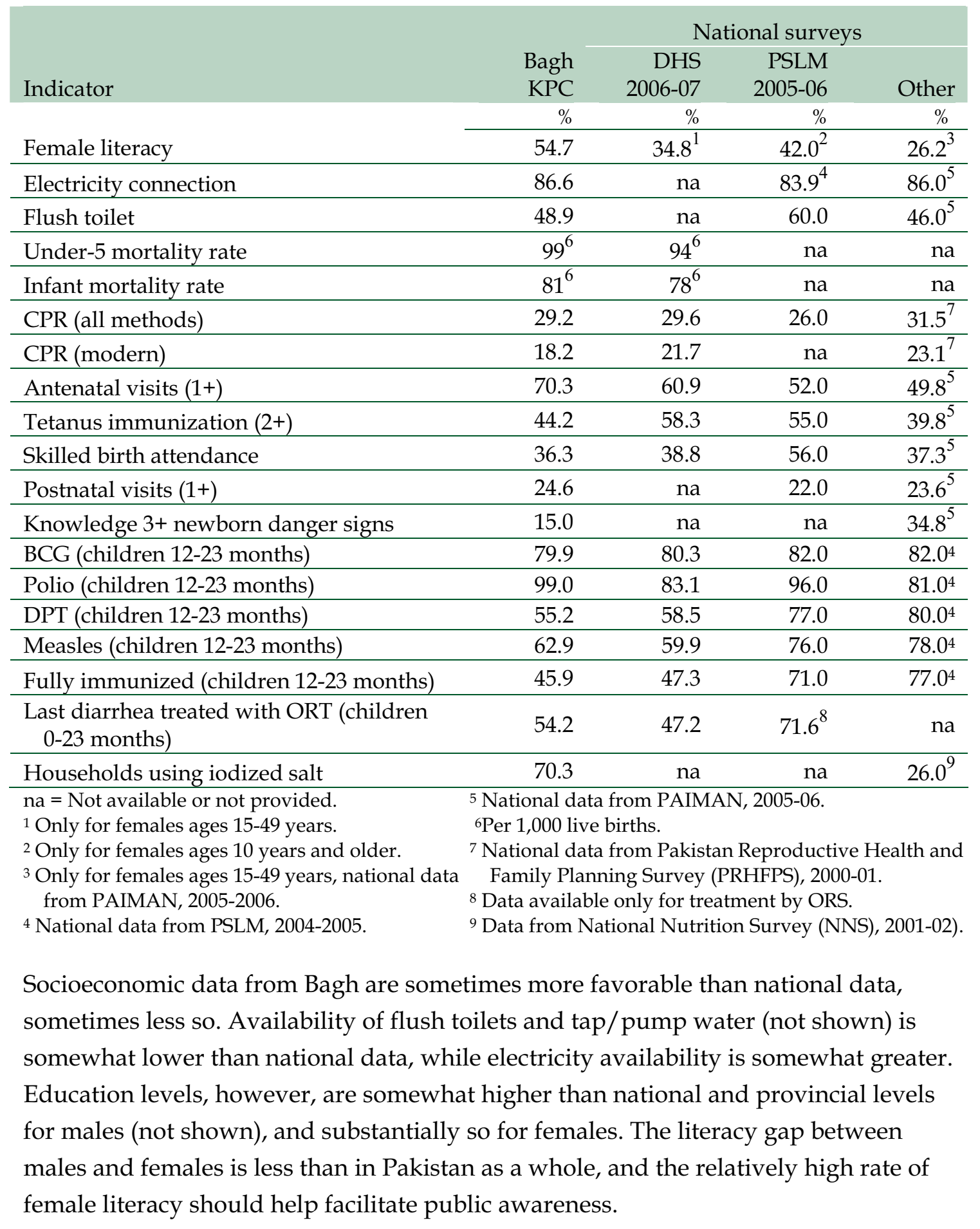

The contraceptive prevalence rate is close to that of the DHS, generally accepted as the national standard; however, use of modern methods is somewhat low, reflecting 
higher than average use of traditional methods, notably periodic abstinence. Among maternal care measures, antenatal care visits are notably higher than the national average, while other indicators are fairly similar to national data. Among indicators of childcare, levels of coverage for full immunization as well as most individual antigens are similar to national estimates; polio, however, shows higher coverage in Bagh - indeed, nearly complete. Levels of treatment of last diarrhea episodes with ORS is higher in the Bagh KPC than in the national DHS, but lower than in the national PSLM surveys. Use of iodized salt is much higher in the Bagh KPC than with other surveys. Infant and under- 5 mortality are similar in the KPC to estimates from other sources.

There is reason to believe that the quality of the various sources is not even. The Demographic and Health Survey and the PAIMAN surveys, for example, were undertaken with highly trained female interviewers under international supervision, and were specific to health issues. The MICS and PSLM data, on the other hand, were collected for a wide variety of purposes (and therefore focus less intensively on health), and interviewers were less intensively trained and often male.

As these comparisons (national and district) show, consistency among the various sources is far from complete. On any given indicator, the KPC data may be higher than other estimates, or lower, or between them; and then other estimates are not particularly consistent with each other. Some trends, however, can be stated. For some maternal health indicators - e.g., ANC, skilled birth attendance - national levels are increasing fairly rapidly according to a variety of sources, and the Bagh KPC data appear to reflect these trends. In other areas, Bagh data look broadly comparable to those for Pakistan as a whole. Of particular interest, infant and child mortality estimates (combined for Bagh and Mansehra) are similar to the best estimates for Pakistan.

\section{Strengths and Limitations}

Household sample surveys have important strengths, which is why they are so commonly used. The also have important limitations, which is why they are useful only for certain variables and topics. The PRIDE KPC surveys share the strengths and limitations of household surveys generally. 


\section{Target Group}

The data from the PRIDE KPC are obtained from married women of reproductive age (MWRA), i.e., ever-married women aged 15-49. Information obtained from such women is of considerable interest to a public health program. They are the best informants available regarding their own health, knowledge and experience, and are usually the best informants available regarding the health of their children. They are also the primary target audiences for many health education messages. In addition, MWRA are also usually reliable respondents regarding the social, educational, and general economic situation of the household.

\section{Sample}

A probability sample such as the Bagh KPC provides a sound representative sample of all the households/MWRA in the district. It is, however, subject to some degree of random variance due to the chance that this particular group of households was selected rather than some other; this random variance decreases as sample size increases. The Bagh KPC, with 1,496 households, is somewhat larger than other samples intended to provide reliable district-level estimates; for example, the MICS, PSLM, and PAIMAN surveys all obtained data on fewer than 1,000 households per district. Sampling errors, taking into account the sample size and design, are shown in Chapter 10, in the form of 95 percent confidence intervals around the point estimates.

\section{Respondent Accuracy}

Respondents in a household survey can be expected to provide better answers on some questions than others. On factual questions, respondents will obviously answer better when they are more knowledgeable; for example, MWRA in Bagh are not generally informants for medical diagnosis, or for functioning of the health system. They also tend to provide better answers on questions that are important (e.g., an episode of childhood diarrhea is more likely to be reported if the mother considered it serious), non-sensitive (e.g., births are more likely to be reported than induced abortions), and specific (e.g., a question on "last time" will generally be answered more often than a question about usual behavior). Data on knowledge and attitudes are particularly sensitive to the skill of the interviewer as well as the wording of the question; it is often useful to think of such answers less as factual information than as the body of answers women give when asked a particular question in a particular place. 
Despite the limitations of household survey data, they are frequently the best feasible source of data. For example, although Census data are indispensable for providing complete data on a whole population, they may be less accurate on many topics because questionnaires are shorter and interviewers less well trained; in addition, as in the present case, they may be out of date. Data from the health system itself - e.g., the Health Management Information System (HMIS) - are necessary for some indicators - e.g., clinic attendance - but tend not to be able to collect accurate information on the health of the general population, since they are generally limited to the individuals they serve directly. The Bagh KPC has focused its attention on those topics for which it was believed that the household survey would provide the best available data.

\section{Perspectives}

The Bagh KPC data reflect the strengths and weaknesses of the Pakistan health system as a whole. On a variety of indicators of general social and economic status, Bagh district appears slightly better developed than Pakistan as a whole. Regarding primary health care, the areas that need attention are generally those of the country as a whole, and the priorities are similar.

Within Bagh district, there is considerable variability on many indicators by tehsil. On the whole, Bagh and Dhirkot tehsils, which are similar on many indicators, are better developed than Haveli. For example, ownership of most household amenities (other than animals) is substantially higher for Bagh and Dhirkot than for Haveli; women in Haveli are less likely to be literate; and so on. These are reflected in better health indicators for Bagh and Dhirkot, including family planning, maternal health, and infant/child health. Haveli has to be treated as a distinctly disadvantaged area.

Whether at the tehsil level or the individual household/woman level (not analyzed in this report), the variability shown in these indicators generally reflects the ease or difficulty in addressing problems at both facility and community levels. The weaker infrastructure in Haveli tehsil, along with distance from towns and the scattered nature of the population, will make it harder to bring facilities up to standard. At the community level, variation in socioeconomic status doubtless reflects in part that smaller, more fragmented and more isolated communities are generally harder to reach and organize than larger and more prosperous places. 
Family planning use in Bagh district, at about 29 percent of MWRA, is similar to Pakistan generally. But with about two-thirds of non-users expressing intent to use in the future, and more than 40 percent of respondents with current unmet need for family planning, there is clearly an opportunity to increase family planning use. The relatively low use of modern family planning methods also probably reflects a need for better family planning and counseling.

There is evidence in Bagh, as elsewhere, that use of professional providers for maternity care (ANC, tetanus immunization, skilled attendance at birth) is rising, suggesting that the traditional view that childbirth is a natural process not requiring medical care may be waning. Efforts to reinforce this trend are likely to be productive. Most important, perhaps will be to meet the need for rapid diagnosis and effective treatment of obstetric emergencies.

A key issue for Bagh, as elsewhere, is improving delivery care. While the proportion of babies delivered by health professionals is rising, it is still only a little more than one-third of deliveries, and improvements here are desirable. However, it is important to focus as well on home deliveries by non-professionals, which are the majority of deliveries. One possibility is to implement effective training of dais (traditional birth attendants). Another national development that PRIDE should consider is the plan to train a national cadre of community midwives; while the numbers will not be large during the life of the PRIDE project, some trained midwives will be available, and efforts to determine how best to utilize them may be of considerable value for the future. Another issue requiring attention is the 35 percent of deliveries conducted by untrained friends and relatives (particularly high in Dhirkot). It is programmatically difficult to train such persons, who individually conduct only a few deliveries each. How to advise mothers who may wish to be delivered by these informal providers is a topic that needs to be addressed by the Intermediate Result (IR3) team.

The low levels of postnatal care and knowledge of newborn emergencies suggests that priority attention should be given to strengthening neonatal care, both through better preparation (training and facilities) in the health system and through community education. Experience elsewhere in Pakistan (as well as internationally) indicates that efforts to treat the mother and her newborn baby as a dyad, with focus on both, may be more effective than sole focus on the mother. 
Data on immunization are relatively high, suggesting a substantial level of contact between the public health system and infants and young children. However, the relatively low levels of knowledge and practice regarding common childhood diseases such as diarrhea and pneumonia suggests that this contact might be better used to improve childcare. Better education as well as service is needed to deal with diarrhea and pneumonia, which (based on other evidence in Pakistan) are probably two of the leading causes of infant and child mortality.

Awareness of malaria and tuberculosis is quite high. However, better solutions are needed to improve prevention and cure. Community-level operations research efforts may point the way for better ways to meet these needs.

It is important to examine and utilize the potential for harnessing care in the private sector. Judging by family planning and antenatal care, recourse to the private sector may be less dominant in Bagh than in Pakistan generally. However, about one-fourth of family planning and nearly half of antenatal care are provided by the private sector, and probably a higher proportion of curative care is provided by private sources. The public sector should not be expected to provide all the medical care in Bagh; strengthening the quality of private sector care should be a priority for the PRIDE project. 



\section{Chapter 10}

\section{Key Indicators for KPC Baseline Survey Bagh District}

The KPC survey served to collect baseline information on key PRIDE indicators. The following table presents a summary of the baseline data for these key indicators, they are also highlighted throughout this report:

Table 10.1: PRIDE key indicators from KPC baseline survey, Bagh district

\begin{tabular}{|c|c|c|c|c|}
\hline & & KРC & Confiden & interval \\
\hline Indicator & Sub-indicator & $\begin{array}{r}\text { baseline } \\
\text { data } \\
(\%)\end{array}$ & $\begin{array}{r}\text { Lower } \\
\text { boundary } \\
(\%)\end{array}$ & $\begin{array}{r}\text { Upper } \\
\text { boundary } \\
(\%)\end{array}$ \\
\hline Contraceptive & - Use of any method & 29.2 & 26.2 & 32.4 \\
\hline prevalence rate & - Use of modern methods & 18.2 & 15.9 & 21.2 \\
\hline Use of iodized salt & & 70.3 & 65.9 & 74.3 \\
\hline Antenatal visits in & - One or more visits & 70.3 & 65.4 & 74.6 \\
\hline last pregnancy & - Four or more visits & 28.6 & 24.0 & 33.5 \\
\hline TT injection during & - One or more injections & 50.2 & 44.8 & 55.7 \\
\hline last pregnancy & - Two TT injections & 44.2 & 39.0 & 49.6 \\
\hline $\begin{array}{l}\text { Delivery attended by } \\
\text { skilled birth } \\
\text { attendants }\end{array}$ & & & & 412 \\
\hline $\begin{array}{l}\text { attendants } \\
\text { Postnatal visit }(+1)\end{array}$ & - At least one visit within 40 & $\frac{36.3}{24.6}$ & $\begin{array}{l}31.6 \\
21.3\end{array}$ & $\frac{41.2}{28.2}$ \\
\hline & days after delivery & & & \\
\hline Knowledge of & - One or more danger signs & 58.0 & 52.9 & 62.5 \\
\hline $\begin{array}{l}\text { danger signs of } \\
\text { newborns }\end{array}$ & - Three or more danger signs & 15.0 & 12.2 & 18.2 \\
\hline Immunization of & - Fully vaccinated & 45.9 & 38.1 & 53.9 \\
\hline children ages 12-23 & - BCG & 79.9 & 73.3 & 85.2 \\
\hline months & - Polio & 99.0 & 95.8 & 99.8 \\
\hline & - DPT & 55.2 & 47.2 & 62.8 \\
\hline & - Measles & 62.9 & 55.3 & 69.9 \\
\hline
\end{tabular}




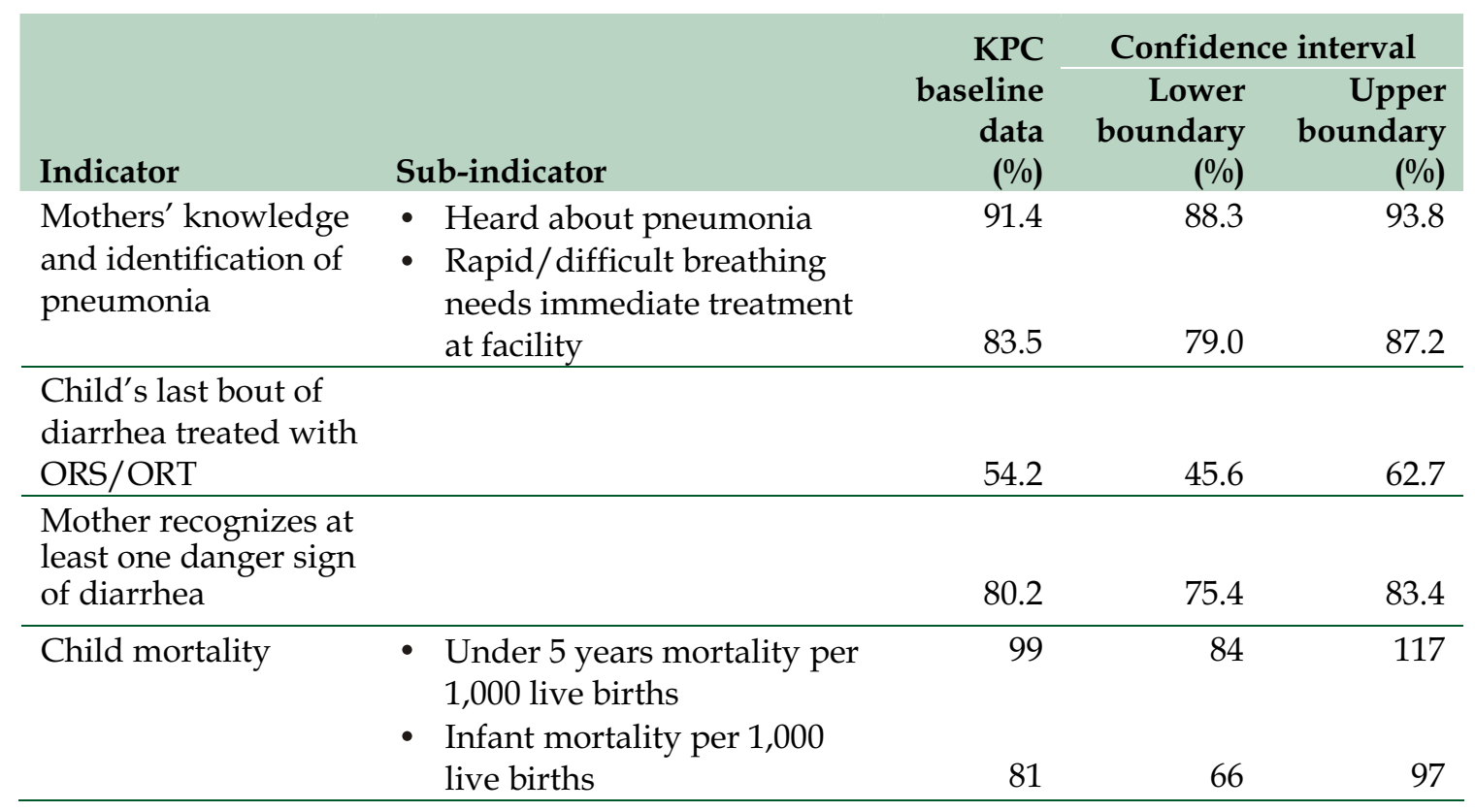

The baseline information gathered will serve as an important part of designing program interventions and activities; for example, when examing data for family planning, the current use of modern methods is only 18 percent, highlighting that there is a great unmet need for family planning. Focused PRIDE interventions at both community and health facility levels will be necessary to address this.

The baseline information will also be crucial to setting program targets that the PRIDE project will use to monitor progress. The KPC survey will be repeated at the end of the project; baseline and endline data will be used to evaluate the achievements of PRIDE. 


\section{References}

Caldwell, John C. Routes to low mortality in poor countries. Population and Development Review, Vol. 12, No. 2 (June 1986), pp. 171-220.

Federal Bureau of Statistics [Pakistan]. 2006. Pakistan Social and Living Standards Measurement Survey, 2004 -2005. Islamabad: Federal Bureau of Statistics, Statistics Division.

Government of NWFP. A district based multiple indicators cluster survey, 2001. Government of NWFP, P\&D department.

Hobcraft, J. Child Spacing and Child Mortality in Proceedings of the Demographic and Health Surveys World Conference, 1991, Vol. 2, Columbia, Md., USA, 1991, pp. 1157-1182.

IRIN. PAKISTAN: Iodine deficiency affecting children in northwest. Asia English Reports, www.irinnews.org, 9 July 2007.

Mahmood, Arshad. Infant and child mortality estimates from Pakistan Population Census 1998, in Abdul Razzaq Kemal, M. Irfan, and Naushin Mahmood (eds.), Population of Pakistan: An Analysis of 1998 Population and Housing Census. Islamabad: Pakistan Institute of Development Economics, 2003.

Population Census Organization. District Census Report Mansehra. Government of Pakistan, Statistics Division, 2000.

Population Council. 2006. PAIMAN Baseline Household Survey Reports, 2006. Islamabad: The Population Council Pakistan.

Singh S. and R. Samara. Early Marriage Among Women in Developing Countries. International Family Planning Perspectives, Vol. 22, No. 4 (Dec. 1996), pp. 148157.

WHO. WHO Global TB Control Report 2007. www.who.int/tb/publications/ global_report/2007.

Zafar, Faiza. IRIN. PAKISTAN: Iodine deficiency affecting children in northwest. Asia English Reports, www.irinnews.org, 9 July 2007. 


\section{PRIDE (0)}

Primary Healthcare Revitalization, Integration and Decentralization in Earthquake-affected areas

House \# 138, St \# 14, E-7, Islamabad, PAKISTAN, Tel: + 92(0)51-2654142

Field Offices:

House No.3, Sector - B, Ghazikot Township, Mansehra, Ph: 0997 302899, 303160 Fax:0997 303049 )

Qandeel Colony, Bagh, Ph:58720-43128 \& 992-519028 Fax: 58720-43128 